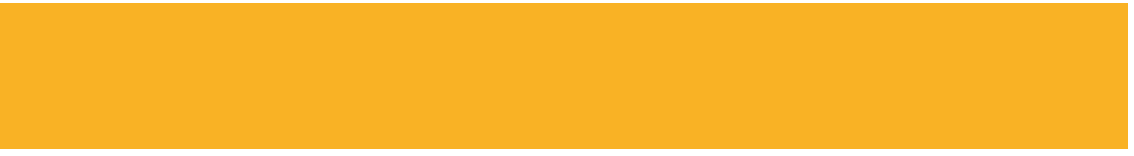

\title{
Flight Testing of an Advanced Airborne Natural Gas Leak Detection System
}

TYPE OF REPORT: Final

RePorting Period Start Date: October 1, 2003

RePorting Period End Date: December 31, 2004

AuthORS: Dr. Dawn Lenz, Dr. Raymond T. Lines,

Dr. Darryl Murdock, Jeffrey Owen,

Dr. Steven Stearns, Michael Stoogenke

October 2005

DOE AWARD NUMBER: DE-FC26-03NT41877

\section{ITT INDUSTRIES SPACE SYSTEMS, LLC 1447 ST. PAUL STREET ROCHESTER, NY 14653}

"This report was prepared as an account of work sponsored by an agency of the United States Government. Neither the United States Government nor any agency thereof, nor any of their employees, makes any warranty, express or implied, or assumes any legal liability or responsibility for the accuracy, completeness, or usefulness of any information, apparatus, product, or process disclosed, or represents that its use would not infringe privately owned rights. Reference herein to any specific commercial product, process, or service by trade name, trademark, manufacturer, or otherwise does not necessarily constitute or imply its endorsement, recommendation, or favoring by the United States Government or any agency thereof. The views and opinions of authors expressed herein do not necessarily state or reflect those of the United States Government or any agency thereof." 


\begin{abstract}
ITT Industries Space Systems Division (Space Systems) has developed an airborne natural gas leak detection system designed to detect, image, quantify, and precisely locate leaks from natural gas transmission pipelines. This system is called the Airborne Natural Gas Emission Lidar (ANGEL) system. The ANGEL system uses a highly sensitive differential absorption Lidar technology to remotely detect pipeline leaks. The ANGEL System is operated from a fixed wing aircraft and includes automatic scanning, pointing system, and pilot guidance systems. During a pipeline inspection, the ANGEL system aircraft flies at an elevation of 1000 feet above the ground at speeds of between 100 and $150 \mathrm{mph}$.

Under this contract with DOE/NETL, Space Systems was funded to integrate the ANGEL sensor into a test aircraft and conduct a series of flight tests over a variety of test targets including simulated natural gas pipeline leaks. Following early tests in upstate New York in the summer of 2004, the ANGEL system was deployed to Casper, Wyoming to participate in a set of DOEsponsored field tests at the Rocky Mountain Oilfield Testing Center (RMOTC).

At RMOTC the Space Systems team completed integration of the system and flew an operational system for the first time. The ANGEL system flew 2 missions/day for the duration for the 5-day test. Over the course of the week the ANGEL System detected leaks ranging from 100 to 5,000 scfh.
\end{abstract}


Table of Contents

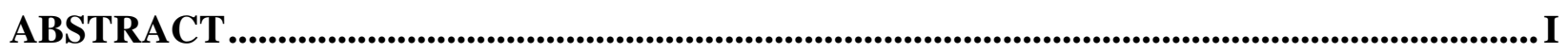

1.0 EXECUTIVE SUMMARY .....................................................................................

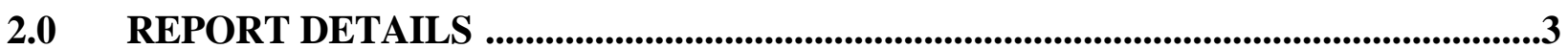

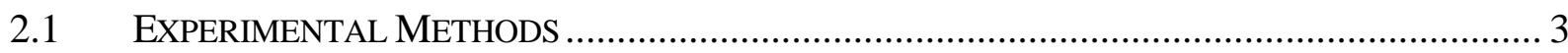

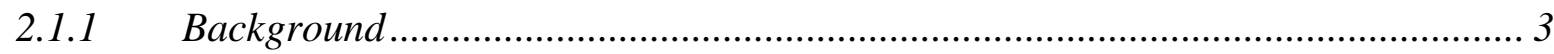

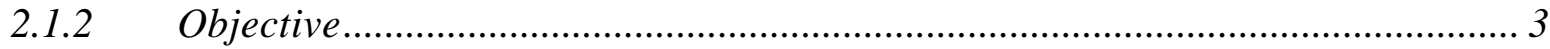

2.1.3 The Physics behind DIAL gas detection ......................................................... 4

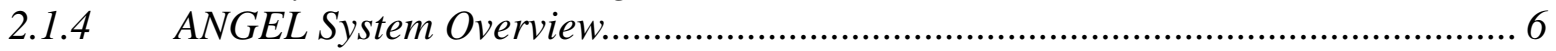

2.2 RESULTS AND DisCUSSION - EARLY FLIGHT TESTS (BUFFALO, NY) .......................... 11

2.2.1 Objective of Early Flight Tests................................................................. 11

2.2.2 Creation of a simulated natural gas leaks for flight testing ............................... 12

2.2.3 Flight One - (3 September 2004).................................................................... 14

2.2.4 Flight Two - (3 September 2004) ................................................................. 15

2.2.5 Flight Three - (7 September 2004) .......................................................... 15

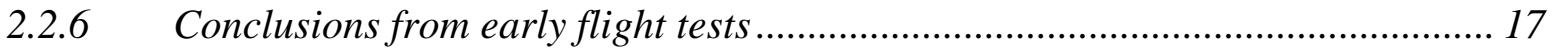

2.3 OVERVIEW OF RMOTC FIELD TEST (CASPER, WY) …...................................... 17

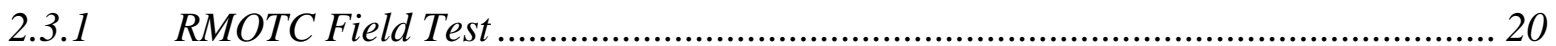

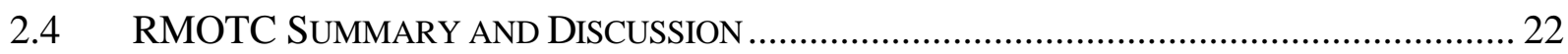

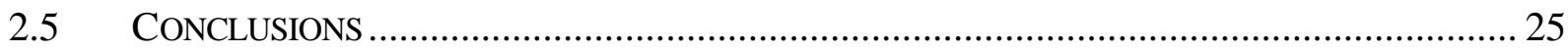

2.5.1 Post RMOTC flight testing ........................................................................ 26

2.5.2 Qualitative Comments on ANGEL Technology .............................................. 28

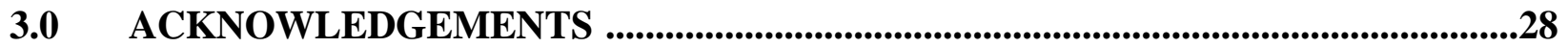

4.0 GRAPHICAL MATERIAL ....................................................................................29

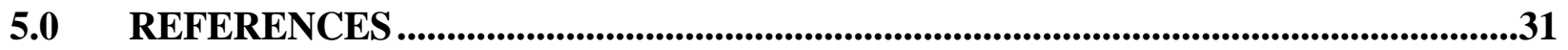

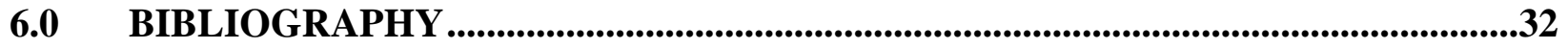

7.0 LIST OF ACRONYMS AND ABBREVIATIONS ...................................................34

ATTACHMENT 1: ITT EQUIPMENT PROVIDER TEST REPORT..............................................................35

ATTACHMENT 2: ITT ANGEL CUSTOMER REPORT - 14 SEPT 2004 COLLECTION................45

ATTACHMENT 3: ITT ANGEL CUSTOMER REPORT - 15 SEPT 2004 COLLECTION................54

ATTACHMENT 4: ITT ANGEL CUSTOMER REPORT - 16 SEPT 2004 COLLECTION...............64

ATTACHMENT 5: ITT ANGEL CUSTOMER REPORT - 17 SEPT 2004 COLLECTION................73 


\subsection{Executive Summary}

The existing U.S. natural gas transmission infrastruc ture consists of over 300,000 miles of buried pipeline. DOE estimates that natural gas consumption will increase by over $50 \%$ percent (to 34 trillion cubic feet) by 2020, placing additional demands on the country's aging natural gas infrastructure. This combination of aging pipeline materials, increased demand, and utility deregulation presents an environment where natural gas emissions may occur with greater frequency and volumes. The reduction of these natural gas transmission pipeline emissions is critical to addressing several subjects of national importance, including: (1) natural gas conservation; (2) public and environmental safety; (3) greenhouse gas emissions; and (4) the overall cost of natural gas.

With the intent of improving the way pipelines are monitored for emissions, in 2001 a team of Space Systems scientists and external consultants was tasked to assess the ideal manner in which to remotely sense natural gas pipeline leaks from the air. Ultimately Differential Absorption Lidar (DIAL) technology was selected as the most sensitive and effective technique for detecting and quantifying the methane and ethane in gas pipeline leaks.

ITT Industries Space Systems Division (Space Systems) has developed an airborne DIAL system designed to detect, image, quantify, and precisely locate leaks from natural gas transmission pipelines. This system is called the Airborne Natural Gas Emission Lidar (ANGEL) system. The ANGEL System is operated from a fixed wing aircraft and includes automatic scanning, pointing, and pilot guidance systems. During a pipeline inspection, the ANGEL system aircraft operates at an elevation of 1,000 feet above the ground flying speeds of between 100 and 150 mph.

The objective of this effort was to flight test the ANGEL system in an operational environment. The two major phases of flight- testing for this effort consisted of early flight tests in Upstate New York, followed by participation in a DOE/DOT funded Field Test of Remote Sensing Gas Leak Detection Systems at the Rocky Mountain Oilfield Testing Center (RMOTC) near Casper Wyoming in September of 2004.

During early flight tests, the major objective was to debug sensor operation in the test aircraft and obtain initial characterization of ANGEL operation and capabilities. During this phase of the effort ITT successfully tested a range of sensor functionality including, ability to operate the system in test aircraft, laser power and stability, receiver system operation and sensitivity, pointing system performance and accuracy, and the ability to successfully process and analyze raw sensor data with ground processing algorithms and software.

In September, the Space Systems ANGEL System participated in a government funded field test of remote sensing leak detection systems. The United States Department of Energy, National Energy Technology Laboratory (NETL) and the United States Department of Transportation, Office of Pipeline Safety (OPS) jointly funded this field test. This field test was held from September 12-17, 2004 at the DOE's Rocky Mountain Oilfield Testing Center (RMOTC). RMOTC's field site is the Teapot Dome Field, 35 miles north of Casper, WY. The test was organized and run by the Southwest Research Institute (SWRI) in cooperation with the NETL, OPS, RMOTC, a number of pipeline industry advisors, and the remote sensing system 
technology providers. A total of 6 industry and government groups (technology providers) were invited to participate in this test.

During the DOE RMOTC field demonstration, the functionality of all major ANGEL systems was verified including gas detection, gas quantification, sensor targeting, laser scanning, data logging, data analysis, mission planning and flight operations. The system was flown at every opportunity from Sunday afternoon through Friday evening for a total of 11 flights.

Approximately 80 gigabytes of raw data was collected for each day of operation. Although no usable DIAL data was collected on Sunday or Monday of the RMTOC demonstration, sensor performance data collected on these early flights allowed the ANGEL team to identify and repair a damaged optical component in the sensor. Much of the system's capability was untested prior to this demonstration and the event provided an unparalleled opportunity to operate, learn and ultimately improve the system.

Space Systems was pleased to participate in the DOE/DOT facilitated Demonstration of Remote Gas Leak Detection Systems at RMOTC. At this event we were able to demonstrate for the first time many aspects of the ANGEL System's capabilities. These included the ability to efficiently detect, quantify, geo-locate and image natural gas leak plumes from the air. During this demonstration the ANGEL team learned a number of very valuable lessons.

- We validated the concept of using Differential Absorption Lidar (DIAL) for gas leak detection and quantification from a fixed wing aircraft. Integration of the sensor into the test aircraft was completed at the Casper Airport. The first fully integrated ANGEL DIAL data ever collected was on 14 September 2004, the second day of the RMOTC test. The ANGEL system was successful at detecting and quantifying a majority of leaks of $500 \mathrm{scfh}$ and larger.

- We confirmed that the ANGEL Intelligent Pointing and Scanning System allowed the aircraft to fly the Virtual Pipeline end-to-end at high speed and inspect $100 \%$ of the pipeline on a single pass. The ability to collect data accurately, rapidly, and efficiently is critical to future commercial operations.

- We challenged the Beta version of our ground data processing software and it worked well throughout the week. The experience of having to rapidly process vast quantities of data during the demonstration is currently driving major improvements in the area of automated data processing and analysis.

- We verified the relationship between laser output power and our ability to detect leaks. This was one of the most important lessons learned at RMOTC. Increasing laser power greatly improves our ability to lock on a set wavelength and greatly improves the signal to noise ratio of the data.

Our understanding of the phenomenology of DIAL gas leak detection has been greatly improved by our participation in this effort. Over the course of this study we imaged gas leak plumes of various sizes and shapes literally hundreds of times. The data collected during this study has been invaluable for gaining a better understanding gas leak behavior under a range of real-world conditions. 


\subsection{Report Details}

\subsection{Experimental Methods}

\subsubsection{Background}

The existing U.S. natural gas transmission infrastructure consists of over 300,000 miles of buried pipeline. DOE estimates that natural gas consumption will increase by over $50 \%$ percent (to 34 trillion cubic feet) by 2020, placing additional demands on the country's aging natural gas infrastructure. This combination of aging pipeline materials, increased demand, and utility deregulation presents an environment where natural gas emissions may occur with greater frequency and volumes. The reduction of these natural gas transmission pipeline emissions is critical to addressing several subjects of national importance, including: (1) natural gas conservation; (2) public and environmental safety; (3) greenhouse gas emissions; and (4) the overall cost of natural gas.

In the U.S., by regulation, all Class 1 and Class 2 pipelines must be inspected for leaks at least once each calendar year. Class 3 and 4 pipelines must be inspected 2 to 4 times each year. Current pipeline leak detection methods rely heavily on inspection crews walking (1-2 mph) or driving slowly (4 mph) along the right of way using flame ionization detectors to sample the air and detect the presence of hydrocarbons at, or near ground, level. This technique is slow, inefficient, and prone to false alarms. Recently developed, truck-mounted optical systems that detect methane are an improvement in some situations but are still quite limited.

With the intent of improving the way pipelines are monitored for leaks, a team of Space Systems scientists and external consultants was tasked to assess the ideal manner in which to remotely sense natural gas pipeline leaks from the air. Participants in this study included world-class experts in active and passive remote sensing and experts in the integration of remote sensing instruments into light aircraft. The approaches investigated included: Hyperspectral Imaging (HSI), Radar Imaging, Backscatter Absorption Gas Imaging (BAGI), Gas Correlation Spectroscopy (GCS), Active Gas Correlation Spectroscopy (AGCS), and Differential Absorption Lidar (DIAL) [3]. This investigation indicated that an active remote sensing approach, using DIAL, would be the most sensitive and effective technique for detecting and quantifying the methane and ethane in natural gas pipeline leaks.

\subsubsection{Objective}

The objective of this effort was to flight test a high sensitivity, broad-coverage, natural gas leak detection systems in an operational environment. Space Systems Airborne Natural Gas Emission Lidar (ANGEL) System was designed to accurately detect, image, quantify, and geo-locate leaks from natural gas transmission pipelines. The system operates in a wide variety of terrain and weather conditions. The ANGEL System, when used commercially, will provide a major breakthrough in speed, cost effectiveness, and safety of monitoring the nation's natural gas transmission pipeline system [1]. The two major phases of flight-testing for this effort consisted of early flight tests in Upstate New York, followed by participation in a DOE/DOT funded Field Test of Remote Sensing Gas Leak Detection Systems at the Rocky Mountain Oilfield Testing Center (RMOTC) near Casper Wyoming in September of 2004. 


\subsubsection{The Physics behind DIAL gas detection}

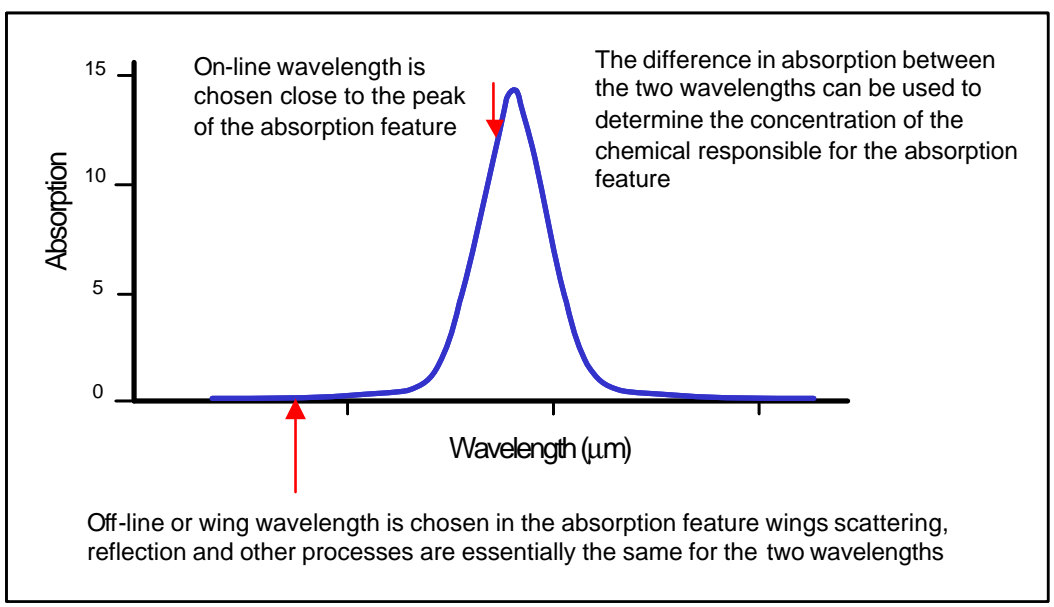

Figure 1. Generic repre sentation of DIAL on-line and off-line positions

Our chosen method of detecting methane plumes is an active remote sensing technology known as Differential Absorption LIDAR (DIAL). DIAL is the use of at least two beams of light tuned on and off of an absorption feature of the gas species to be measured. By comparing the light from the on-resonance beam to the light in the off-resonance beam, the concentration of gases from long range may be inferred (Figure 1).

Our design uses lasers to generate the light beams. The system takes light reflected from the ground to generate a signal on a detector. Each wavelength is detected separately. The basic LIDAR equation describing the light reflected from the surface is shown in Figure 2.

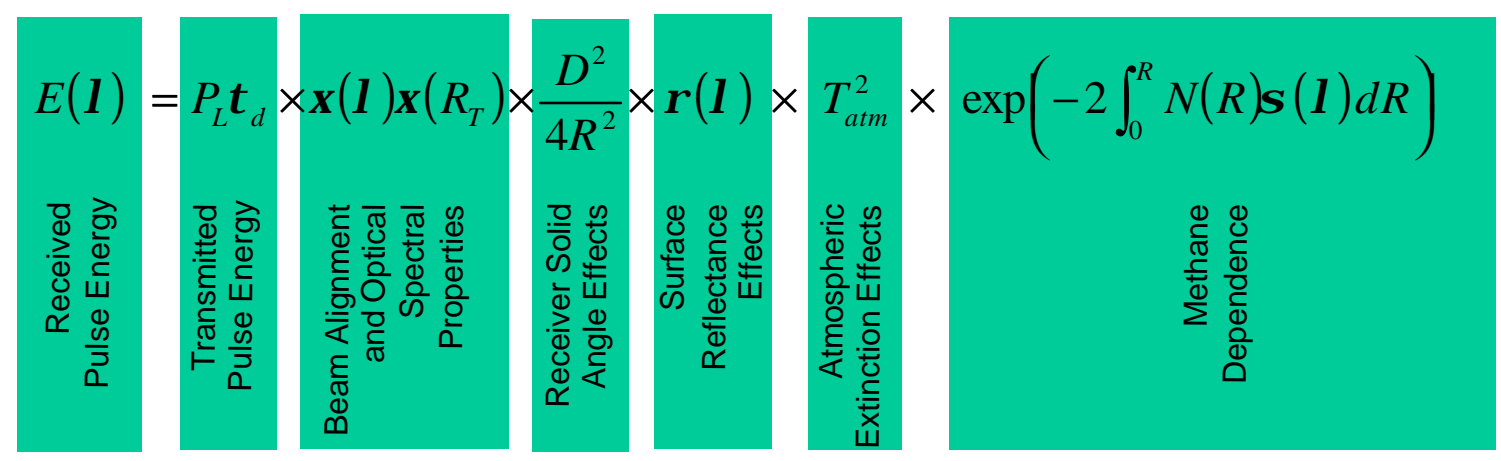

Figure 2. Basic DIAL equation 
The term $\mathrm{E}(\lambda)$ is the energy contained in the pulse that has traveled to the ground and back. This return energy depends on many things as expressed by the right hand side of the equation. The first term on the right hand side, gives the per-pulse energy of the transmitter. The second term combines effects from the optical system alignment and spectral response. The next term shows the effect of the receiver solid angle. These terms are governed largely by the lidar optical design. The next two terms show the dependence on the surface reflectivity (assumed Lambertian in this equation) and the atmosphere. The final term shows the effect of the concentration of methane, $\mathrm{N}(\mathrm{R})$, and the optical properties of methane as represented by $\sigma(\lambda)$, the methane absorption cross-section.

These return signals are used to determine the methane concentration multiplied by the depth of the methane plume. This quantity is called the concentration path length or CPL and is given by the following equation:

$$
C P L=N h=\frac{C}{2 \sigma(\lambda)}\left(\ln \left(\frac{E_{\text {off }}}{E_{\text {on }}}\right)\right)
$$

The CPL is an integrated concentration and can be thought of as giving a measure of the concentration of a cylindrical shaped sample of the plume of height (or path length) h. (Figure 3)

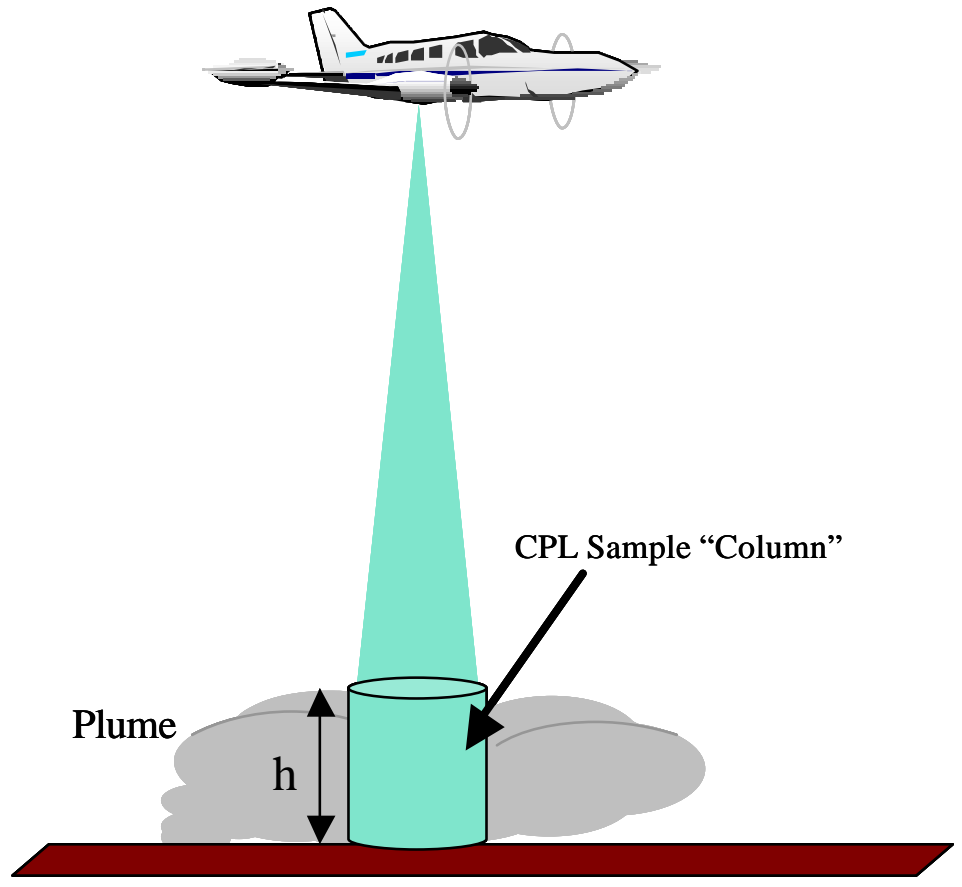

Figure 3. Concentration Path Length (CPL) of a plume as measured from an aircraft.

The signal to noise ratio (SNR) for any given measurement determines the sensitivity of the system and will be the number of signal photons divided by the total noise of the system and solar reflected and thermal background photons incident on the system during the measurement and other effects such as scintillation in the atmosphere and speckle, a surface roughness effect. Both will reduce the overall SNR in a real system. 


\subsubsection{ANGEL System Overview}

The DIAL Sensor in the ANGEL System [4] is built around solid-state laser sources (Transmitter) combined with a telescope system (receiver) to collect the laser light reflected from the ground surface. Figure 4 provides an artist conceptual drawing of the in-flight survey of a natural gas transmission line right-of-way.

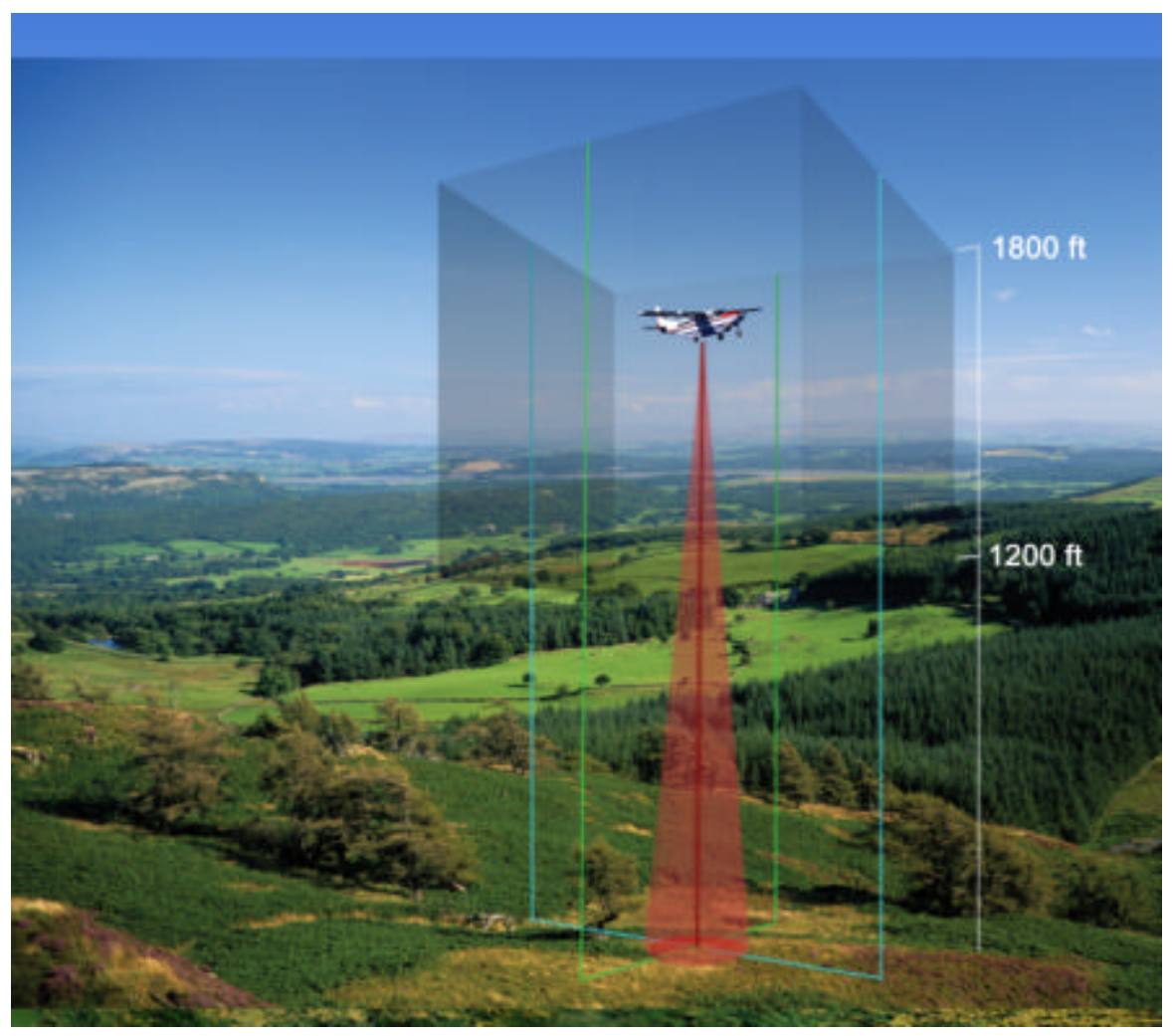

Figure 4 Conceptual view of the airborne ANGEL Service capturing leak survey data along a pipeline right-of-way.

In addition to the DIAL transmitter and receiver subsystems, the ANGEL System onboard the aircraft includes a computer controlled pointing and scanning subsystem designed to compensate for aircraft motion while keeping the lasers scanning over pipeline. For a typical flight operation, the Operations Center provides mission planning data for a selected pipeline to the flight crew. This data is loaded into the airborne system. The aircraft and crew then proceed to the starting point for a pipeline survey and fly the pre-selected natural gas pipeline route. During the flight, the Payload ingests and records precise real-time position and attitude data. This positional information is then used in conjunction with the targeting data from the Operations Center to assure the continuous collection of raw sensor data along the route.

A scanning subsystem allows the collection of data over a wide swath of ground as the aircraft flies above the right-of-way. The System also provides navigational aids to the pilot to assure the aircraft is located in the correct position, thus allowing the pointing and scanning subsystems 
to accurately acquire data over the pipeline right-of-way. Use of an automatic scanning and pointing system combined with a pilot navigational aid allows the ANGEL system to fly a smooth route while collecting data over a very irregular pipeline (Figure 5).

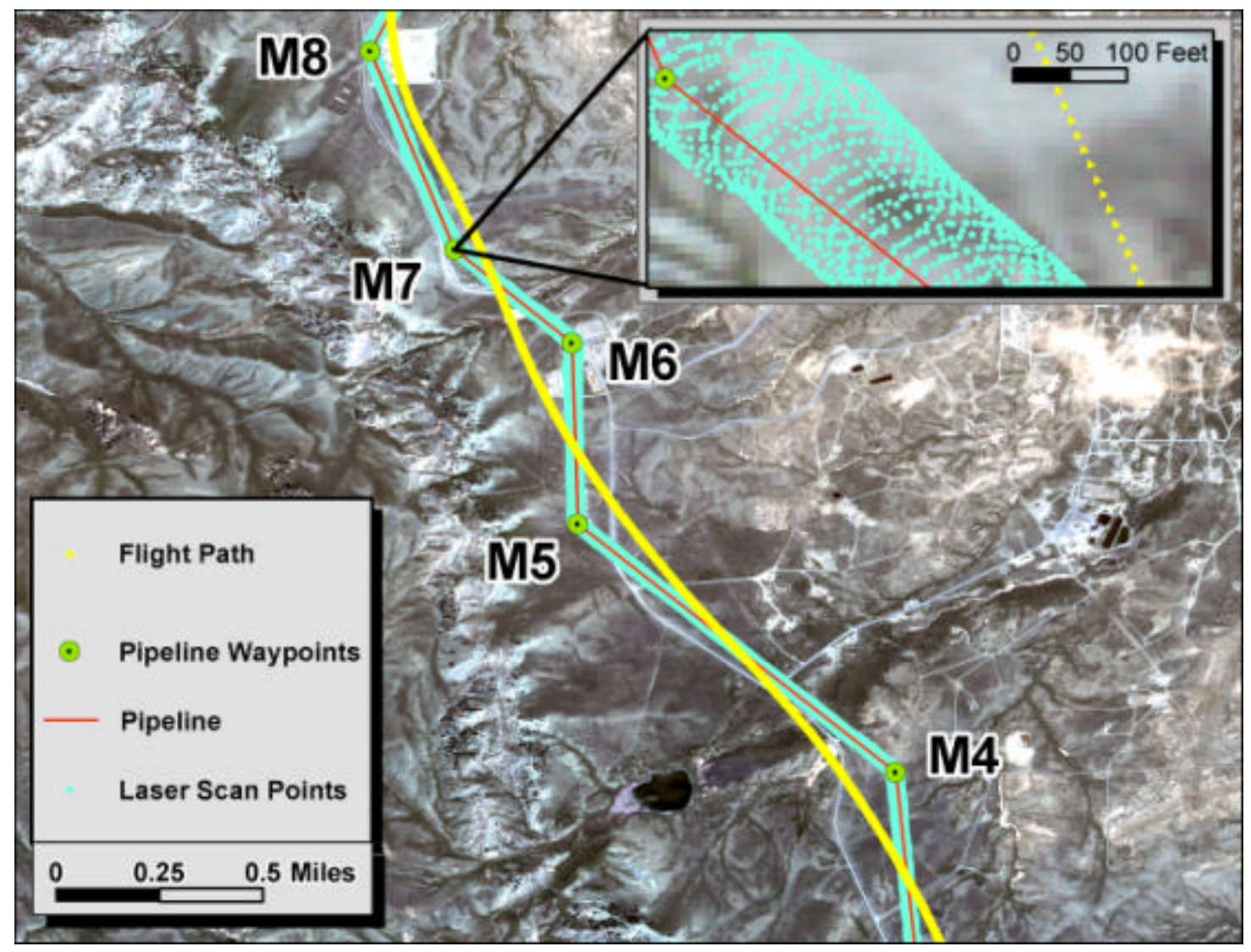

Figure 5 Space Systems ANGEL pointing results from a short section of the Virtual Pipeline Route at RMOTC. The aircraft path is shown in yellow. The pipeline position is shown in red. The position of each data point is shown in green forming a coverage swath 110 feet wide. The sensor pointing and scanning system allows full coverage of the ROW corridor in a single pass.

\subsubsection{Aircraft Platform Description}

The airborne portion of the ANGEL System consisted of a test aircraft and an integrated sensor payload. The test aircraft used was a modified Air Force owned Convair 580 (NC-131H) Turboprop known as the Total In-Flight Simulator (TIFS), operated by General Dynamics. This aircraft was used for both Early Flight Testing and for the Field Test at RMOTC. The TIFS aircraft shown in Figure 6 is illustrated in Figure 7. Although the ANGEL System was later integrated into a much smaller (and more economical) Cessna Grand Caravan following early flight tests, the TIFS aircraft was chosen for early flight tests in order to accelerate the development schedule and allow the ITT team to participate in the DOE sponsored RMOTC field test in Wyoming. The TIFS aircraft is a very large and very powerful test aircraft with ample room for the sensor and multiple operators, easy access to the sensor once installed, ample 
electrical power, payload carrying capacity, and a history of carrying FAA approved experimental payloads. The skilled General Dynamics test pilots, flight crew, and ground crews mitigated the risk of conducting early flight tests on an accelerated schedule. Early integration and testing in the TIFS aircraft greatly simplified the later integration of the sensor into the much smaller Cessna aircraft.

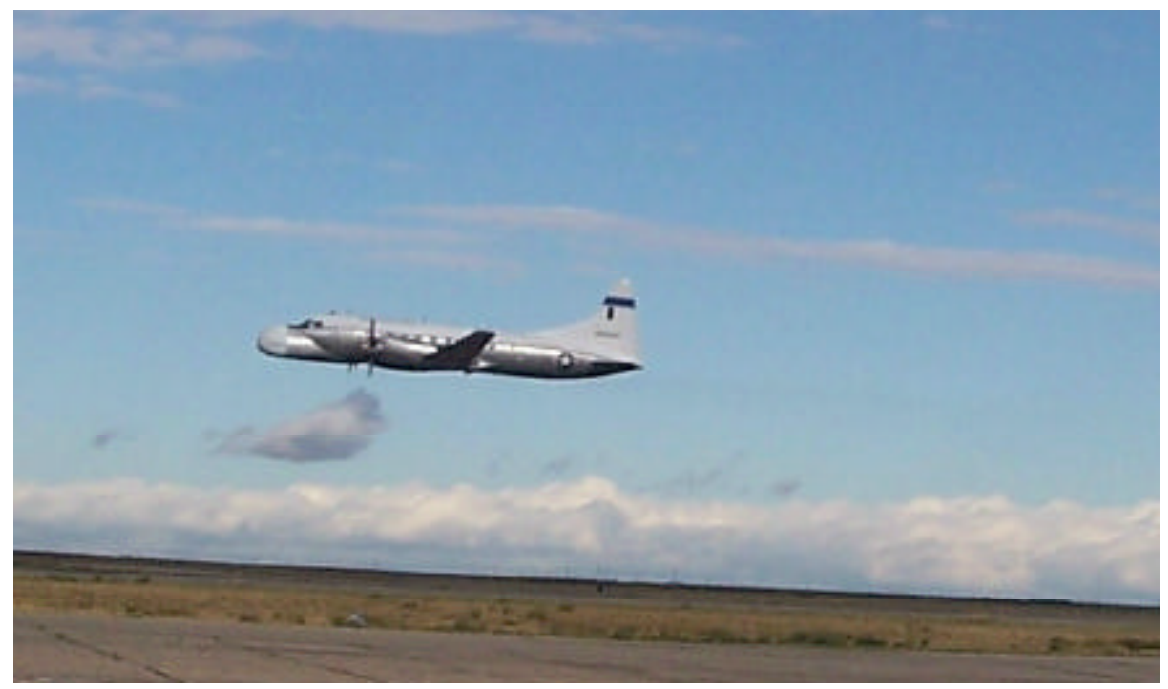

Figure 6. Space Systems' ANGEL System test aircraft-General Dynamics Convair 580 (NC$131 H$ ) turboprop landing at the Natrona County International Airport, Casper, Wyoming

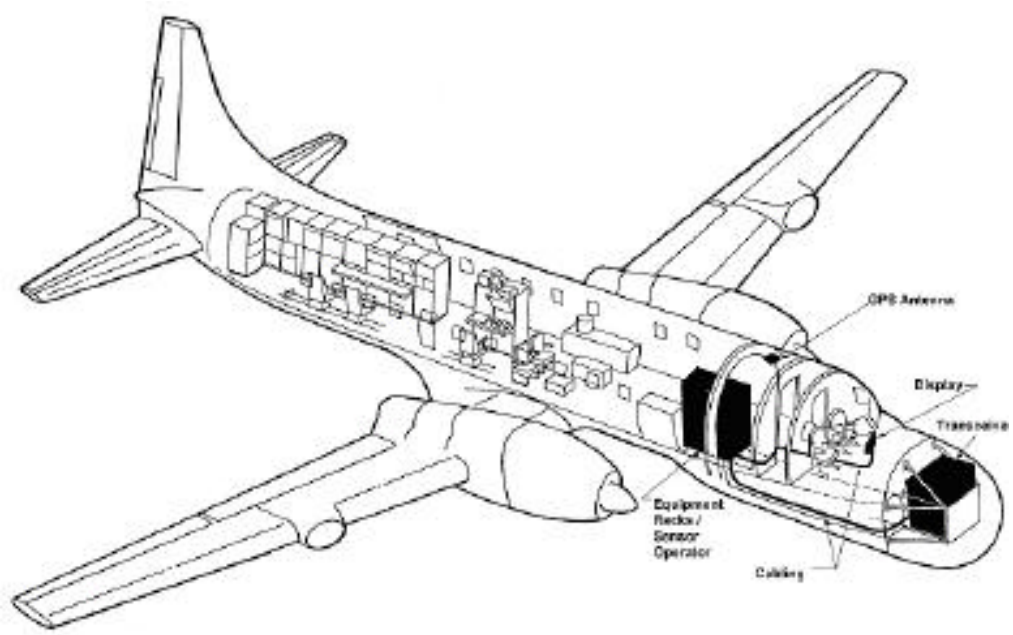

Figure 7. Diagram of Space Systems ANGEL System Test Aircraft illustrating placement of the major sensor components. 

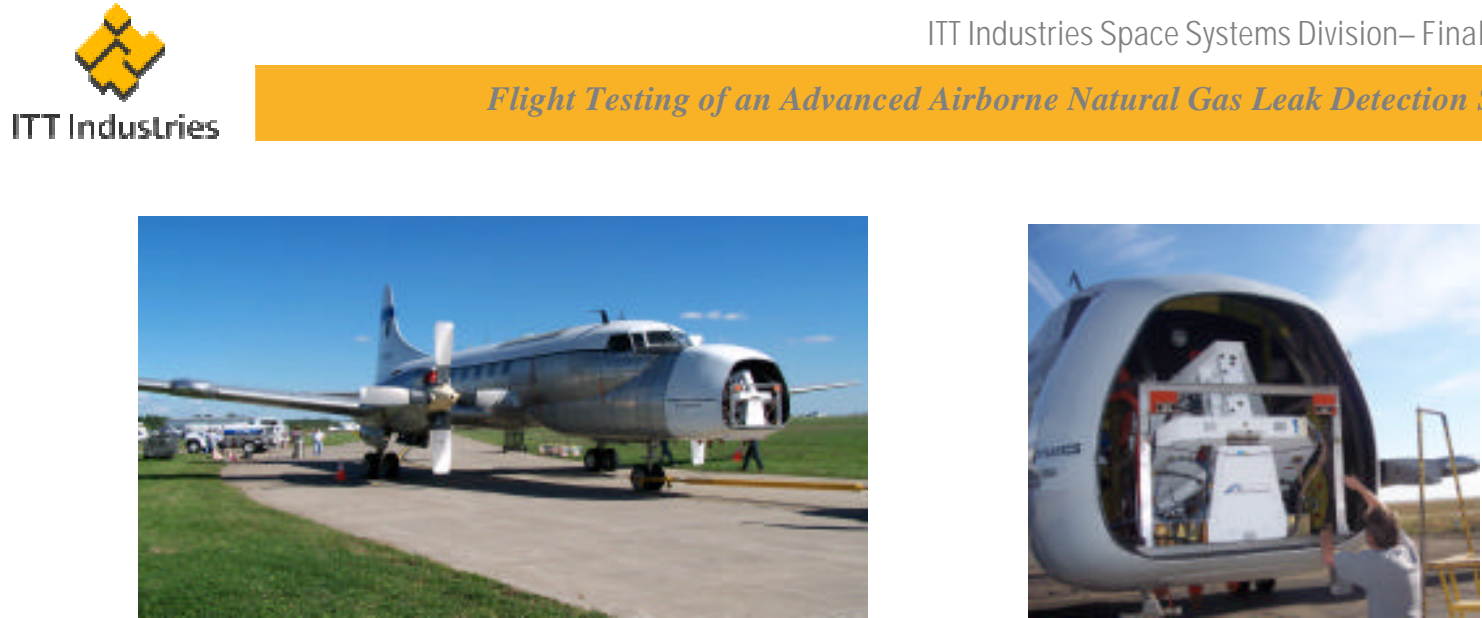

Figure 8. Space Systems ANGEL System Test Aircraft showing placement of the transceiver in the nose of the aircraft during preparation for early flight tests in Buffalo, NY.

The Payload used in the early flight-testing phase of sensor development is the same basic hardware and software that will be used in commercial operations. In general, the Payload consists of a Transceiver Assembly, two aircraft electronic Rack Assemblies, cables, and other miscellaneous hardware and software. Payload integration within the TIFS flight test aircraft is illustrated in Figure 8.

The DIAL data, continuous aircraft positional data (yaw, pitch, roll), sensor performance data, and meta-data such as atmospheric pressure and temperature are recorded on the aircraft on a removable hard drive. On-board digital camera data used to record imagery of the survey route (Figure 9) in real time is recorded to writeable DVD as a separate data set.

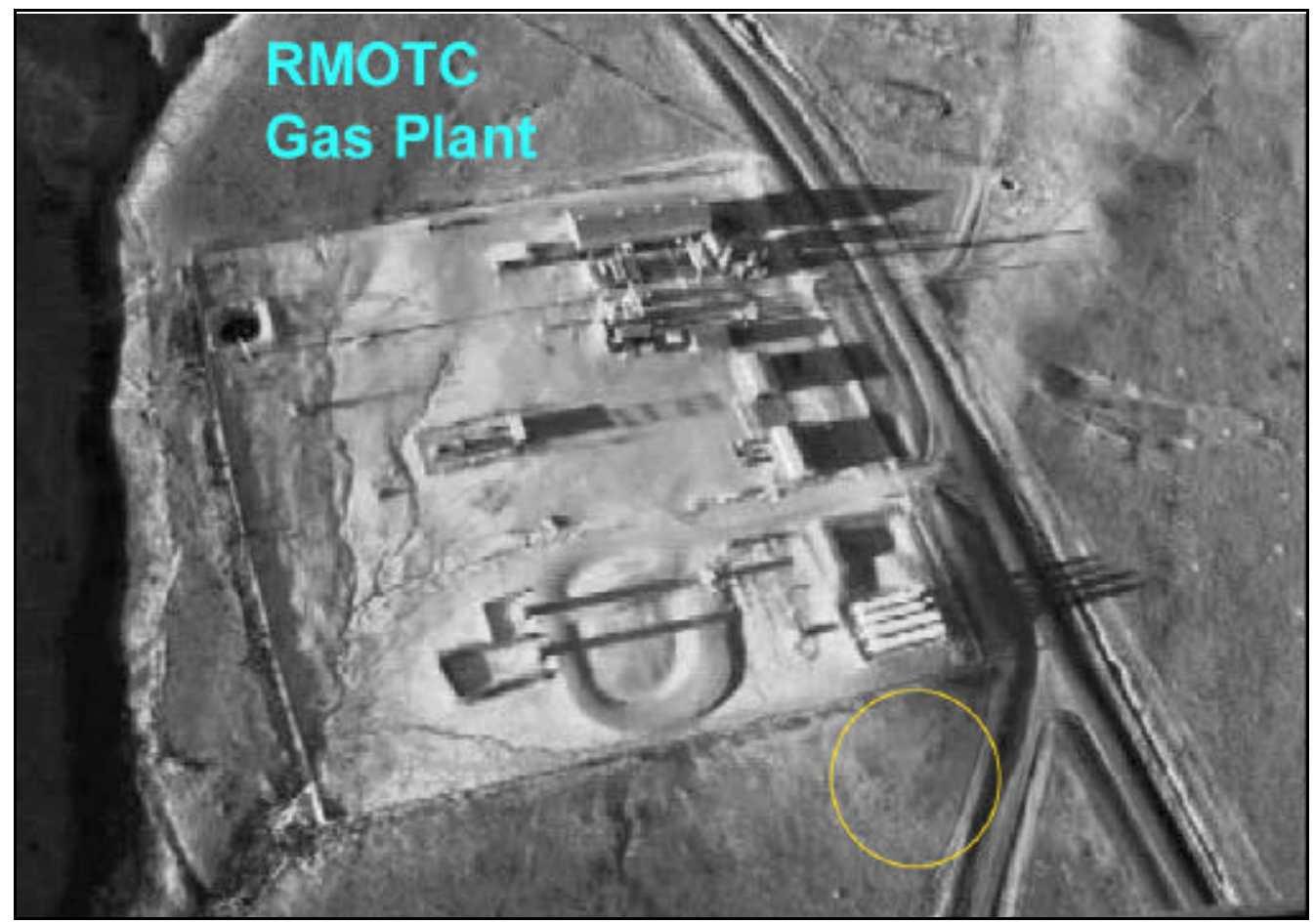

Figure 9 Aerial view of the Gas Plant at the Rocky Mountain Oilfield Testing Center acquired with the ANGEL Sensor engineering camera. The yellow circle indicates the approximate position of a leak detected with the DIAL subsystem. 


\subsubsection{Data Processing and Analysis}

A major element of the ANGEL System is the Operations Center where data is processed and analyzed. Once the aircraft lands, data is transferred from the aircraft to the Operations Center and archived to ground storage disks. The sensor data is processed using software based on Space Systems' proprietary DIAL/Lidar algorithm set. During initial processing, data points are geo-located and assessed for the presence of the natural gas. The level of gas detected is computed in terms of concentration path length (CPL).

The output of the processing step includes 1) GIS shape files that will be used by analysts to create customer reports and 2) engineering data that details sensor and related subsystem performance. Space Systems engineers use this latter information to assess data quality and to compensate for various environmental, surface and operational variables that can effect data interpretation.

GIS maps of CPL measurements are used to create a visual graphic of elevated gas concentrations (Figure 10). This data is then interpreted visually and run through additional algorithms to automatically identify the presence and quantity of natural gas. Reports and visualizations are generated using Space Systems ANGEL Pipeline Visual Inspection and Analysis Software - APVIAS. The APVIAS software package is based upon Space Systems' wholly owned subsidiary Research Systems Inc. IDL/ENVI software and has been customized for the analysis and interpretation of ANGEL data. The ANGEL data is fully geo-referenced so analysts can overlay the ANGEL data with other geo-referenced images or DEMs to aid in interpretation. 


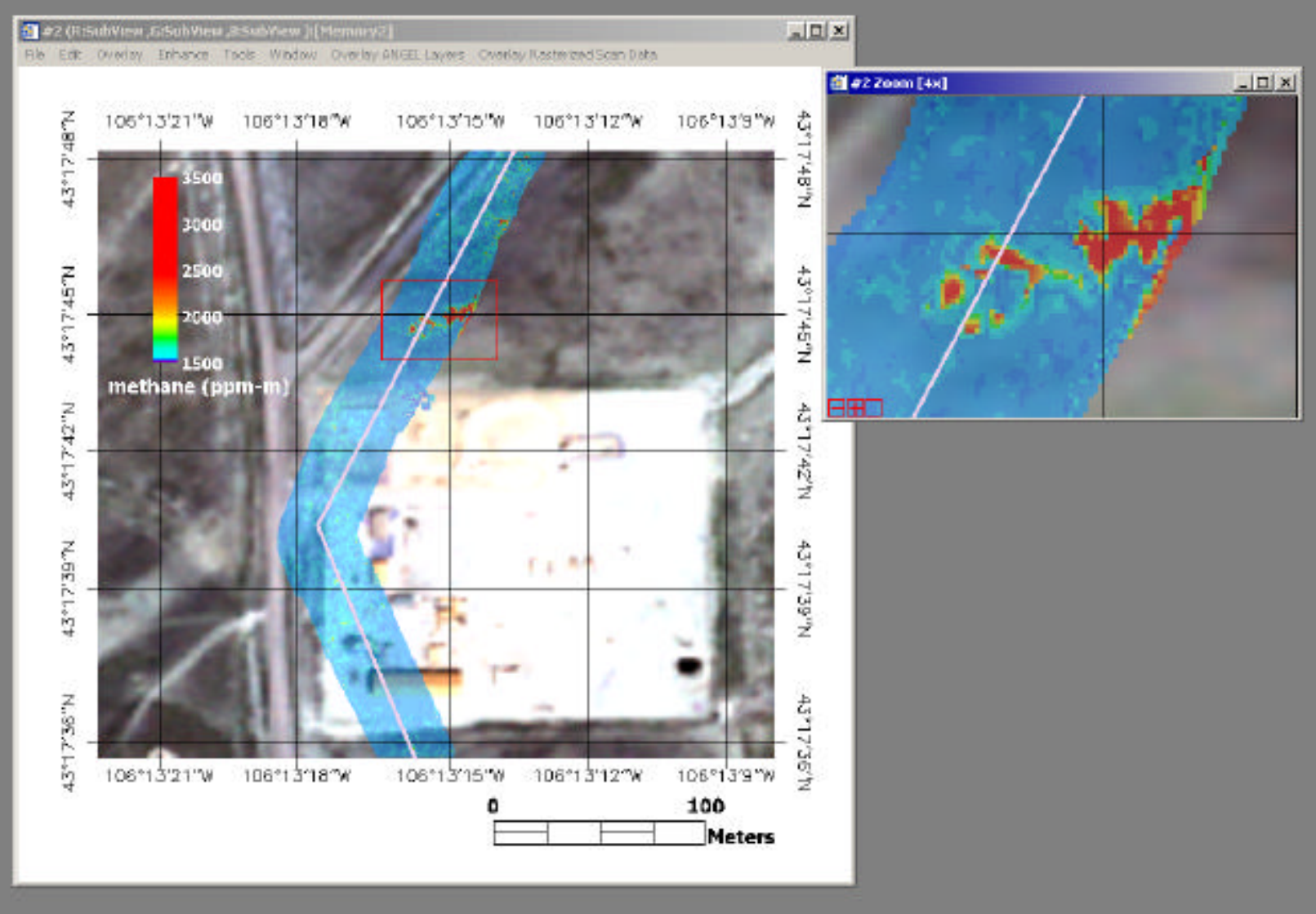

Figure 10 Detection, quantification, visualization, and geolocation of a natural gas plume at RMOTC.

\subsection{Results and Discussion - Early Flight Tests (Buffalo, NY)}

\subsubsection{Objective of Early Flight Tests}

The objective of the first three flights was to concentrate on verifying the following basic ANGEL sensor functionality:

- Demonstrate the sensor can operate in the Convair 580 environment and determine typical physical flight characteristics relating to sensor operation including vibration, temperature and that it can operate with aircraft power.

- Demonstrate that the lasers maintain power output throughout the flight.

- Demonstrate robustness of laser frequency locking mechanism.

- Demonstrate the receiver system can receive adequate laser energy regardless of ground reflectivity.

- Demonstrate the pointing system meets accuracy requirements.

- Demonstrate the post mission data processing system can process the raw ANGEL sensor data and produce acceptable results. 
The initial flight tests were intended to debug sensor operation in the test aircraft and obtain initial characterization of ANGEL operation and capabilities. This section describes the test flight sequence prior to departure for the Department of Energy demonstration exercise in Casper, Wyoming.

\subsubsection{Creation of a simulated natural gas leaks for flight testing}

Over the summer of 2004 the Space Systems team worked with National Fuel gas Pipeline Company in upstate New York with the goal of creating a series of simulated leaks along actual pipeline Rights-of-Way in Upstate New York. Early planning efforts included a physical survey of the Empire Pipeline and an assortment of other National Fuel lines and facilities between Rochester and Buffalo. Two sites along the pipeline were selected as ideal for the creation of moderate to large natural gas leaks (Figure 11). The sites chosen were on property owned by National Fuel, close to the airport and away from public roads. Ultimately only the sites closest to the airport were used to create simulated leaks.

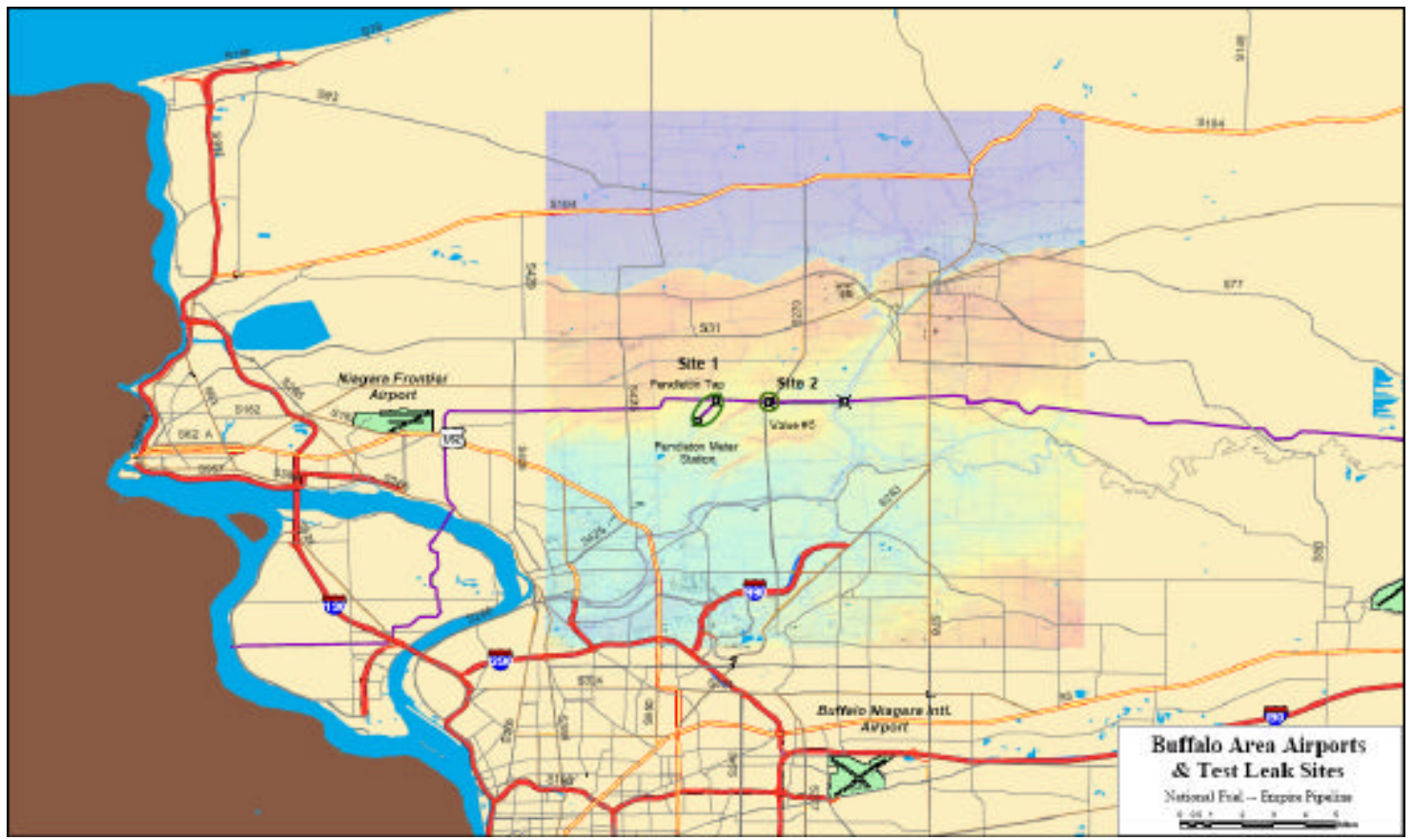

Figure 11. Map showing the location of the Niagara Frontier Airport and 2 sites selected for possible simulated leaks along the Empire Pipeline (shown in purple).

During early flight testing, National Fuel supplied gas for the simulated leaks using a set of portable high pressure natural gas storage tanks mounted on a trailer. Gas from these tanks was run through a 2-stage regulator to control the release rate and flowed through a 30 foot length of copper tubing to the actual release site. A flow meter was used to accurately set the regulator to a given release rate before each ITT Industries ANGEL System overflight. At the actual simulated leak site the copper tube was run to the bottom of an 18 inch deep post hole filled with coarse gravel. A heavy weight was place on the copper tube at the leak site to prevent movement of the copper tube during large releases. Calibrated natural gas leaks from near 0 to 5,000 standard cubic feet per hour (scfh) were possible with this setup( Figure 12). 


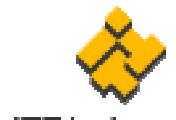

ITT Industries

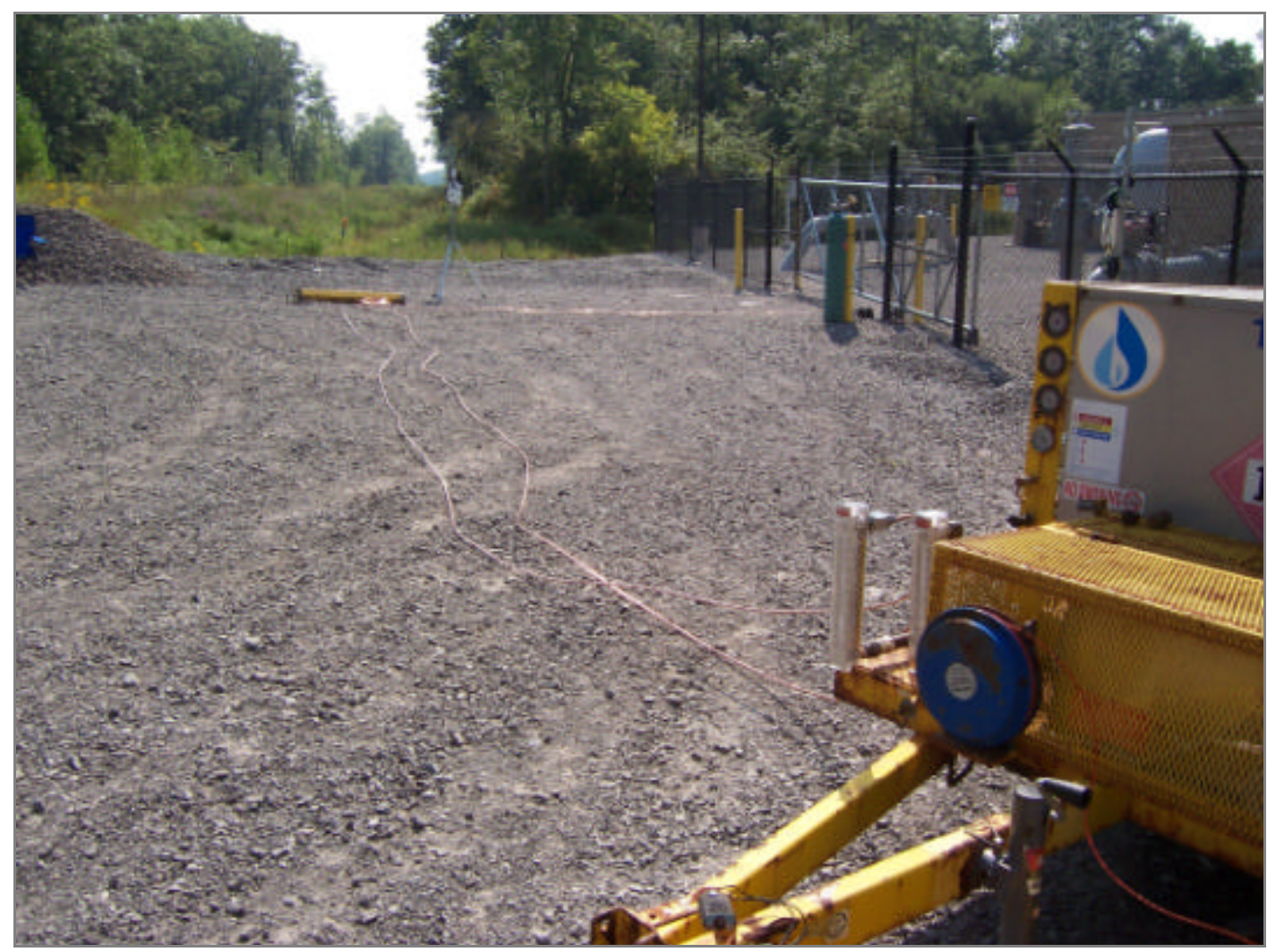

Figure 12. Image of a simulated natural gas leak site along a pipeline right-of-way near Buffalo, New York.

The DOE used a very similar simulated leak setup for many of the smaller leaks at the Rocky Mountain Area Test Center [2].

During each release, the simulated leak site was instrumented with a portable meteorology station equipped with a data logger to record wind speed, direction, and a range of other weather measurements at one minute intervals. The ground test team was equipped with air-to-ground radios to allow communication with the aircraft crew. Gas releases were started one to two minutes before the aircraft was overhead and shut off after the aircraft passed over the target.

One major advantage of selecting the Empire Pipeline system for flight testing was the availability of recently acquired GIS information for these lines. GIS information supplied by National Fuel combined with GPS locations of selected simulated leak sites were used to create Mission Planning files to guide the pilot and point the sensor. GIS information from National Fuel was draped over publicly available 1-meter geo-referenced imagery of the area (Figure 13) to roughly verify the accuracy of the GIS data and ultimately to provide context to the data collected. 

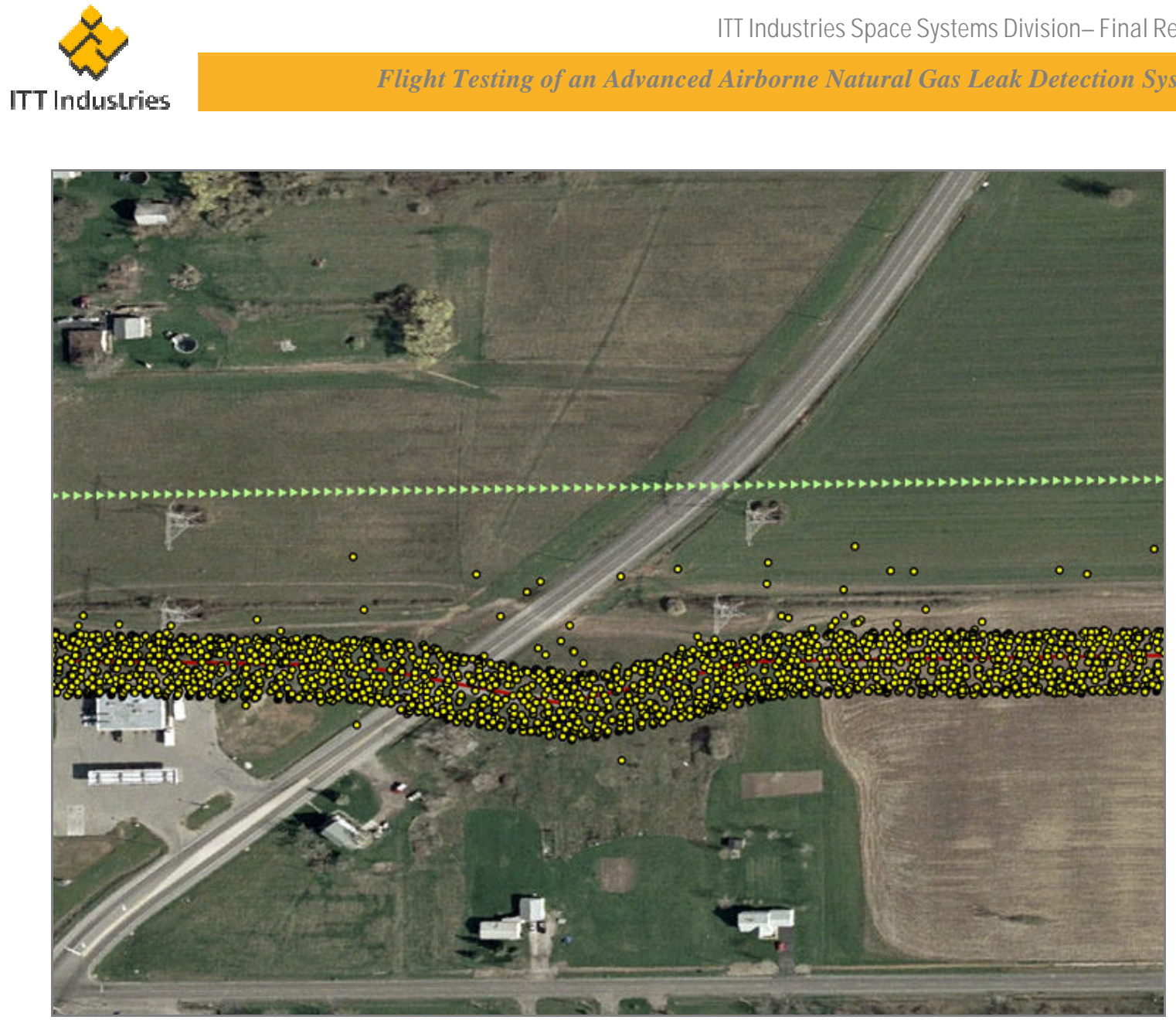

Figure 13. A geo-referenced color image of the pipeline right-of-way is used as a base GIS raster imagery layer. The GIS vector layer of the pipeline supplied by National Fuel is indicated in red, the track of the ANGEL system aircraft as it flew the line is marked in green. Yellow dots indicate the position of individual laser spots along the inspection swath of the DIAL system.

\subsubsection{Flight One - (3 September 2004)}

\subsubsection{Objectives}

The objectives of the first flight were to fly multiple events over pre-determined ground based test targets. The first flight was scheduled over a calibrated gas leak to collect data for basic sensor functionality characterization. The second event was to fly a series of passes over an accurately geo-located building to calibrate the system's geo-location capabilities. The third event was to again pass over a calibrated leak to see if natural gas could be detected.

\subsubsection{Results}

During this first flight the ANGEL System encountered multiple difficulties. The sensor computer went down during this flight and despite multiple attempts to recover operations no useful DIAL data was collected. Total time in the air was 1 hour and 23 minutes. Software fixes were implemented at the conclusion of the flight to remedy the problems encountered. 


\subsubsection{Flight Two - (3 September 2004)}

\subsubsection{Objectives}

The original objectives for the second flight were to continue attempts to detect natural gas. Due to the difficulties experienced during the first flight, the flight plan attempted on flight number Two were scaled back and focused solely on detection of simulated leaks

\subsubsection{Results}

The aircraft shutter door could not be operated properly because of an aerodynamic pressure differential problem. Future flights were initiated with the shutter door slightly opened to equalize pressure and allow the shutter to easily be retracted the rest of the way in flight. Total time - engine running - 1 hours and $26.5 \mathrm{~min}$.

\subsubsection{Flight Three - (7 September 2004)}

\subsubsection{Objectives}

The main goal of the third flight was to again to get a general idea of the performance of the sensor. Secondary objectives were to observe the pointing accuracy of the sensor. Prior to the third flight, software changes were made to various program elements to improve reliability.

\subsubsection{Results}

This flight was the first time that DIAL data was successfully collected from the air. The weather on this flight, however, became a problem. Rain coupled with low ceilings made the flight challenging.

The robustness of inter-computer communications software needed be addressed prior to deployment to RMOTC. Software guiding the pilot required modification as the flight path flown was several hundred yards to the east of the pipeline right of way. Although no DIAL data was collected over the simulated leak site, DIAL data was collected over nearby agricultural areas and trees providing confidence that our pointing accuracy could be greatly improved with a software adjustment during ground data processing. GIS processing of the data to plot range to target info for each offline laser pulse resulted in a crude 3-Dimensional lidar image of the ground and vegetation under the plane (Figure 14). When flying at 1,000 feet, the conical scan pattern generated by the sensor provided excellent coverage of a $>100$ foot wide swath. Early DIAL measurements of methane concentration over agricultural areas and forests proved to be very noisy, particularly over forested areas (Figure 15). Improving system signal to noise characteristics remained a major focus of the engineering and analytical teams. 


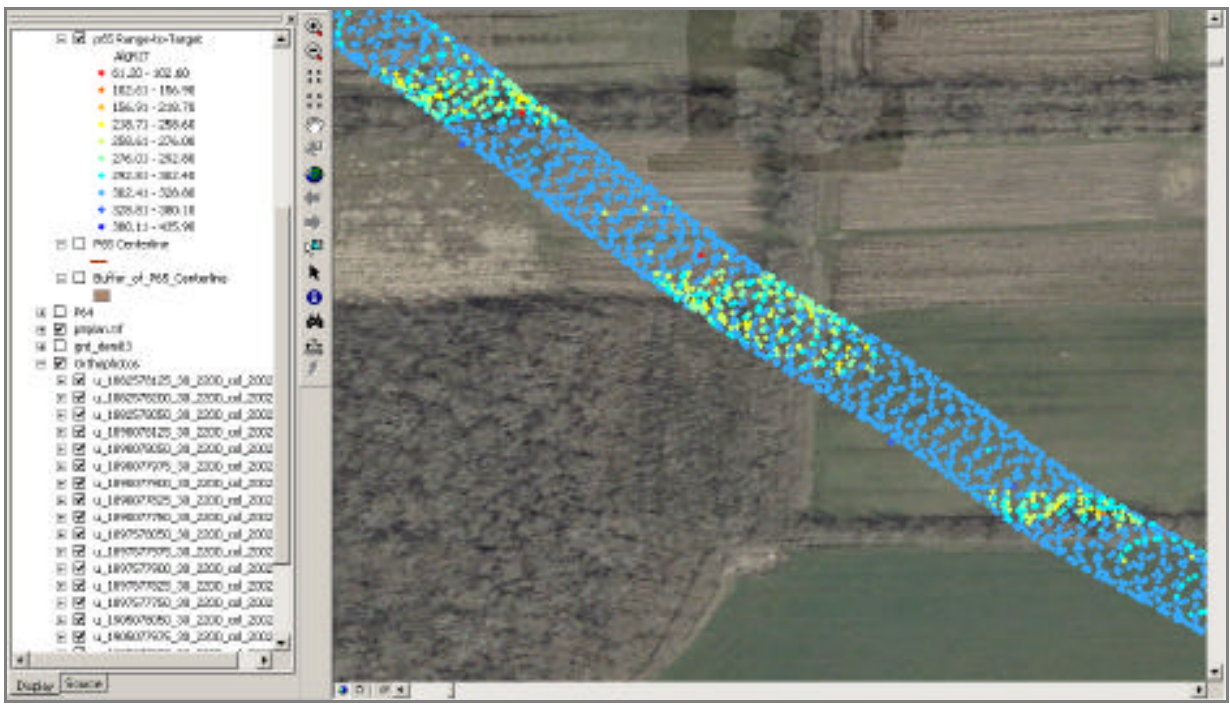

Figure 14. First airborne DIAL data set from the ANGEL sensor processed color-coded for range-to-target (distance from the sensor to the land surface). Areas colored blue correspond to agricultural fields (low vegetation = greater range to target), Yellow areas of the scan swath roughly correspond to forested areas which reflect the laser light before it gets to the ground and results in a smaller range-to-target values. low areas

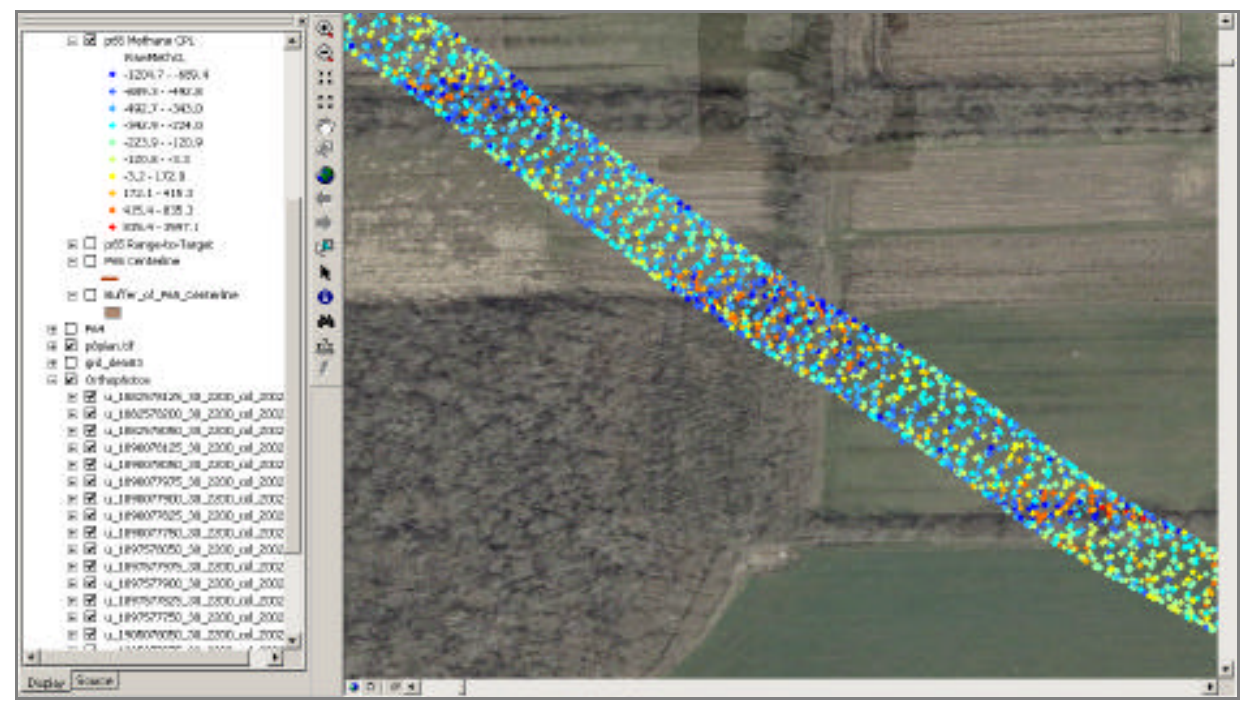

Figure 15. First airborne DIAL data set from the ANGEL sensor processed color-coded for methane concentration path length (CPL). Methane CPL in this "first light" image are highly variable and greatly effected by vegetation. A variety of hardware and software have been implemented to improve the quality the ANGEL data. 


\subsubsection{Conclusions from early flight tests}

The operation of the system improved on every flight. Several additional flights were highly desired to get the sensor ready for the DOE Field Test of remote sensing leak detection systems in Wyoming. With no time left to debug the sensor, the decision was made to deploy to Wyoming and attempt to finish the sensor integration in conjunction with the DOE Field Test.

\subsection{Overview of RMOTC Field Test (Casper, WY)}

In 2004, the Space Systems ANGEL System participated in a government funded field test of remote sensing leak detection systems. The field test was held at the DOE's Rocky Mountain Oilfield Testing Center (RMOTC). RMOTC's field site is the Teapot Dome Field, 35 miles north of Casper, WY (Figure 16). The United States Department of Energy, National Energy Technology Laboratory (NETL) and the United States Department of Transportation, Office of Pipeline Safety (OPS) jointly funded this field test. The test was organized and run by the Southwest Research Institute (SWRI) in cooperation with the NETL, OPS, RMOTC, a number of pipeline industry advisors, and the remote sensing system technology providers. A total of 6 industry and government groups (technology providers) were invited to participate in this test [2]. RMOTC's field site is the Teapot Dome Field, 35 miles north of Casper, WY (Figure 17 ). The field test was held from September 12-17, 2004 after a number of months of planning and preparation. ITT involvement in early planning for the field test consisted of numerous telcons throughout the year, participating in Advisory Panel meetings and Field trips (Figure 16 \& Figure 17) to the proposed test area with test organizers and other participants in March and June.

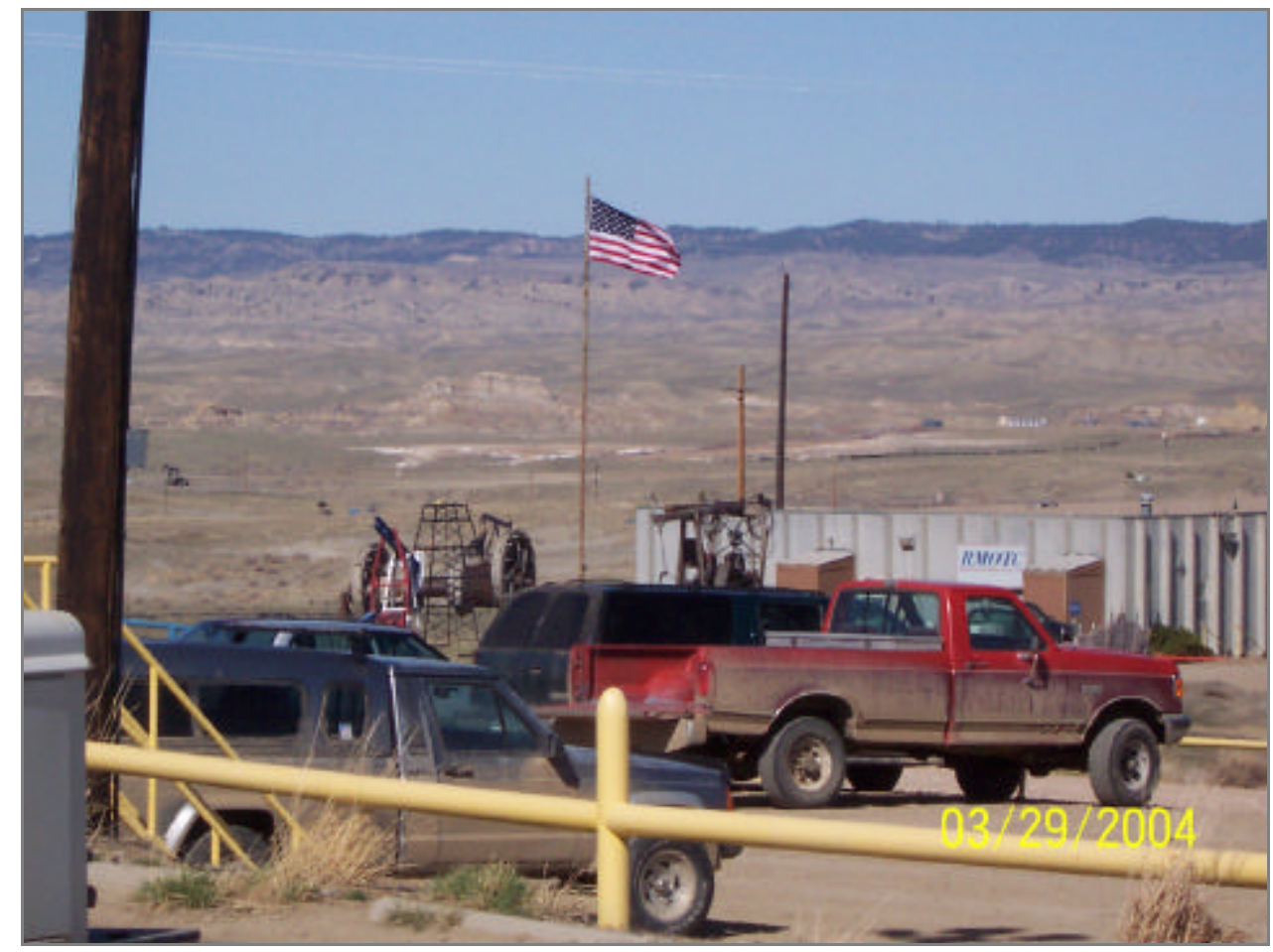

Figure 16. Photograph of the RMOTC test area taken from RMOTC headquarters building. 

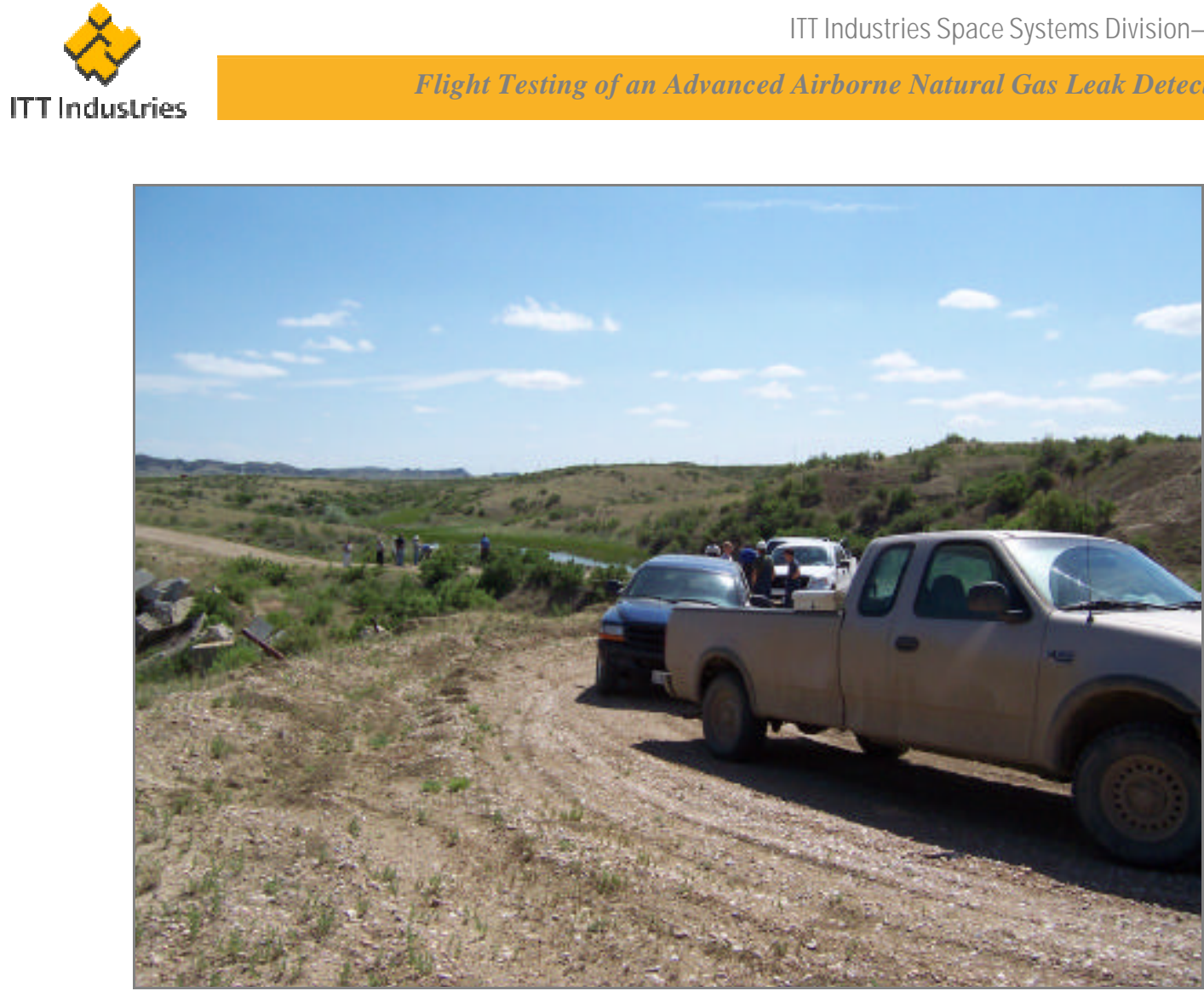

Figure 17. Inspection of Proposed Virtual Pipeline Route at RMOTC in June 2004.

RMOTC was established by the U.S. Department of Energy (DOE) to partner with the petroleum industry to improve domestic oil and gas production through the field testing of new technology, evaluation of new equipment, and demonstration of new processes. The field test site is a 10,000-acre operating oil field. There are approximately 1,200 well bores and approximately 600 producing oil and gas wells, in nine producing reservoirs ranging in depth from $500 \mathrm{ft}$. to $5000 \mathrm{ft}$.

For this test, a virtual pipeline route approximately 7.55 miles in length was set up by the test organizers at the western edge of the RMOTC area (Figure 18). The test organizers created a series of leak sites along this virtual pipeline to simulate pipeline leaks of a variety of sizes. Leaks ranged in size from 1 standard cubic feet per hour ( $\mathrm{scfh}$ ) to 5,000 scfh. With the exception of a known calibration leak on the southern end of the test course, the size and location of each of the leak sites were hidden by the test organizers and remained unknown until after each of the test participants submitted their final leak detection report.

Participants in the RMOTC Field Test fielded a range of different sensors operated from ground vehicles, fixed wing aircraft, helicopter, and UAV platforms. One of the major challenges of using a sensor at RMOTC was the relatively windy condition. During planning meetings with the test organizers in early 2004, the Space Systems team requested flight times in the early morning and late afternoon to avoid the mid-day atmospheric turbulence and high winds. Test organizers provided a 50-minute inspection time slot on each day of the test September 13-17 (a total of 10 inspection times). In addition, Space Systems was provided a 50- minute practice time slot on Sunday September 12th before the start of the test. Leak rates and locations were changed daily throughout the test. 


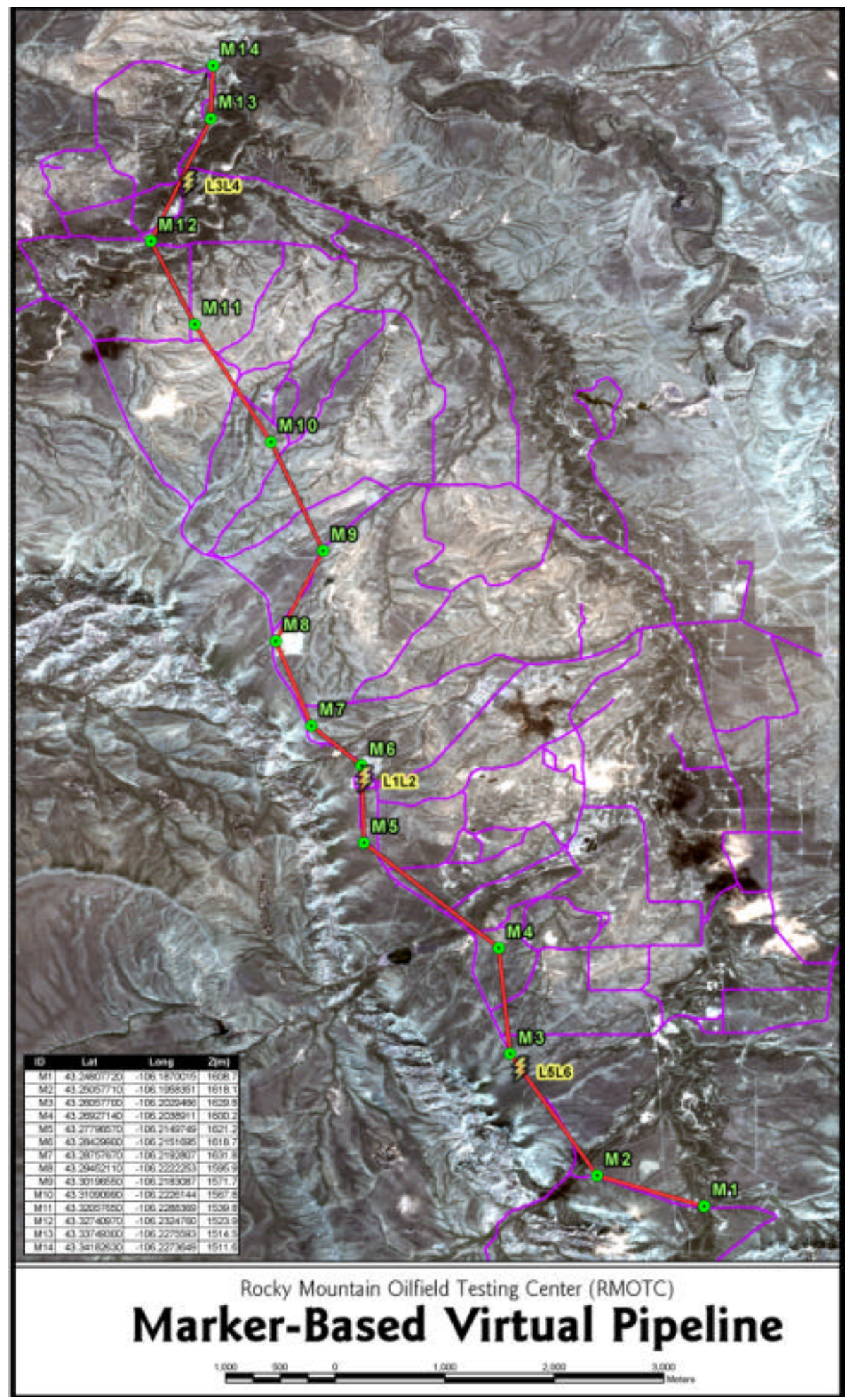

Figure 18. Map of the Marker-Based Virtual Pipeline along the western edge of the Rocky Mountain Oilfield Testing Center in Wyoming. Virtual pipeline in shown in Red, 14 pipeline markers of known location are shown in green, meteorology stations are shown in yellow. 


\subsubsection{RMOTC Field Test}

Between the days of Sunday, 9/12/2004 to Friday, 9/17/2004, ITT Industries deployed a total of 26 employees and subcontractors to Casper Wyoming to participate in the RMOTC Field Test. The ITT team consisted of the aircraft pilot and crew, sensor operators, and a team of engineers, scientists, and leadership at hanger and ground data processing facilities at the Casper Airport (Figure 19 and Figure 20).

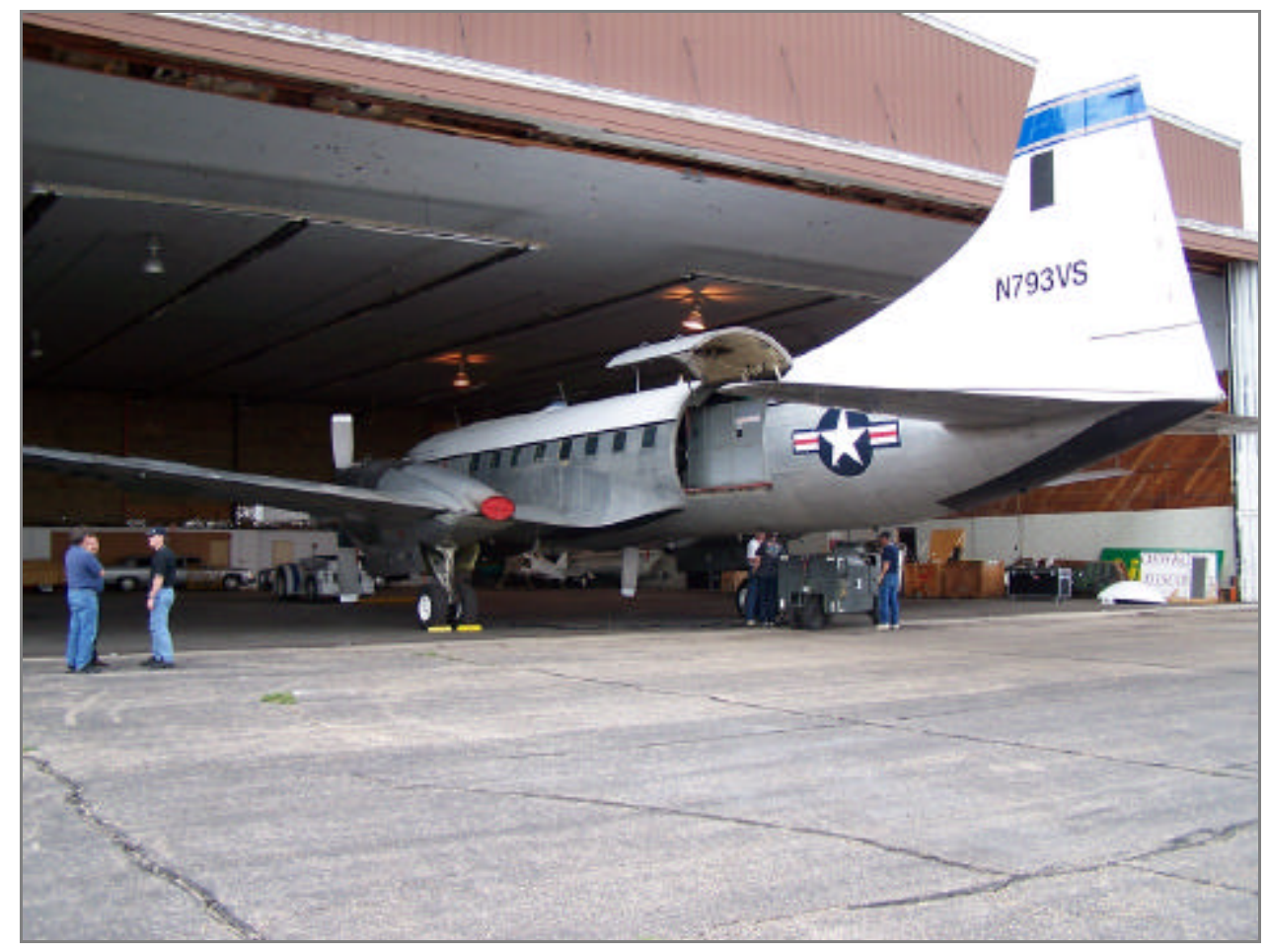

Figure 19. ITT Industries ANGEL system test aircraft in Casper, Wyoming

Over the course of the week the test aircraft flew and collected data during every available time slot. A total of 11 flights were conducted from Sunday, 9/12/2004 to Friday, 9/17/2004. A detailed description of each of these flights is included in Attachment 1.

After some initial problems on Sunday and Monday, large amounts of usable DIAL data was collected from Tuesday through Friday. The RMOTC Virtual Pipeline was 7.5 miles in length and the test aircraft was able to inspect the entire Virtual Pipeline route 6 to 7 times in each 50 minute window. Although the RMOTC Virtual Pipeline contains a number of relatively sharp

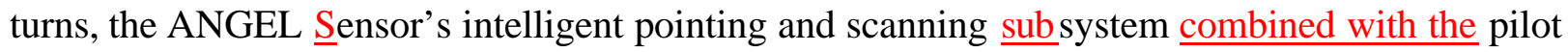
guidance system allowed coverage of $100 \%$ of the pipeline route in a single pass.

At RMOTC the ANGEL sensor collected approximately 3 gigabytes of data for each complete pass. During every pass the sensor measured for the presence of methane more than 250,000 times. This allowed the creation of a methane map the entire length of the pipeline. By the end of the week the Space Systems Ground Data Processing team filled a 500 gigabyte server hard drive with raw and processed ANGEL data. 


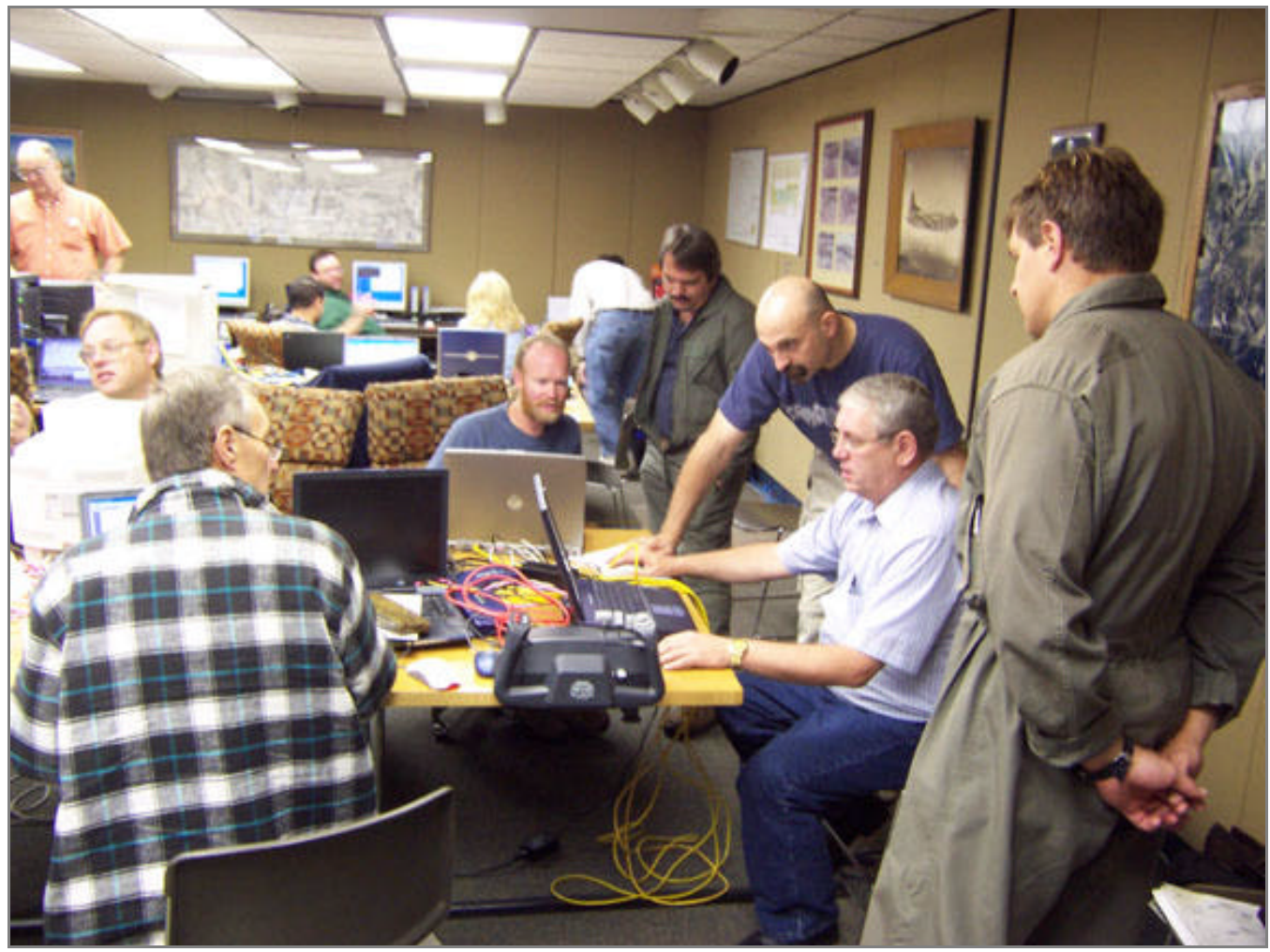

Figure 20. ITT Industries RMOTC Field Test Operations Center at the Casper Airport

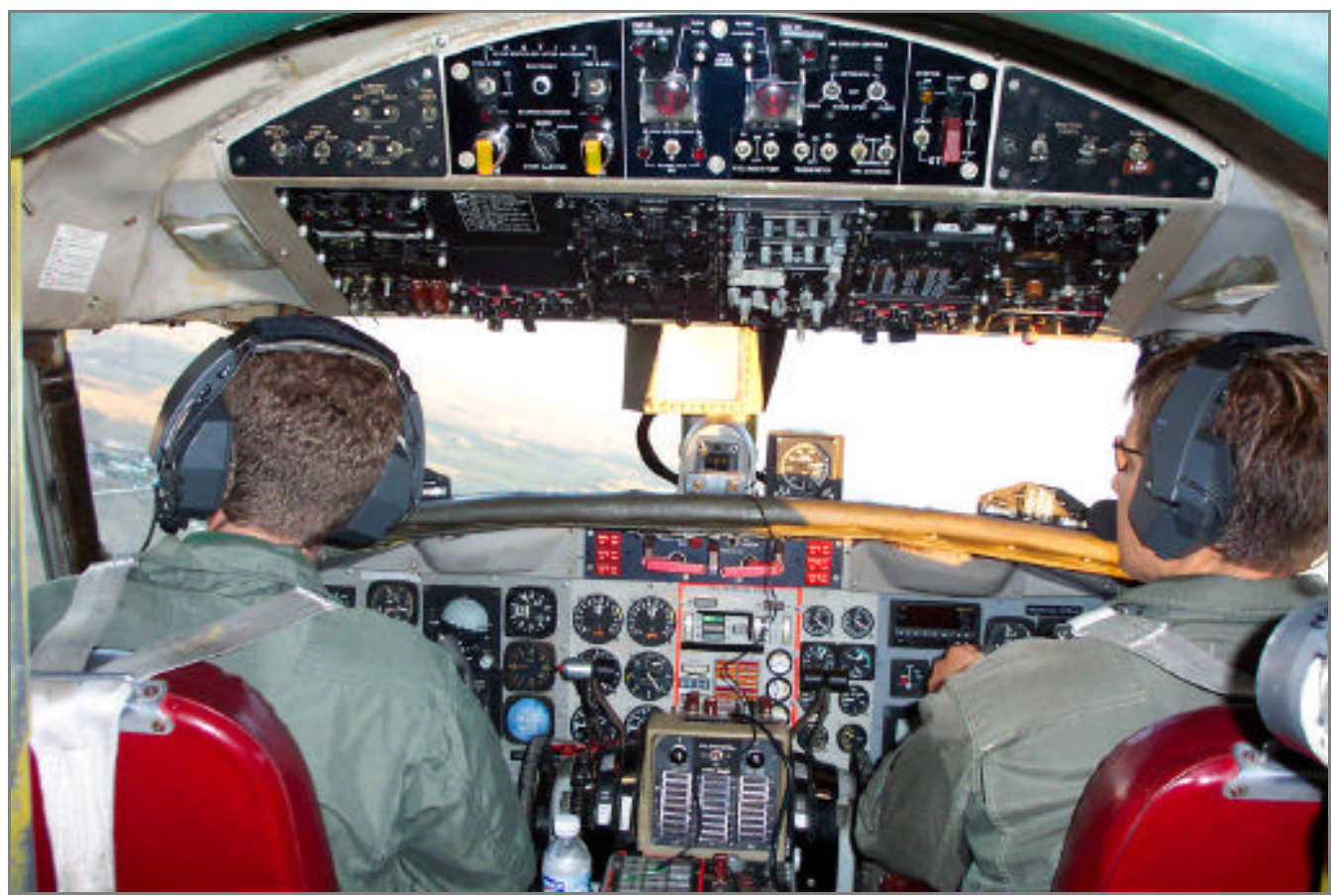

Figure 21. Pilots view of the RMOTC test area from 1,000 feet 


\subsection{RMOTC Summary and Discussion}

During the DOE RMOTC field trials, the ITT ANGEL System verified the function of all major systems including gas detection, gas quantification, sensor targeting, laser scanning, data logging, data analysis, mission planning and flight operations. The system was flown at every opportunity from Sunday afternoon through Friday evening for a total of 11 flights and 58 field passes. The sensor collected approximately 80 gigabytes of data each day. Sensor pointing and laser scanning systems successfully provided $100 \%$ pipeline corridor coverage. Given that much of the system's total performance was untested prior to these trials, the event provided an extraordinary opportunity to test, learn and improve the system.

During each pass the sensor measured the concentration path length of methane more than 250,000 times, allowing the creation of a methane map for the entire length of the pipeline. Emissions were detected at a number of locations along the virtual pipeline on Tuesday, Wednesday, Thursday and Friday. Results were reported as high confidence when signals indicating high concentration path length (CPL) were detected on multiple passes of both morning and afternoon flights. The degree of confidence was proportional to the number of detections.

The ANGEL System was constrained during this field test by three known system level limitations. These constraints led to reduced performance throughout the week and were not addressable until the system was returned to the lab following the field trials. The three primary limitations of the system were:

1. Reduced laser output power. Overall, during the RMOTC field trial, the ANGEL system was producing less than $50 \%$ of the normal operating laser output power. Laser power is directly linked to low-end gas detection ability. Many of the issues related to reduced laser output power were traced and attributed to the coated optics. Although some basic sensor repairs and adjustments were completed in the hanger at Casper, more involved sensor repairs/upgrades could only be completed at ITT facilities after the conclusion of the RMOTC effort.

2. Disabled ethane detection laser bench. The system is designed for detection of both methane and ethane via companion laser benches tuned to different absorption frequencies. Prior to leaving for RMOTC, the ethane laser bench was not functioning properly and was taken "off-line" for the event. The detection of ethane with methane is a telltale sign of natural gas and significantly reduces the potential of false alarm due to various and abundant natural sources of methane.

3. Signal degradation with the scanner optics. The computer controlled scanner moves the lasers across the right-of-way as the plane flies its route. Throughout the week the scanner was able to consistently and accurately scan the lasers above the pipeline, yet performance issues within the scanner significantly contributed to overall system "noise" and degraded signal detectability. 


\section{RESULTS}

The final report on "Field Testing of Remote Sensor Leak Detection Systems" included a complete set of sensor performance data for all test participants and was published by the DOE in 2005. Following submission of the ITT final reports to the RMTOC Field Test Organizers (included as Attachments 1-5), ITT was provided the actual location and size of the leaks.

\section{Table 1 - Leaks detected during the RMOTC Field Test}

\begin{tabular}{|c|c|c|c|c|c|c|c|c|c|c|}
\hline Leak ID & Gas Source & Leak Type & Size Tues & Detected? & Size Wed & Detected? & Size Thu & Detected? & Size_Fri & Detected? \\
\hline 1 & RMOTC gas & below ground & 1000 & 1 & 500 & 0 & 100 & 1 & 15 & \\
\hline & RMOTC gas & below ground & & & & & & & 5000 & 1 \\
\hline $2 \mathrm{~A}$ & cylinder & below ground & & & & & & & 15 & 0 \\
\hline $2 B$ & cylinder & below around & & & & & & & & \\
\hline $2 \mathrm{C}$ & cylinder & below ground & & & 15 & 0 & & & & \\
\hline 3 & RMOTC gas & above ground & 2000 & 1 & 100 & 0 & 2000 & 1 & 500 & 0 \\
\hline 4 & RMOTC gas & below ground & 500 & 0 & 2000 & 1 & 1000 & 0 & 2000 & 0 \\
\hline $2 \mathrm{D}$ & cylinder & below ground & 15 & 0 & & & & & & \\
\hline 5 & RMOTC gas & below ground & 5000 & 1 & 5000 & 1 & & & 5000 & 1 \\
\hline P1 & RMOTC gas & side-drilled & 1000 & 0 & 1000 & 0 & 1000 & 1 & 1000 & 0 \\
\hline $\mathrm{P} 2$ & RMOTC gas & side-drilled & 100 & 0 & 100 & 0 & 100 & 0 & 100 & 0 \\
\hline 6 & RMOTC gas & below ground & 100 & 1 & 1000 & 0 & 500 & 0 & 1000 & 1 \\
\hline $2 \mathrm{E}$ & cylinder & below around & & & & & 15 & 0 & & \\
\hline P3 & RMOTC gas & side-drilled & 10 & 0 & 10 & 0 & 10 & 0 & 10 & 0 \\
\hline P4 & RMOTC gas & side-drilled & 500 & 1 & 500 & 1 & 500 & 0 & 500 & 0 \\
\hline $\mathrm{P} 5$ & cylinder & side-drilled & 1 & 0 & 1 & 0 & 1 & 0 & 1 & 0 \\
\hline
\end{tabular}

The data in Table 1 is a summary of leaks created by the test organizers combined with a list of what leaks were detected and successfully reported during each day of the week. Figure 22 provides an overview of the leaks detected at RMOTC from September 14-17. This figure clearly indicates that the larger the leak the more likely the ANGEL system would detect it.

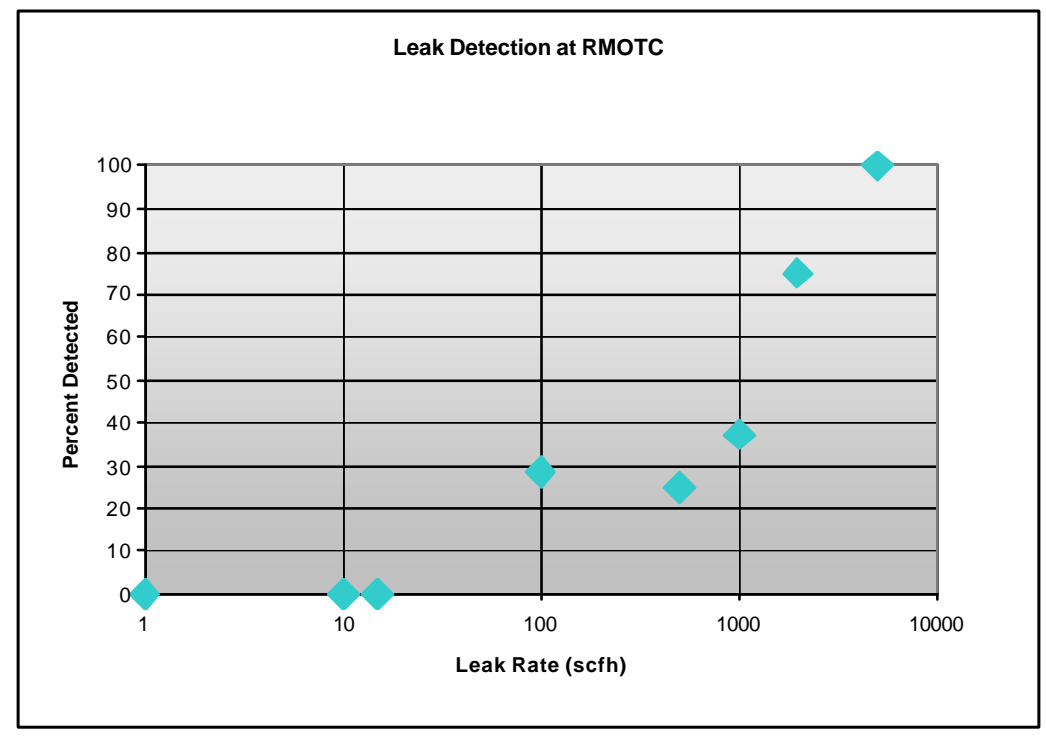

Figure 22. ANGEL System leak detection summary for RMOTC Field Test, Sept. 14-17 
Leaks 2A, 2B, 2C, 2D, 2E and P5 were created by burying gas cylinders along the virtual pipeline route. Due to the limited supply of gas for these leak sites, the leaks created at these sites by the test organizers were all small $15 \mathrm{scfh}$ or smaller. The prototype ANGEL system did not detect any of these small leaks throughout the course of the week. One important fact to remember with all optical remote gas detection systems is that the these systems "see" the plume of gas in the air and the size of the plume is affected by a variety of factors beyond just simple leak. Factors such as wind speed, surface roughness, diameter of the leak as it exits the ground, and atmospheric stability can all have a major effect on the size, shape and geometry of the gas plume. Leaks at sites P2 and P3 were not detected during the week due to their small size and the more diffuse plumes created by side-bore method of simulating leaks. The ANGEL system was much more successful in detecting the medium to large leaks created by tapping into the RMOTC pipeline network. Throughout the week, leaks were detected at sites 1,3,4, 5, 6, P1, and $\mathrm{P} 4$. The large 5,000 scfh leak at site 5 was detected and imaged on every day it was in operation.

The sensitivity of the ANGEL system reflects its prototype status. As one can see from Figure 22 , the system reliably detected methane releases between 2,000 and 5,000 scfh. As the release leak size decreased, the system detectors experienced two issues. First, the methane concentrations of the medium leaks were approaching detector threshold sensitivity. The system was therefore unable to detect releases below $100 \mathrm{scfh}$. Second, the amount of background noise made analysis difficult when the release size dipped below approximately 1,200 scfh.

Background noise levels coupled with low levels of target methane contributed to a fairly large number of false positives reported by the team.

One major factor contributing to the background noise and high number of false alarms was discovered in the weeks following RMOTC. Several weeks after RMOTC it was discovered that the lasers at range were misaligned and at a range of 1,000 feet the methane laser and the off-line lasers were offset by several inches. In areas of the virtual test range where surface material varied greatly in reflectivity it was possible to hit a non-reflective material with the methane laser while hitting a more reflective material with the off-line. This resulted in a spuriously high methane value at that position leading to a large number of false positive calls in some areas of the pipeline route.

One major advantage of our system was our ability to precisely point our system from the air. As a result we were able to fly over the same route numerous times over the course of the day use GIS to efficiently merge data from many individual runs. This proved to be a very effective way to effectively improve our signal to noise. By combining the information of many different runs ANGEL System analysts were able to compensate for the low laser power and poor signal to noise characteristics in the early stages of flight testing. Following adjustments to the system after RMTOC the ANGEL system was able to significantly improve the signal to noise ratio and no longer required multiple and intense GIS processing to detect leaks.

Since the RMOTC trials, the ITT Industries team has focused on addressing sensitivity and robustness issues. The system has been reconfigured to provide more laser power and higher degree of frequency lock. Beam overlap has also been greatly improved. Furthermore, our analysts are continually developing enhanced data filtering algorithms (numeric and spatial), which has helped reduce data noise, and improved our methane concentration detection threshold 


\subsection{Conclusions}

ITT Industries Space Systems was pleased to participate in the DOE/DOT facilitated Demonstration of Remote Gas Leak Detection Systems at RMOTC. The tests conducted at RMOTC from September $13^{\text {th }}$ to September $17^{\text {th }} 2004$ provided a unique opportunity to demonstrate the capabilities, value, and challenges of an airborne natural gas detection system. In spite of known performance limitations of our prototype system, the ITT ANGEL System has successfully demonstrated its ability to fly, point, scan, detect, quantify, geo-locate and ultimately provide comprehensive visualization of pipeline gas emissions in a rugged natural environment.

During each flight, the ANGEL System successfully ingested GPS/GIS data, accurately pointed at the virtual pipeline route, fully scanned the ROW (100\% coverage), and collected all necessary differential GPS information to precisely locate leak locations. The Ground Data Processing systems processed all the raw data to "image" gas emissions and geo-positioned the data.

Despite the relatively windy conditions experienced during testing, the ANGEL Sensor successfully detected more than half the leaks of $500 \mathrm{scfh}$ and higher. Ongoing improvements in the hardware and software will greatly improve performance of the system in the upcoming weeks readying it for commercial use in 2006. These included the ability to efficiently detect, quantify, geo-locate and image natural gas leak plumes from the air. During this demonstration the ANGEL team learned a number of very valuable lessons.

- We validated the concept of using Differential Absorption Lidar (DIAL) for gas leak detection and quantification from a fixed wing aircraft. Integration of the sensor into the test aircraft was completed at the Casper Airport. The first fully integrated ANGEL DIAL data ever collected was on 14 September 2004, the second day of the RMOTC test.

- We confirmed that the ANGEL Intelligent Pointing and Scanning System allowed the aircraft to fly the Virtual Pipeline end-to-end at high speed and inspect $100 \%$ of the pipeline on a single pass. The ability to collect data accurately, rapidly, and efficiently is critical to future commercial operations.

- We challenged the Beta version of our ground data processing software and it worked well throughout the week. The experience of having to rapidly process vast quantities of data during the demonstration is currently driving major improvements in the area of automated data processing and analysis.

- We verified the relationship between laser output power and our ability to detect leaks. This was one of the most important lessons learned at RMOTC. Increasing laser power greatly improves our ability to lock on a set wavelength and greatly improves the signal to noise ratio of the data. On Monday of the test, the ANGEL team more than doubled sensor laser power output by replacing a damaged optic and further hardware improvements are continuing. 


\subsubsection{Post RMOTC flight testing}

Immediately after participation in the RMOTC exercise, the simulated leaks at Pendleton Tap were re-flown. During this effort, simulated calibration leaks were flown a total of 8 separate times in wind speeds which ranged from $0 \mathrm{mph}$ to speeds of up to $14 \mathrm{mph}$. Results from a single overflight are shown in Figure 23. Results from all 8 runs are shown in Figure 24. During these runs the leak rate ranged from 3,500 to 4,680 scfh. Most notable was the major effect of the wind. As predicted by the gas plume modeling, gas tends to "pool" near the leak under light wind conditions. Winds greater than $10 \mathrm{mph}$ tend to rapidly disperse the leaking gas and result in plumes that are very chopped up and hard to detect.

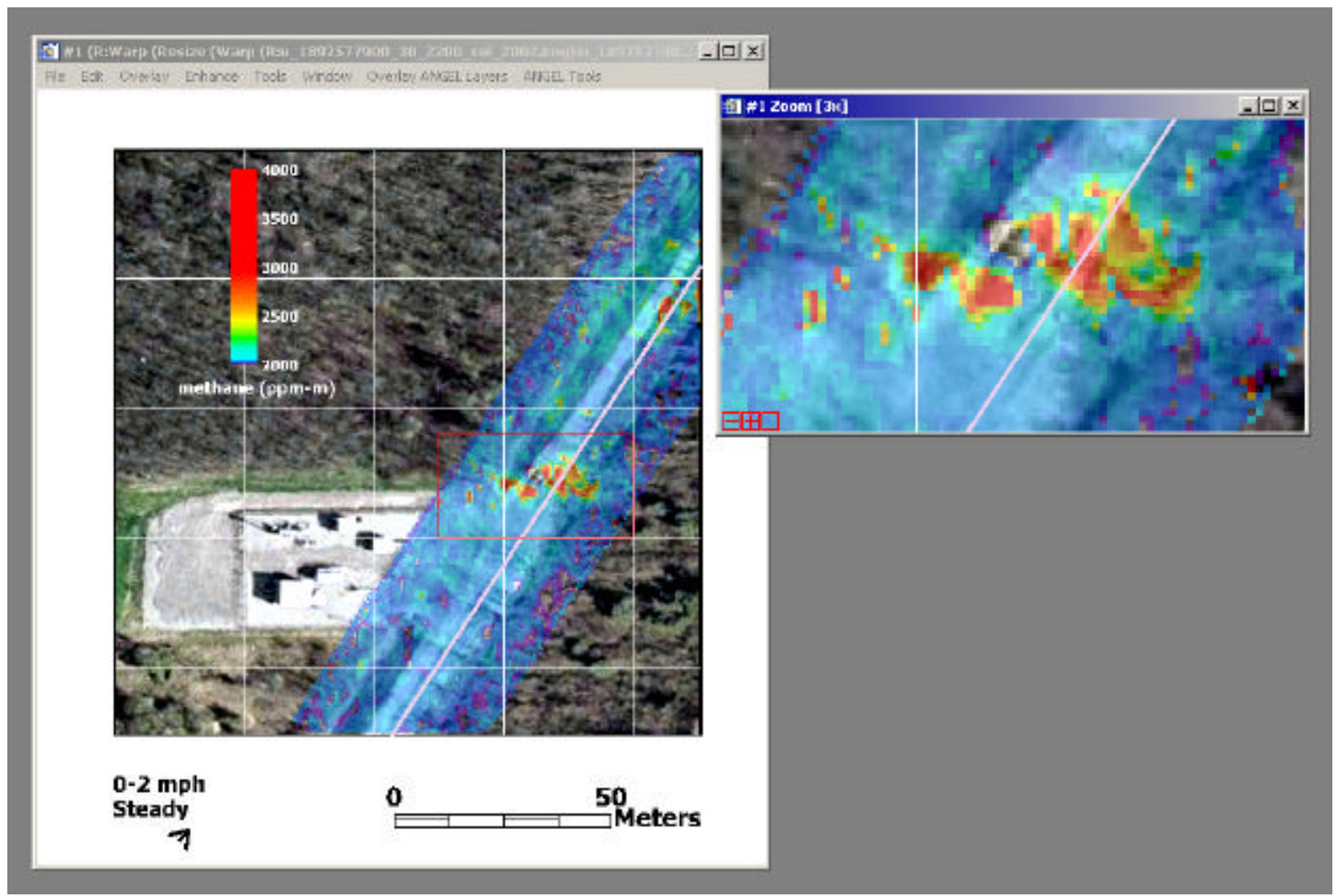

Figure 23. ANGEL DIAL system image of a gas plume from a 3,500 scfh methane release along a tree-lined pipeline right-of-way near Buffalo, NY. This data was in October, 2004 from the TIFS test aircraft flying at $150 \mathrm{mph}$ from a height of 1,000 feet above the ground. This simulated leak was created in cooperation with National Fuel near the Pendleton Meter Station. 


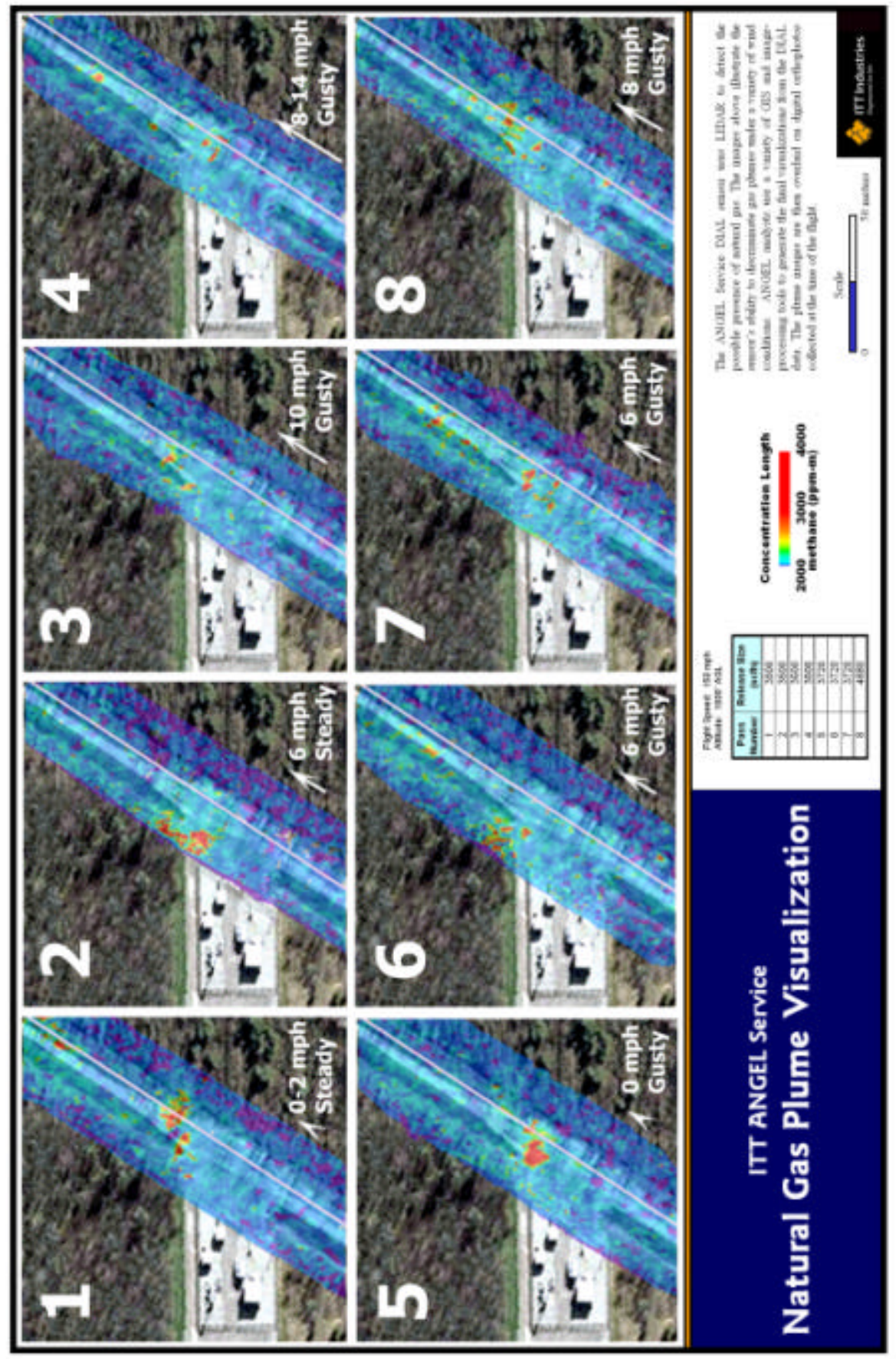

Figure 24. Eight separate ANGEL DIAL system images of a gas plume from a 3,500 scfh methane release along a tree-lined pipeline right-of-way near Buffalo, NY. This data was collected in October, 2004 from the TIFS test aircraft flying at $150 \mathrm{mph}$ from a height of 1,000 feet above the ground. These simulated leaks were created in cooperation with National Fuel near the Pendleton Meter Station. These images indicate that lower wind speeds at ground level allow the accumulation of higher concentrations of gas. These images were collected over a 


\subsubsection{Qualitative Comments on ANGEL Technology}

The ANGEL technology demonstrated at RMOTC proved to be enormously productive. Flying at over 130 Knots, the test aircraft was able to fully inspect the relatively short 7.5 mile Virtual Pipeline route in roughly 4.5 minutes. As a result, we were able to collect 7 complete inspections of the RMOTC Virtual Pipeline in our allotted 50-minute window. Productivity would have been even greater if the aircraft didn't have to circle back after each 7.5 mile pipeline pass. During pre-RMOTC ground tests, ANGEL laser power levels were less than $50 \%$ of specification. Modeling of expected sensor performance given these output levels predicted that ANGEL would be able to confidently detect leaks of roughly $1000 \mathrm{scfh}$. Upon receipt of the actual size and position of the leaks from SWRI, we demonstrated our ability to detect and image a number of leaks of $100 \mathrm{scfh}$ or larger despite the relatively high wind conditions experienced at RMOTC.

While the ANGEL system demonstrated at RMOTC is at an early stage of development, data collection of this quality at this stage is extremely encouraging.

Initial data analysis focused on the spatial aspects of multiple collections in a single day. Data from multiple passes improved our confidence in our ability to interpret ANGEL data and detect leaks. Recent algorithmic improvements (since the submission of the final report to DOE) now allow better leak identification with the data from a single pass. Over the next few months, sensor hardware upgrades will allow confident detection of appreciably smaller leaks. Integration of the ethane laser bench (not used at RMOTC) combined with improvements in signal-to-noise ratio will result in significant sensor system performance.

Custom software designed to process the ANGEL data and display an image of a gas plume worked extremely well from the first day of the demonstration, and this software was continuously improved over the course of the week. Subsequent improvements in determining the exact position of "laser spots" on the ground now allow us to more accurately display the size and shape of natural gas plumes.

Our understanding of the phenomenology of DIAL gas leak detection has been greatly improved by our participation in the DOE/DOT sponsored field test. Over the course of the week we imaged gas leak plumes of various sizes and shapes literally hundreds of times. The data collected during our time in Wyoming has been invaluable for gaining a better understanding gas leak behavior under a range of conditions.

\subsection{Acknowledgements}

The authors would like to acknowledge of numerous members of the ITT Space Systems Division Engineering and Business Staff. In particular, we would like to acknowledge the contributions of the following individuals who's dedication and expertise made this work possible: Steve Bauer, Paul Blaszkowiak, Janice Brooks, Dan Brake, Charles Cacciato, Mark Carducci, Mike Clayton, Mike Crowder, Tim Cutler, Rita Hasenauer, Mark Janosky, Hooshmand Kalayeh, Joseph Lippert, Norm Lopez, Lisa McConnell, Wendy Minotti, Craig Oswald, Brian Nagy, Roger Pawlowski, Matt Severski, Gene Wess, John Winterberger, Gregg Wright. We would also like to acknowledge the contributions of the following organizations: Coherent Technologies Inc., Critical Link, General Dynamics, and PhilCon. 


\subsection{Graphical Material}

\section{List of Figures}

Figure 1. Generic representation of DIAL on- line and off-line positions ................................. 4

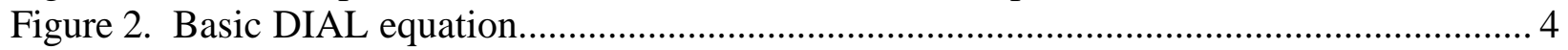

Figure 3. Concentration Path Length (CPL) of a plume as measured from an aircraft. ............... 5

Figure 4 Conceptual view of the airborne ANGEL Service capturing leak survey data along a pipeline right-of-way.

Figure 5 Space Systems ANGEL pointing results from a short section of the Virtual Pipeline Route at RMOTC. The aircraft path is shown in yellow. The pipeline position is shown in red. The position of each data point is shown in green forming a coverage swath 110 feet wide. The sensor pointing and scanning system allows full coverage of the ROW corridor in a single pass. .................................................................... 7

Figure 6. Space Systems' ANGEL System test aircraft - General Dynamics Convair 580 (NC$131 \mathrm{H})$ turboprop landing at the Natrona County International Airport, Casper, Wyoming......

Figure 7. Diagram of Space Systems ANGEL System Test Aircraft illustrating placement of the major sensor components.

Figure 8. Space Systems ANGEL System Test Aircraft showing placement of the transceiver in the nose of the aircraft during preparation for early flight tests in Buffalo, NY.

Figure 9 Aerial view of the Gas Plant at the Rocky Mountain Oilfield Testing Center acquired with the ANGEL Sensor engineering camera. The yellow circle indicates the approximate position of a leak detected with the DIAL subsystem.

Figure 10 Detection, quantification, visualization, and geolocation of a natural gas plume at RMOTC.

Figure 11. Map showing the location of the Niagara Frontier Airport and 2 sites selected for possible simulated leaks along the Empire Pipeline (shown in purple).

Figure 12. Image of a simulated natural gas leak site along a pipeline right-of-way near Buffalo, New York.

Figure 13. A geo-referenced color image of the pipeline right-of-way is used as a base GIS raster imagery layer. The GIS vector layer of the pipeline supplied by National Fuel is indicated in red, the track of the ANGEL system aircraft as it flew the line is marked in green. Yellow dots indicate the position of individual laser spots along the inspection swath of the DIAL system.

Figure 14. First airborne DIAL data set from the ANGEL sensor processed color-coded for range-to-target (distance from the sensor to the land surface). Areas colored blue correspond to agricultural fields (low vegetation = greater range to target), Yellow areas of the scan swath roughly correspond to forested areas which reflect the laser light before it gets to the ground and results in a smaller range-to-target values. low areas . 16 
Figure 15. First airborne DIAL data set from the ANGEL sensor processed color-coded for methane concentration path length (CPL). Methane CPL in this "first light" image are highly variable and greatly effected by vegetation. A variety of hardware and software have been implemented to improve the quality the ANGEL data.

Figure 16. Photograph of the RMOTC test area taken from RMOTC headquarters building..... 17

Figure 17. Inspection of Proposed Virtual Pipeline Route at RMOTC in June 2004................ 18

Figure 18. Map of the Marker-Based Virtual Pipeline along the western edge of the Rocky Mountain Oilfield Testing Center in Wyoming. Virtual pipeline in shown in Red, 14 pipeline markers of known location are shown in green, meteorology stations are

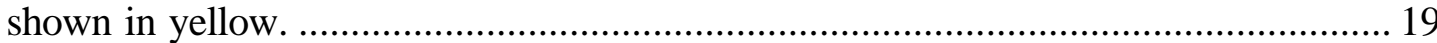

Figure 19. ITT Industries ANGEL system test aircraft in Casper, Wyoming ........................... 20

Figure 20. ITT Industries RMOTC Field Test Operations Center at the Casper Airport........... 21

Figure 21. Pilots view of the RMOTC test area from 1,000 feet ........................................... 21

Figure 22. ANGEL System leak detection summary for RMOTC Field Test, Sept. 14-17 ........ 23

Figure 23. ANGEL DIAL system image of a gas plume from a 3,500 scfh methane release along a tree-lined pipeline right-of-way near Buffalo, NY. This data was in October, 2004 from the TIFS test aircraft flying at $150 \mathrm{mph}$ from a height of 1,000 feet above the ground. This simulated leak was created in cooperation with National Fuel near the Pendleton Meter Station.

Figure 24. Eight separate ANGEL DIAL system images of a gas plume from a 3,500 scfh methane release along a tree-lined pipeline right-of-way near Buffalo, NY. This data was collected in October, 2004 from the TIFS test aircraft flying at $150 \mathrm{mph}$ from a height of 1,000 feet above the ground. These simulated leaks were created in cooperation with National Fuel near the Pendleton Meter Station. These images indicate that lower wind speeds at ground level allow the accumulation of higher concentrations of gas. These images were collected over a

\section{List of Tables}

Table 1 - Leaks detected during the RMOTC Field Test 23 


\subsection{References}

[1] Brake, D., Clayton, M., Stearns, S., 2004, New Airborne Remote Sensing Service Enhances Pipeline Integrity Assessment, Pipeline and Gas Journal, Vol. 231, Number 6, July 2004.

[2] Buckingham, J.C., Grimley, T.A., Burkey, R.C., 2004, Field Testing of Remote Sensor Gas Leak Detection Systems, SwRI Project Number 18.10485 for the U.S. Department of Energy and U.S. Department of Transportation (web published), pp. I-15-39 and J-1-38 http://www.rmotc.com/pdfs/SwRI_Final.pdf

[3] Stearns, S.V., Lines, R.T., Grund, C.J., Philbrick, R., 2004, Technology Status Report on Active Remote Detection of Natural Gas Pipeline Leaks, Prepared for the U.S. Department of Energy National Energy Technology Lab (web published) http://www.netl.doe.gov/scngo/Natural\%20Gas/projects/transmission/ngi/td/pubs/DOENETL \%20 Technology\%20Status\%20ReportFINAL.pdf

[4] Stearns, S.V., 2005, ITT Industries Airborne Natural Gas Emission Lidar (ANGEL) Service, Gas Technology Institute Natural Gas Technologies Conference Orlando, Florida, 11 pp. 


\subsection{Bibliography}

Browell, E. V., S. Ismail, and B. E. Grossmann, “Temperature sensitivity of differential absorption lidar measurements of water vapor in the 720-nm region," Applied Optics, vol. 30, no. 12, pp. 1517-1524, April 1991.

Browell, E. V., A. F. Carter, S. T. Shipley, R. J. Allen, C. F. Butler, M. N. Mayo, J. H. Siviter Jr., and W. M. Hall, "NASA multipurpose airborne DIAL system and measurements of ozone and aerosol profiles," Applied Optics, vol. 22, no. 4, pp. 522-534, October 1983.

Browell, E. V., S. Ismail, and W. B. Grant, "Differential absorption lidar (DIAL) measurements from air and space," Applied Physics B, vol. 67, no. 4, pp. 399-410, 1988.

Buckingham, J.C., Grimley, T.A., Burkey, R.C., 2004, Field Testing of Remote Sensor Gas Leak Detection Systems, SwRI Project Number 18.10485 for the U.S. Department of Energy and U.S. Department of Transportation (web published), pp. I-15-39 and J-1-38 http://www.rmotc.com/pdfs/SwRI_Final.pdf

Byer, R. L. and M. Garbuny, "Pollutant detection by absorption using Mie scattering and topographic targets as retroreflectors," Applied Optics, vol. 12, no. 7, pp. 1496-1505, July 1973.

Ehret, G., K. P. Hoinka, J. Stein, A. Fix, C. Kiemle, and G. Poberaj, "Low stratospheric water vapor measured by and airborne DIAL," Journal of Geophysical Research vol. 104, no. D24, pp. 31 351-31 359, December 1999.

Grant, W. B., "Effect of differential spectral reflectance on DIAL measurements using topographic targets," Applied Optics, vol. 21, no. 13, pp. 2390-2394, July 1982.

Jelalian, A. V., Laser Radar Systems. Norwood, MA: Artech House, 1992.

Ismail, S. and E. V. Browell, "Airborne and spaceborne lidar measurements of water vapor proles: A sensitivity analysis," Applied Optics, vol. 28, no. 17, pp. 36036E3606, September 1989.

Kamerman, G. W., Advanced Coherent Laser Radars: Short Course Notes SPIE ${ }^{\mathrm{TM}_{\mathrm{S}}}$ 14th Annual Internation Symposium on AerospaceDefense Sensing, Simulation and Controls, 24-28 April. Orlando, Florida: SPIE, 2000.

Measures, R. M., Laser Remote Sensing: Fundamentals and Applications, NY: John Wiley \& Sons, 1984.

Prassad, N. S. and A. R. Geiger, "Remote sensing of propane and methane by means of a differential absorption lidar by topographic reflection," Optical Engineering, vol. 35, no. 4, pp. 1105-1111, April 1996. 
Stearns, S.V., Lines, R.T., Grund, C.J., Philbrick, R., 2004, Technology Status Report on Active Remote Detection of Natural Gas Pipeline Leaks, Prepared for the U.S. Department of Energy National Energy Technology Lab (web published)

http://www.netl.doe.gov/scngo/Natural\%20Gas/projects/transmission/ngi/td/pubs/DOENETL\%2 $\underline{0}$ Technology\%20Status\%20ReportFINAL.pdf

Stearns, S.V., 2005, ITT Industries Airborne Natural Gas Emission Lidar (ANGEL) Service, Gas Technology Institute Natural Gas Technologies Conference Orlando, Florida, 11 pp. 


\section{Flight Testing of an Advanced Airborne Natural Gas Leak Detection System}

\subsection{List of Acronyms and Abbreviations}

$\begin{array}{ll}\text { AGCS } & \text { Active Gas Correlation Spectroscopy } \\ \text { AGL } & \text { Above Ground Level } \\ \text { ANGEL } & \text { Airborne Natural Gas Emission Lidar } \\ \text { APVIAS } & \text { ANGEL Pipeline Visual Inspection and Analysis Software } \\ \text { BAGI } & \text { Backscatter Absorption Gas Imaging } \\ \text { CPL } & \text { Concentration Path Length } \\ \text { DIAL } & \text { Differential Absorption Lidar } \\ \text { DOE } & \text { Department of Energy } \\ \text { DOT } & \text { Department of Transportation } \\ \text { GCS } & \text { Gas Correlation Spectroscopy } \\ \text { GDP } & \text { Ground Data Processing } \\ \text { GIS } & \text { Geographic Information Systems } \\ \text { GPS } & \text { Global Positioning System } \\ \text { HIS } & \text { Hyperspectral Imaging } \\ \text { LIDAR } & \text { Light Detection and Ranging } \\ \text { mph } & \text { miles per hour } \\ \text { NETL } & \text { National Energy Technology Laboratory } \\ \text { nm } & \text { nanometers } \\ \text { OPS } & \text { Office of Pipeline Safety } \\ \text { RMOTC } & \text { Rocky Mountain Oilfield Testing Center } \\ \text { ROW } & \text { Right of Way } \\ \text { scfh } & \text { standard cubic feet per hour } \\ \text { SNR } & \text { Signal to Noise Ratio } \\ \text { tcf } & \text { Trillion cubic feet } \\ \text { TIFS } & \text { Total In-Flight Simulator } \\ & \end{array}$


Attachment 1: ITT Equipment Provider Test Report 


\section{ANGEL Service Customer Report}

\section{Rocky Mountain Oilfield \\ Testing Center (RMOTC) \\ Virtual Pipeline Inspection}

\section{DATE(s) INSPECTION DATA ACQUIREID:}

September 14,2004

CONTRACT NUMBER:

DOE/National Energy Technology Laboratory Cooperative Development Agreement \# DE-FC26-03NT41877

IN RESPONSE TO RFP:

DOE Program Solicitation (PS) No. DE-PS26-02NT41613

\section{SUBMITTED BY:}

Steven Stearns

ITT Industries Space Systems Division

1447 St. Paul St.

Rochester, NY 14653-7225

TEL. (585) 762-5494

steven.stearns@itt.com

\section{SUBMITTED TO:}

Chris Buckingham

Southwest Research Labs

6220 Culebra Road (78238-5166)

P.O. Drawer 28510 (78228-0510)

San Antonio, Texas

REPORT DATE:

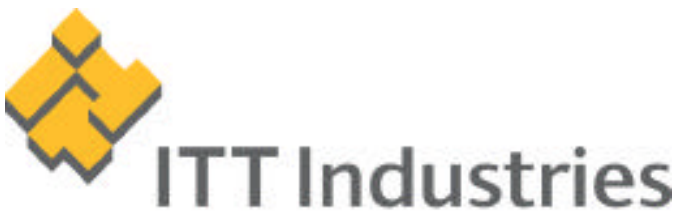

Engineered for life

October 8, 2004 


\section{Executive Summary:}

On September 14, 2004 we flew the route identified as "RMOTC Virtual Pipeline" with the ITT Industries ANGEL Sensor. This route was flown multiple times to ensure we had fully covered the complete Virtual Pipeline Route and to provide increased sample density to improve detection of smaller emissions. Analysis of the information collected indicates a number of areas of significant methane concentration along the pipeline right of way. The locations and relative size/concentration patterns for these are described in detail in this report.

The route flown is depicted below. All detected concentration areas are labeled with crosses. Color-coding is used to indicate detection of the methane concentration on multiple passes, with red indicating that the specific methane concentration was detected (within 30 meters) on five separate passes. Eleven distinct methane concentration areas were detected with sufficient quantity and frequency ( 5 or 6 passes) that they are high confidence. Elevated concentrations of methane in the area of a 1,000 scfh calibration leak near M1 were detected 4 times throughout the day. 


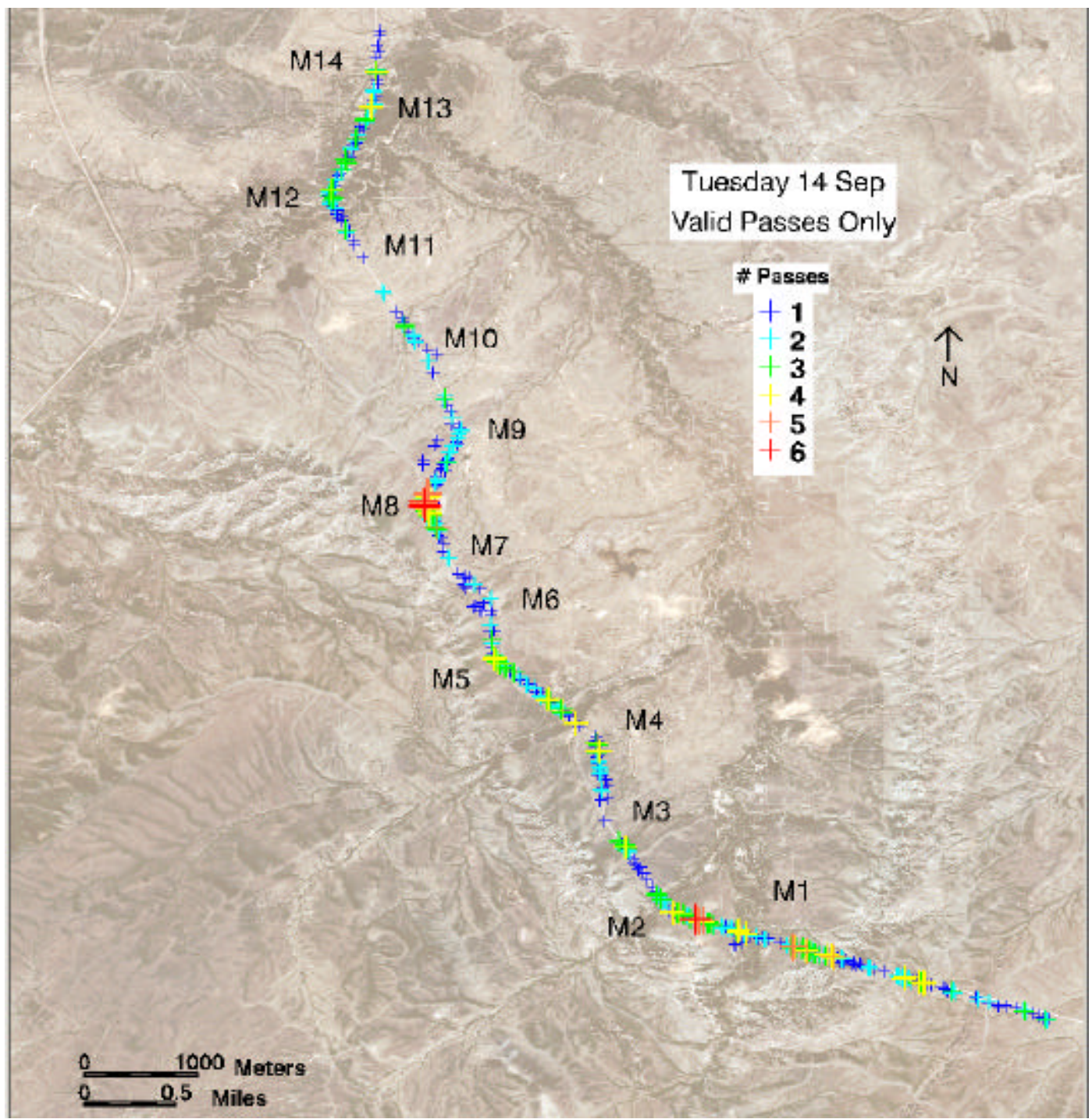

\section{Methane Detections}

The methane emissions with the highest confidence were captured on a relatively large number of passes as indicated in this table. The geographic coordinates provide the location of the aggregated multiple detections. 


\begin{tabular}{|c|c|c|c|c|c|c|}
\hline NAD 27 Data (DMS) & & & & & & \\
\hline Latitude & Longitude & Leak Detection & Date & AM Passes & PM Passes & Comments \\
\hline 431457.966 & -1061127.3228 & 6 & $09 / 14 / 04$ & 3 & $1,2,3,4,6$ & south of M2 \\
\hline 431458.992 & -1061131.6464 & 5 & $09 / 14 / 04$ & 3 & $2,3,4,7$ & $\mathrm{M} 1-\mathrm{M} 2$ \\
\hline 43150.0216 & -1061135.0844 & 5 & $09 / 14 / 04$ & 3 & $2,3,4,7$ & south of M2 \\
\hline 43151.0188 & -1061137.7412 & 5 & $09 / 14 / 04$ & 3 & $2,3,4,7$ & vicinity of $\mathrm{M} 2$ \\
\hline 431639.8244 & -1061250.6232 & 5 & $09 / 14 / 04$ & 3,4 & $1,2.7$ & vicinity of M5 \\
\hline 431745.3624 & -1061315.4164 & 6 & $09 / 14 / 04$ & 3 & 1.2 .4 .6 .7 & already have M8 (gas plant) \\
\hline 43186.048 & -106134.1844 & 5 & $09 / 14 / 04$ & 3,4 & $1,2,7$ & vicinity of $\mathrm{M9}$ \\
\hline 431857.0096 & -1061330.9792 & 5 & $09 / 14 / 04$ & & $2,3,4,6,7$ & south of M11 \\
\hline 431937.128 & -1061353.7888 & 5 & $09 / 14 / 04$ & 3,4 & $1,3,7$ & many discrete points just south of $\mathrm{M} 12$ \\
\hline 431940.0908 & -1061353.7852 & 6 & $09 / 14 / 04$ & 3,4 & $1,2,3,4$ & just north of M12 \\
\hline 431951.2508 & -1061348.5724 & 5 & $09 / 14 / 04$ & 3 & $2,4,6,7$ & single small area $\mathrm{M} 12-\mathrm{M} 13$ \\
\hline
\end{tabular}

Methane emissions detected with lesser, but still significant confidence are listed in the table below. In all cases these were detected on multiple passes as well, but not as consistently as the detections documented above.

\begin{tabular}{|c|c|c|c|}
\hline NAD 27 Data (DMS) & & & \\
\hline Latitude & Longitude & Date & Comments \\
\hline 431954.7284 & -1061347.3628 & 14-Sep-04 & M12-M13 \\
\hline 431525.2 & -1061158.9632 & 14-Sep-04 & M2-M3 \\
\hline 431614.304 & -1061217.406 & 14-Sep-04 & M4-M5 \\
\hline 431728.8132 & -1061312.5976 & 14-Sep-04 & M8 - south of gas plant \\
\hline 431745.7188 & -1061315.3012 & 14-Sep-04 & M8 (gas plant) \\
\hline 431940.08 & -1061353.778 & 14-Sep-04 & just north of M12 \\
\hline 431457.9336 & -1061127.3732 & 14-Sep-04 & north of M1 \\
\hline 431856.826 & -1061330.6768 & 14-Sep-04 & south of M11 \\
\hline 431459.964 & -1061135.2896 & 14-Sep-04 & south of $\mathrm{M} 2$ \\
\hline 43151.0728 & -1061138.3712 & 14-Sep-04 & vicinity of $\mathrm{M} 2$ \\
\hline 43155.5764 & -1061145.0348 & 14-Sep-04 & just north of $\mathrm{M} 2$ \\
\hline 431623.0772 & -1061229.3076 & 14-Sep-04 & north of M4-M5 \\
\hline 431459.0316 & -1061131.704 & 14-Sep-04 & north of M1 \\
\hline 431951.0384 & -1061348.5292 & 14-Sep-04 & single small area M12-M13 \\
\hline 431937.2 & -1061353.7888 & 14-Sep-04 & just south of M12 \\
\hline 431931.6884 & -1061350.8584 & 14-Sep-04 & many discrete points south of $\mathrm{M} 12$ \\
\hline 43208.0916 & -1061340.4868 & 14-Sep-04 & south of M13 \\
\hline 431649.8504 & -1061251.5232 & 14-Sep-04 & south of M6 \\
\hline 431453.9196 & -1061114.2692 & 14-Sep-04 & vicinity of $\mathrm{M1}$ \\
\hline 431639.954 & -1061250.5296 & 14-Sep-04 & vicinity of M5 \\
\hline 43186.246 & -106134.044 & 14-Sep-04 & vicinity of $\mathrm{M} 9$ \\
\hline
\end{tabular}




\section{Significant Emissions}

In this survey there are several areas that stand out due to the size and concentration-pathlength values of methane plume and frequency of detection. These are identified in the images provided below with red and orange plume position markers. The green markers are areas where there were potential indicators for methane but these were only detected on single passes. These do not represent highly significant indicators.
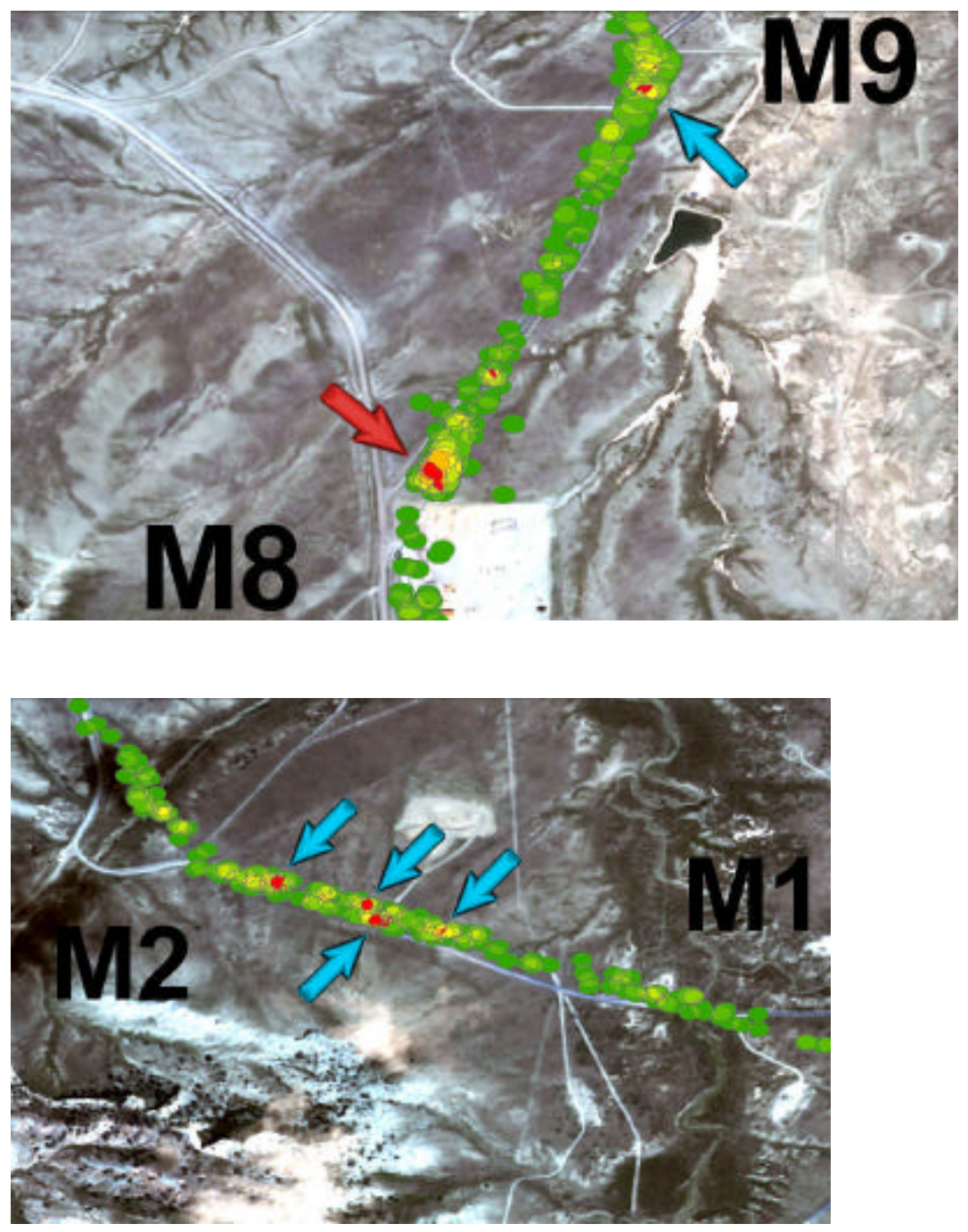

○ $\quad \mathrm{N} 43186.048$

○ W -106 134.1844

- Detected on 5 passes

$\circ$ Vicinity of M9

○ $\quad \mathrm{N} 431745.3624$

○ W - 1061315.4164

- Detected on 6 passes

- Area North of Gas Plant

- Note $2^{\text {nd }}$ possible area (without arrow) to the NE
○ N 431457.966

○ W -106 1127.3228

- Detected on 6 passes

- South of M2

○ N 431458.992

○ W -106 1131.6464

○ Detected on 5 passes

○ $\quad \mathrm{N} 43150.0216$

○ W - 1061135.0844

○ Detected on 5 passes

○ $\quad \mathrm{N} 43151.0188$

○ W -106 1137.7412

○ Detected on 5 passes 

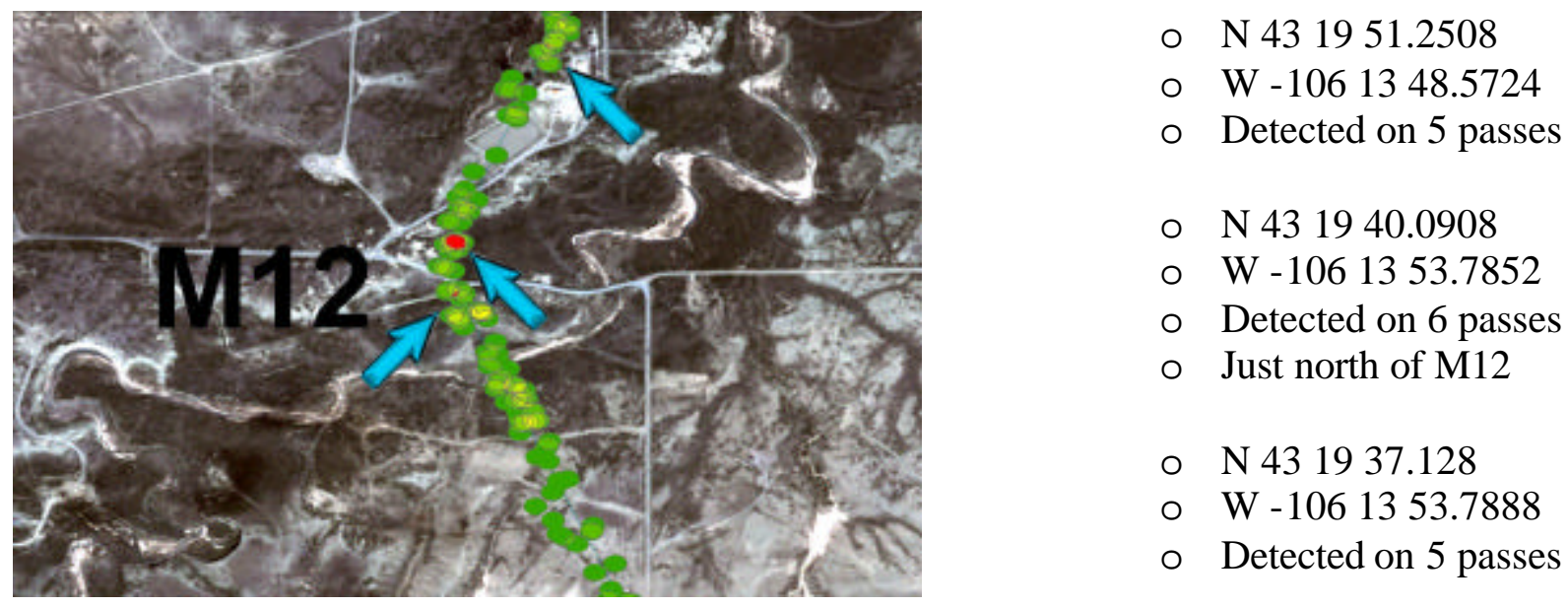

○ N 431940.0908

○ W - 1061353.7852

○ Detected on 6 passes

○ Just north of M12
○ N 431937.128
○ W - 1061353.7888
○ Detected on 5 passes

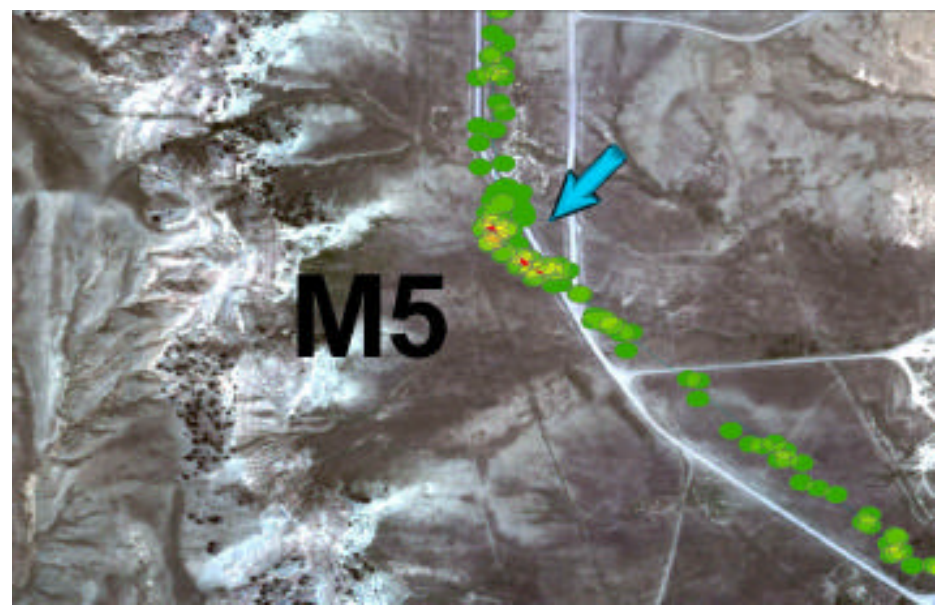




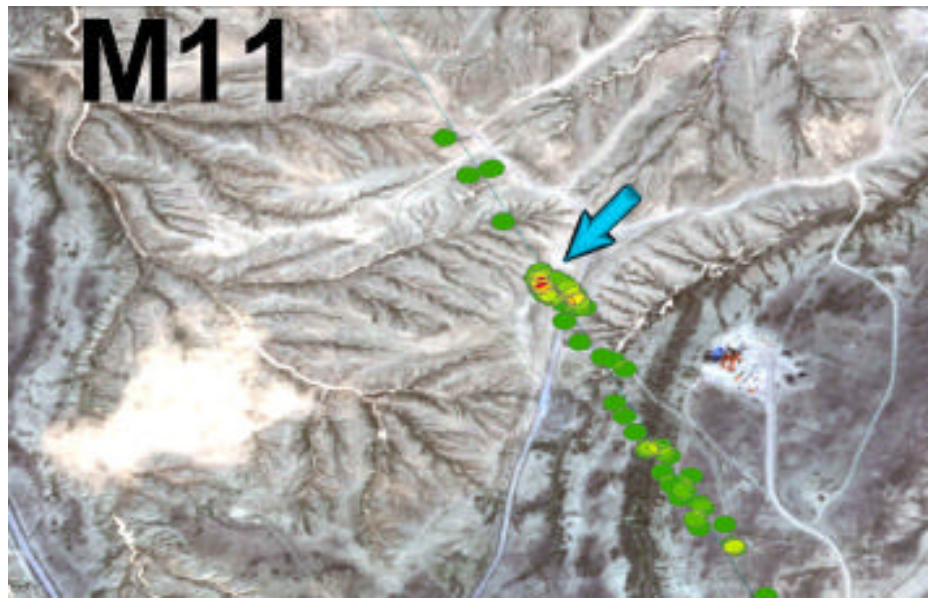

○ $\quad \mathrm{N} 431857.0096$

○ W - 1061330.9792

○ Detected on 5 passes

○ South of M11

\section{Special Case Analysis}

From the collection on Tuesday, September 14, 2004 one location north of M8 stood out above all the others and warranted additional analysis. A raster-based analysis and methane images of the area north of the RMOTC Gas Plant area and an area of significant emission are shown below. This is the methane image map from pass 4 on the AM of Tuesday, September $14^{\text {th }}, 2004$.

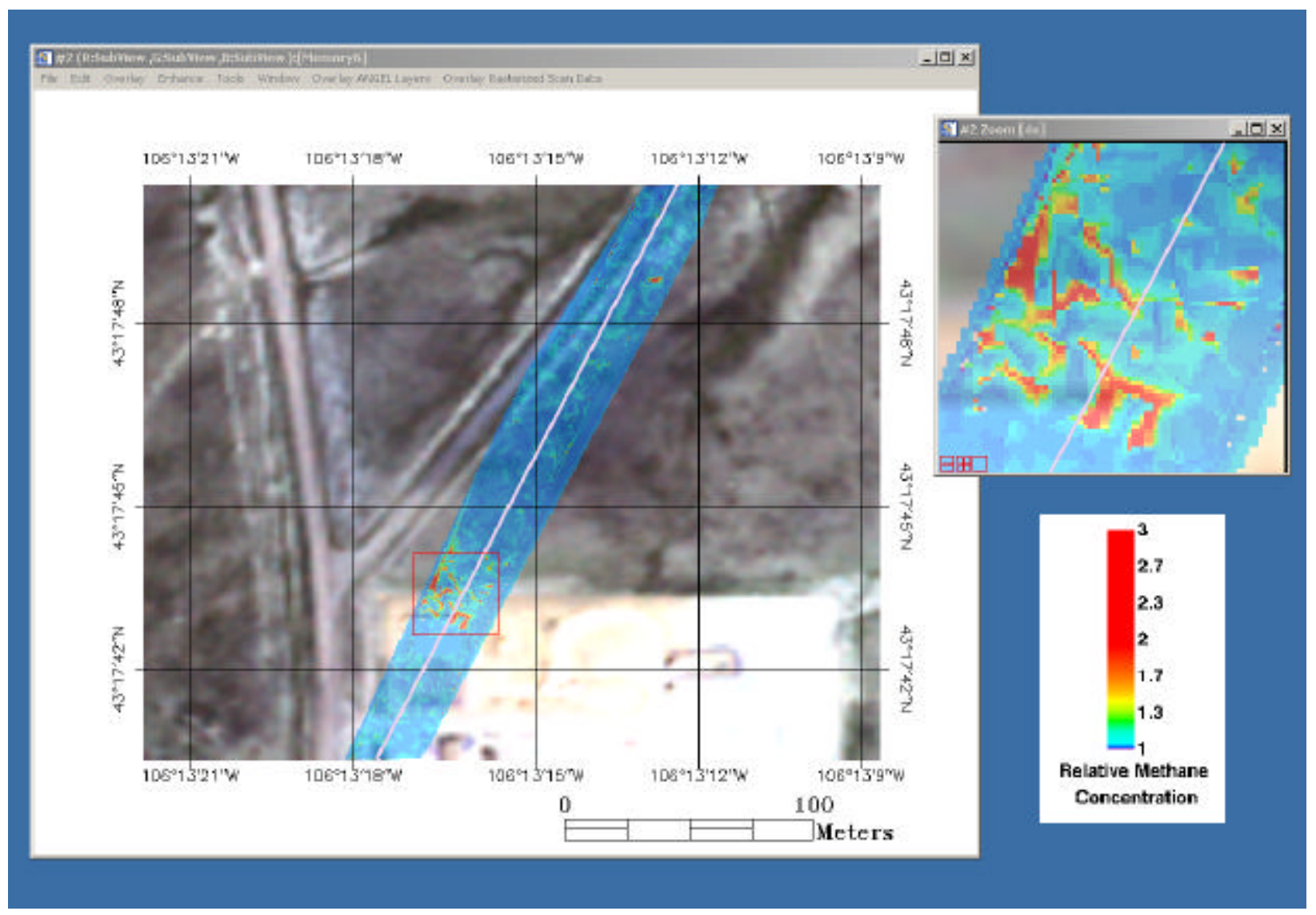




\section{Right of Way Coverage}

ANGEL collection planning starts with developing a flight plan that will place the aircraft over the pipeline route. In most cases the aircraft flight path cannot perfectly match the pipeline route but the ANGEL sensor can still track the full right of way. This is important to ensure that we provide adequate collection coverage of the full right of way for the entire length of the pipeline segment being surveyed. As the aircraft then flies the designated route, the sensor tracks and images the actual right of way, even when not directly under the aircraft and regardless of minor flight variations. The information collected from each flight is analyzed to determine that the right of way was fully covered as planned. The graphic below shows the actual results from a small segment of one such flight path over the designated pipeline route. The green line is the path of the aircraft and the red band is made up of all the individual sensor collects throughout the flight. In this case the sensor accurately tracked the pipeline and provided full coverage of the right of way. This post flight analysis provides confidence that we have adequately covered the pipeline path and right-of-way for the full 7.5-mile length of the survey.

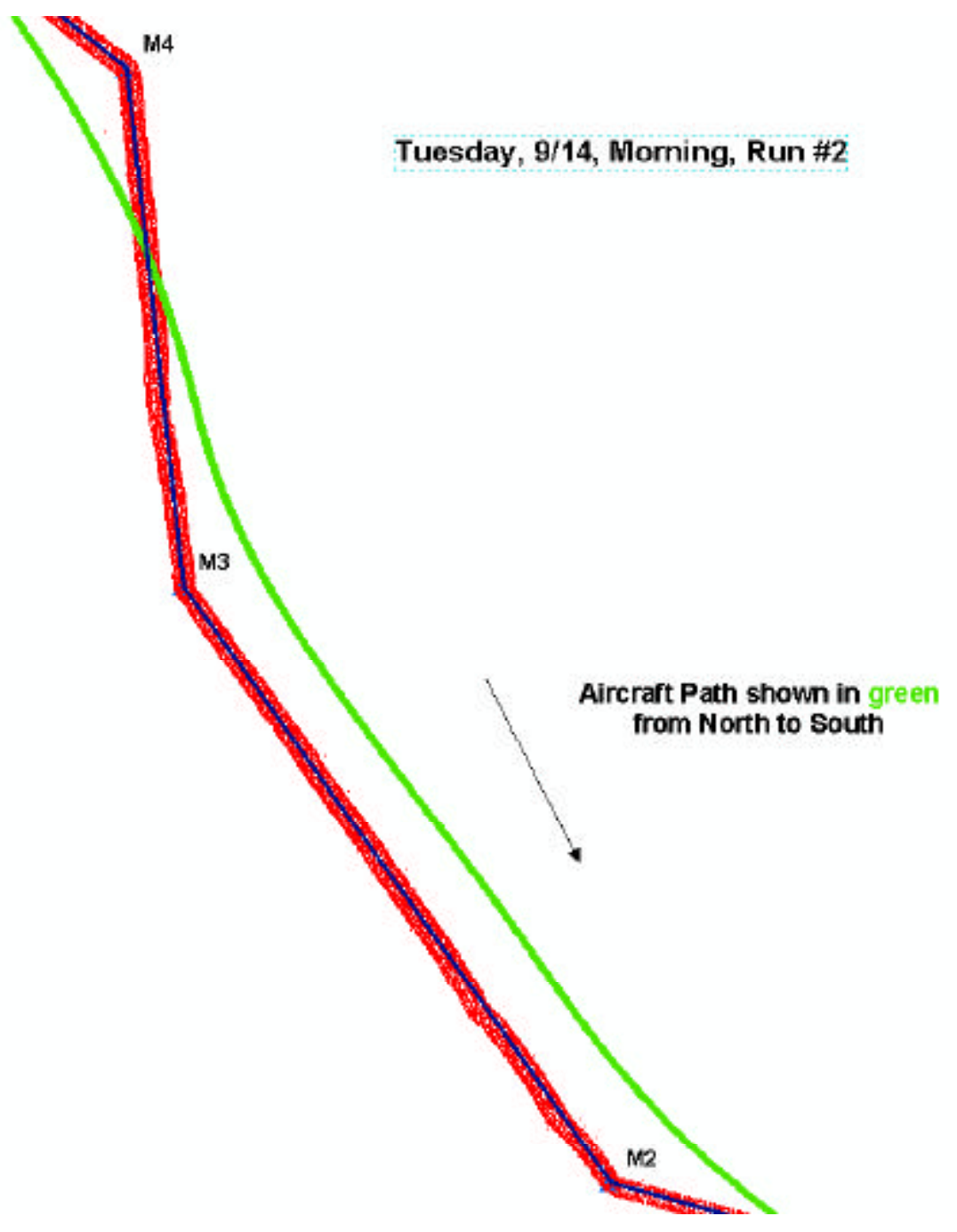




\section{Flight Path Verification}

The base imagery for this analysis is from Quickbird multispectral collection provided by DOE/NETL. The methane concentration pathlengths were measured from a single pass $\left(4^{\text {th }}\right.$ flight on the morning of September 14, 2004) and the colors represent the relative concentration pathlength of methane within the ANGEL swath. Normal background methane levels are shown in dark blue. ANGEL collector scan swath is approximately 25 meters wide and is superimposed on the base image. Elevated concentrations of methane clearly stand out in red and the highest concentrations are located north of the Gas Plant (north of location M8 on the Virtual Pipeline route). It should be noted that the imagery used as purchased was not perfectly geo-registered and is provided to give approximate context (+/- 15 meters) to the ANGEL analysis data, not absolute positioning.

If no satellite or aerial photography imagery is available for a survey, the ANGEL aircraft has been fitted with a monochrome video camera that is used for flight path verification. This camera collects looking forward at 15 degrees from nadir and provides MPEG2 motion video imagery with approximately $1.4 \mathrm{ft}$ raw GSD resolution. A sample frame is shown below. The video camera currently in use was designed only to provide engineering flight test information and will soon be replaced with a much higher resolution color and false color IR digital camera designed to collect a continuous strip of geo-referenced imagery as the sensor is flown along the pipeline right-of-way.

The ANGEL aircraft image below shows the RMOTC Gas Plant viewed from the North during one of the early morning passes. The yellow circle indicates the approximate location of the elevated levels of methane seen throughout the day in the Northwest corner of the Gas Plant.

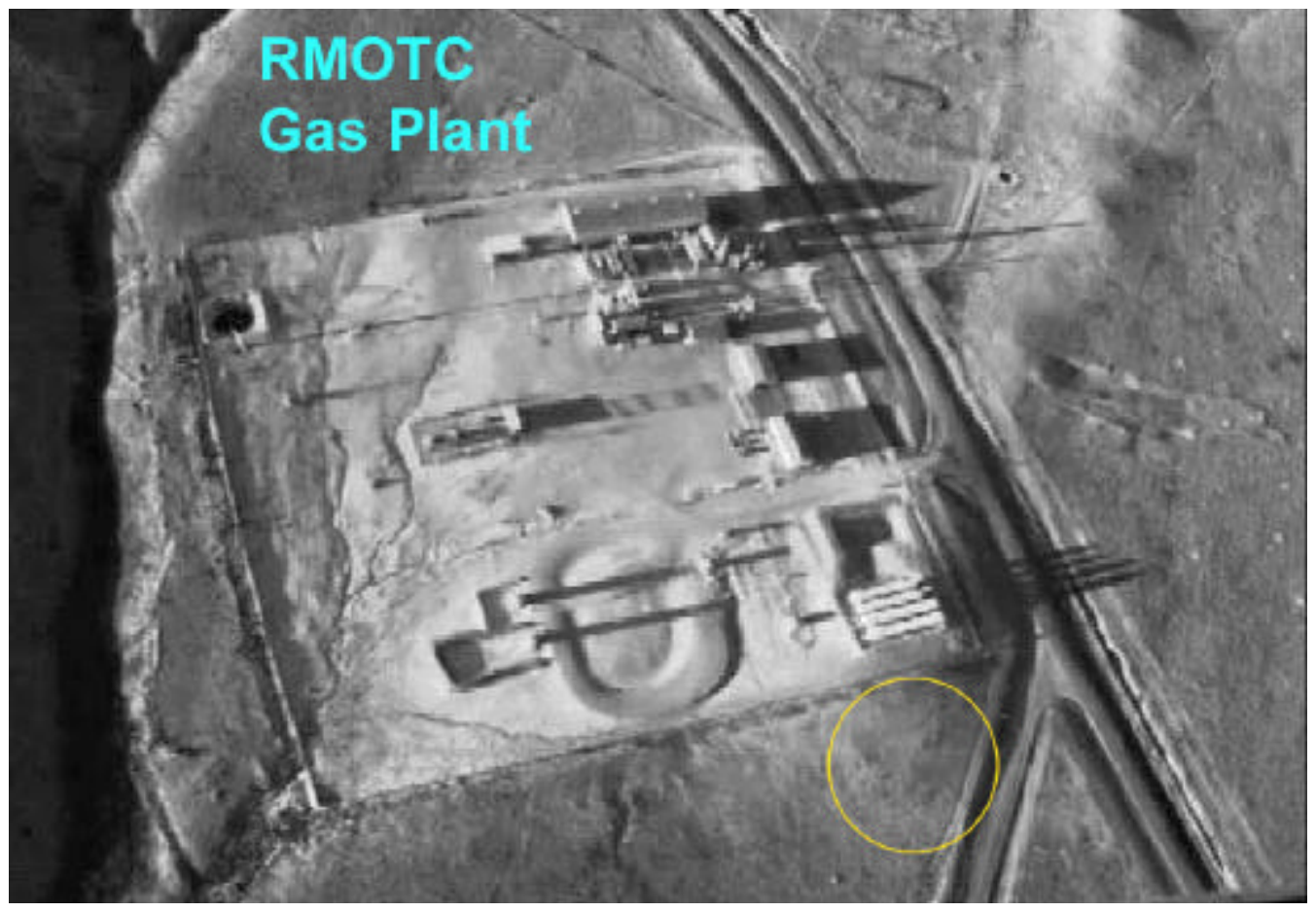




\section{Attachment 2: ITT ANGEL Customer Report - 14 Sept 2004 Collection}


ANGEL Service Customer Report

\section{Rocky Mountain Oilfield \\ Testing Center (RMOTC) \\ Virtual Pipeline Inspection}

\section{DATE(s) INSPECTION DATA ACQUIREID:}

September 14,2004

CONTRACT NUMBER:

DOE/National Energy Technology Laboratory Cooperative Development Agreement \# DE-FC26-03NT41877

IN RESPONSE TO RFP:

DOE Program Solicitation (PS) No. DE-PS26-02NT41613

\section{SUBMITTED BY:}

Steven Stearns

ITT Industries Space Systems Division

1447 St. Paul St.

Rochester, NY 14653-7225

Tel. (585) 762-5494

steven.stearns@itt.com

\section{SUBMITTED TO:}

Chris Buckingham

Southwest Research Labs

6220 Culebra Road (78238-5166)

P.O. Drawer 28510 (78228-0510)

San Antonio, Texas

REPORT DATE:

October 8, 2004

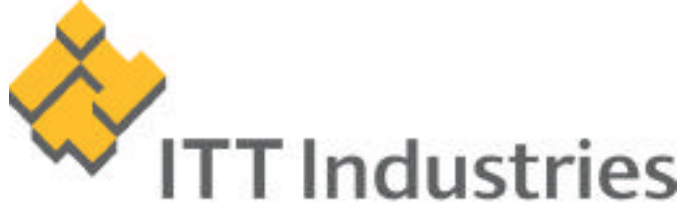

Engineered for life 


\section{Executive Summary:}

On September 14, 2004 we flew the route identified as "RMOTC Virtual Pipeline" with the ITT Industries ANGEL Sensor. This route was flown multiple times to ensure we had fully covered the complete Virtual Pipeline Route and to provide increased sample density to improve detection of smaller emissions. Analysis of the information collected indicates a number of areas of significant methane concentration along the pipeline right of way. The locations and relative size/concentration patterns for these are described in detail in this report.

The route flown is depicted below. All detected concentration areas are labeled with crosses. Color-coding is used to indicate detection of the methane concentration on multiple passes, with red indicating that the specific methane concentration was detected (within 30 meters) on five separate passes. Eleven distinct methane concentration areas were detected with sufficient quantity and frequency ( 5 or 6 passes) that they are high confidence. Elevated concentrations of methane in the area of a 1,000 scfh calibration leak near M1 were detected 4 times throughout the day.

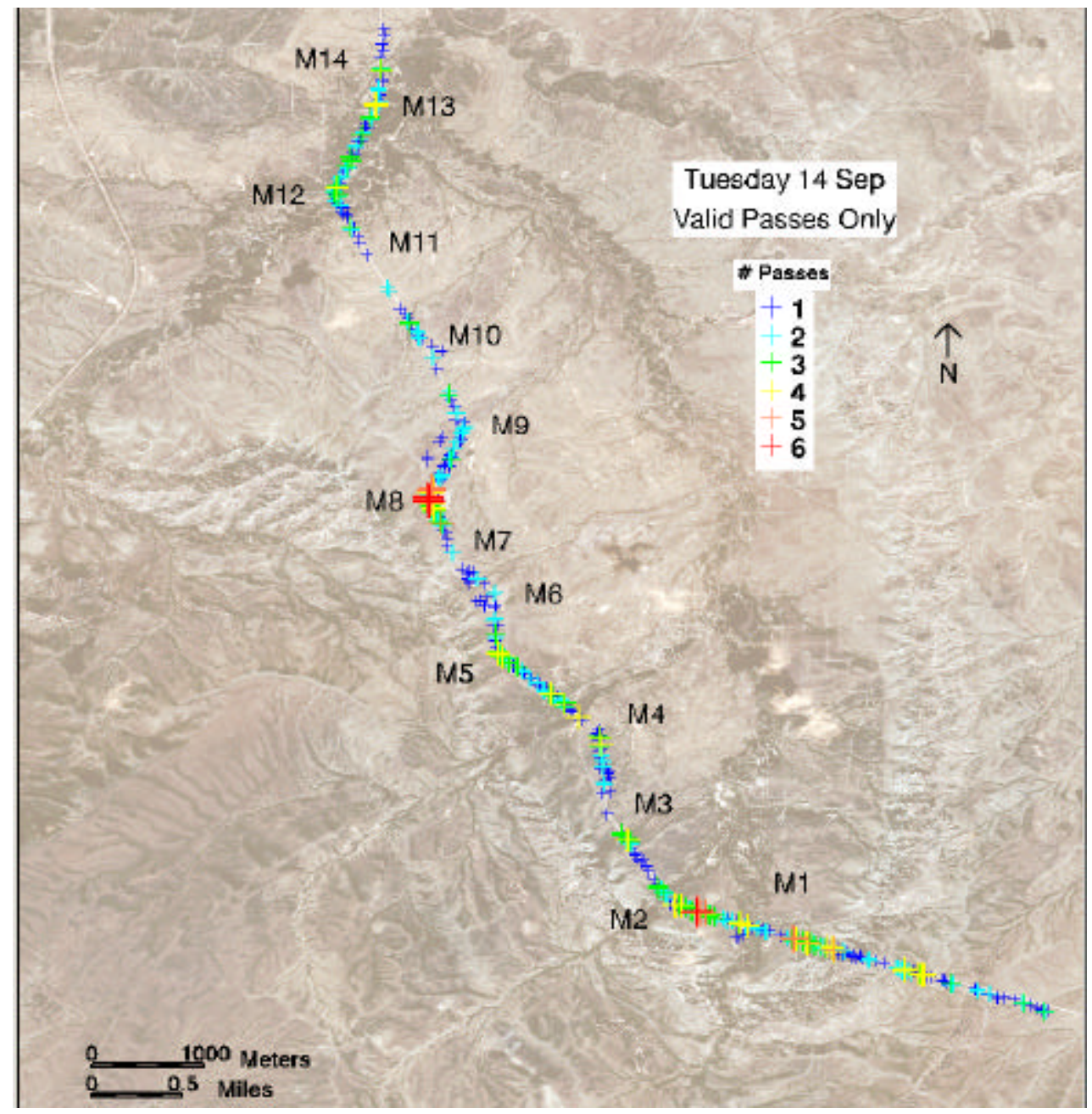




\section{Methane Detections}

The methane emissions with the highest confidence were captured on a relatively large number of passes as indicated in this table. The geographic coordinates provide the location of the aggregated multiple detections.

\begin{tabular}{|c|c|c|c|c|c|c|}
\hline NAD 27 Data (DMS) & & & & & & \\
\hline Latitude & Longitude & Leak Detection & Date & AM Passes & PM Passes & Comments \\
\hline 431457.966 & -1061127.3228 & 6 & $09 / 14 / 04$ & 3 & $1,2,3,4,6$ & south of M2 \\
\hline 431458.992 & -1061131.6464 & 5 & $09 / 14 / 04$ & 3 & $2,3,4,7$ & $\mathrm{M} 1-\mathrm{M} 2$ \\
\hline 43150.0216 & -1061135.0844 & 5 & $09 / 14 / 04$ & 3 & $2,3,4,7$ & south of $\mathrm{M} 2$ \\
\hline 43151.0188 & -1061137.7412 & 5 & $09 / 14 / 04$ & 3 & $2,3,4,7$ & vicinity of $\mathrm{M} 2$ \\
\hline 431639.8244 & -1061250.6232 & 5 & $09 / 14 / 04$ & 3,4 & $1,2,7$ & vicinity of M5 \\
\hline 431745.3624 & -1061315.4164 & 6 & $09 / 14 / 04$ & 3 & 1.2 .4 .6 .7 & alreadv have M8 (qas plant) \\
\hline 43186.048 & -106134.1844 & 5 & $09 / 14 / 04$ & 3,4 & $1,2,7$ & vicinity of $\mathrm{M} 9$ \\
\hline 431857.0096 & -1061330.9792 & 5 & $09 / 14 / 04$ & & $2,3,4,6,7$ & south of M11 \\
\hline 431937.128 & -1061353.7888 & 5 & $09 / 14 / 04$ & 3,4 & $1,3,7$ & many discrete points just south of $\mathrm{M} 12$ \\
\hline 431940.0908 & -1061353.7852 & 6 & $09 / 14 / 04$ & 3,4 & $1,2,3,4$ & just north of M12 \\
\hline 431951.2508 & -1061348.5724 & 5 & $09 / 14 / 04$ & 3 & $2,4,6,7$ & single small area M12-M13 \\
\hline
\end{tabular}

Methane emissions detected with lesser, but still significant confidence are listed in the table below. In all cases these were detected on multiple passes as well, but not as consistently as the detections documented above.

\begin{tabular}{|c|c|c|c|}
\hline NAD 27 Data (DMS) & & & \\
\hline Latitude & Longitude & Date & Comments \\
\hline 431954.7284 & $-106 \quad 13 \quad 47.3628$ & 14-Sep-04 & $\mathrm{M} 12-\mathrm{M} 13$ \\
\hline 431525.2 & -1061158.9632 & 14-Sep-04 & M2-M3 \\
\hline 431614.304 & -1061217.406 & 14-Sep-04 & M4-M5 \\
\hline 431728.8132 & -1061312.5976 & 14-Sep-04 & M8 - south of gas plant \\
\hline 431745.7188 & -1061315.3012 & 14-Sep-04 & M8 (gas plant) \\
\hline 431940.08 & -1061353.778 & 14-Sep-04 & just north of $\mathrm{M} 12$ \\
\hline 431457.9336 & -1061127.3732 & 14-Sep-04 & north of M1 \\
\hline 431856.826 & -1061330.6768 & 14-Sep-04 & south of M11 \\
\hline 431459.964 & -1061135.2896 & 14-Sep-04 & south of $\mathrm{M} 2$ \\
\hline 43151.0728 & -1061138.3712 & 14-Sep-04 & vicinity of $\mathrm{M} 2$ \\
\hline 43155.5764 & -1061145.0348 & 14-Sep-04 & just north of M2 \\
\hline 431623.0772 & -1061229.3076 & 14-Sep-04 & north of M4-M5 \\
\hline 431459.0316 & -1061131.704 & 14-Sep-04 & north of $\mathrm{M} 1$ \\
\hline 431951.0384 & $-10613 \quad 48.5292$ & 14-Sep-04 & single small area M12-M13 \\
\hline 431937.2 & -1061353.7888 & 14-Sep-04 & just south of M12 \\
\hline 431931.6884 & $-106 \quad 1350.8584$ & 14-Sep-04 & many discrete points south of $\mathrm{M} 12$ \\
\hline 43208.0916 & -1061340.4868 & 14-Sep-04 & south of $\mathrm{M} 13$ \\
\hline 431649.8504 & -1061251.5232 & 14-Sep-04 & south of $M 6$ \\
\hline 431453.9196 & -1061114.2692 & 14-Sep-04 & vicinity of $\mathrm{M} 1$ \\
\hline 431639.954 & -1061250.5296 & 14-Sep-04 & vicinity of M5 \\
\hline 43186.246 & -106134.044 & 14-Sep-04 & vicinity of M9 \\
\hline
\end{tabular}




\section{Significant Emissions}

In this survey there are several areas that stand out due to the size and concentration-pathlength values of methane plume and frequency of detection. These are identified in the images provided below with red and orange plume position markers. The green markers are areas where there were potential indicators for methane but these were only detected on single passes. These do not represent highly significant indicators.

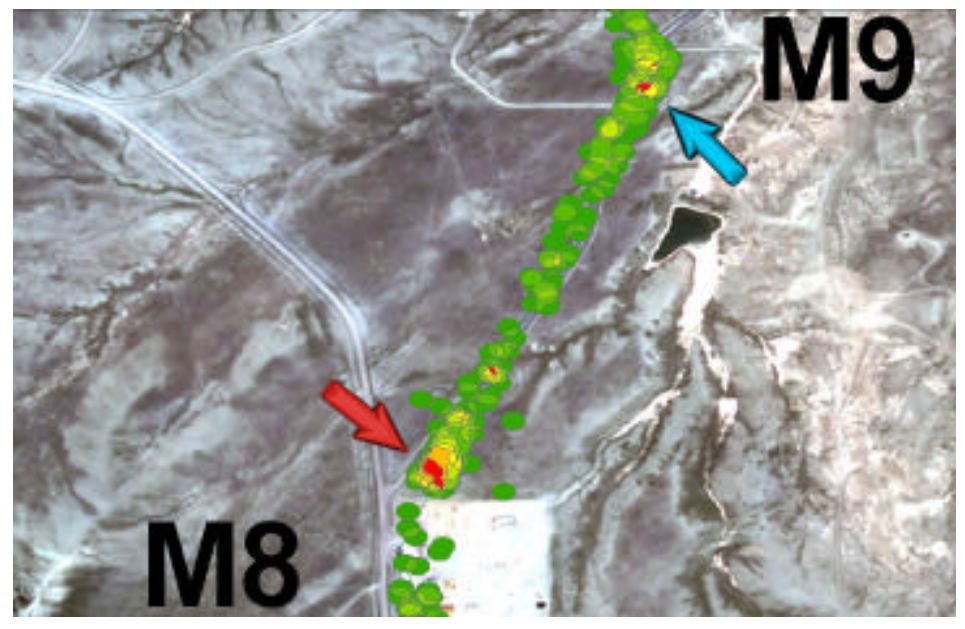

○ $\quad \mathrm{N} 43186.048$

○ W - 106134.1844

○ Detected on 5 passes

$\circ$ Vicinity of M9

○ $\quad \mathrm{N} 431745.3624$

○ W - 1061315.4164

- Detected on 6 passes

- Area North of Gas Plant

- Note $2^{\text {nd }}$ possible area (without arrow) to the NE

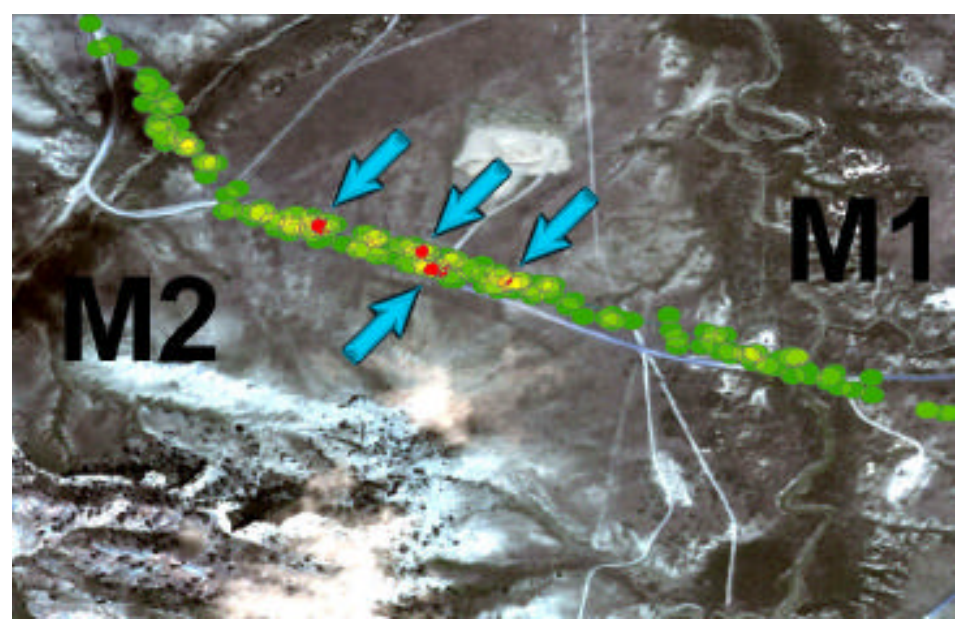
○ N 431457.966
o W - 1061127.3228
- Detected on 6 passes
- South of M2
○ N 431458.992
o W -106 1131.6464
○ Detected on 5 passes
○ N 43150.0216
○ W -106 1135.0844
○ Detected on 5 passes
$\begin{array}{ll}\circ & \mathrm{N} 43151.0188 \\ \circ & \mathrm{W}-1061137.7412 \\ \circ & \text { Detected on } 5 \text { passes }\end{array}$ 


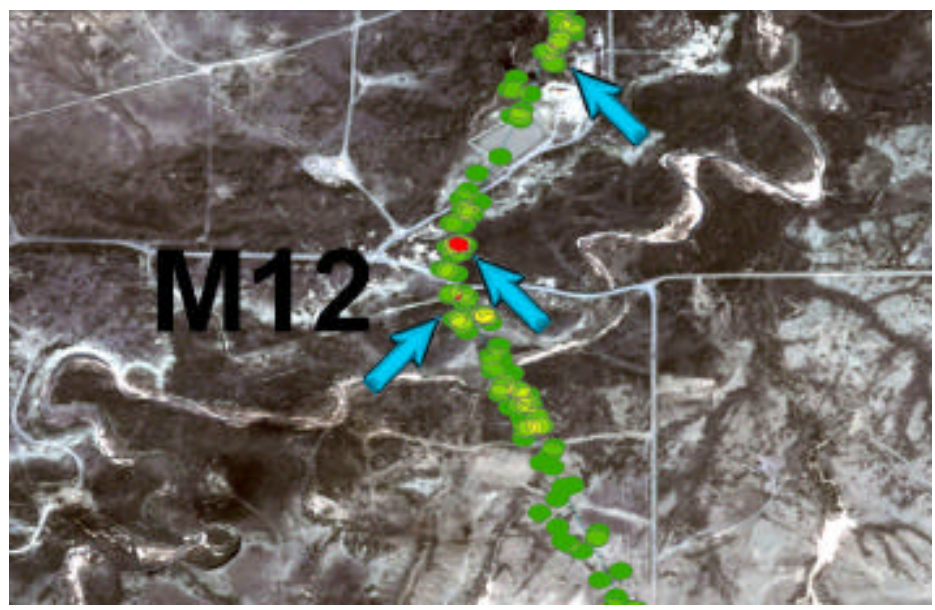

○ N 431951.2508

○ W - 1061348.5724

$\circ$ Detected on 5 passes

○ N 431940.0908

○ W - 1061353.7852

- Detected on 6 passes

○ Just north of M12

○ N 431937.128

○ W - -1061353.7888

○ Detected on 5 passes

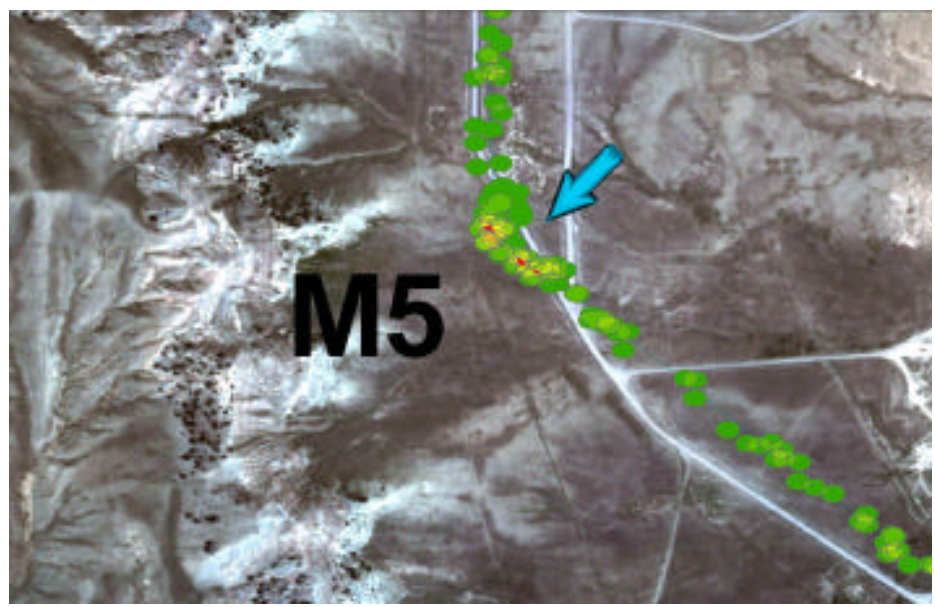

○ N 431639.8244

○ W - -1061250.6232

$\circ$ Detected on 5 passes

○ Vicinity of M5

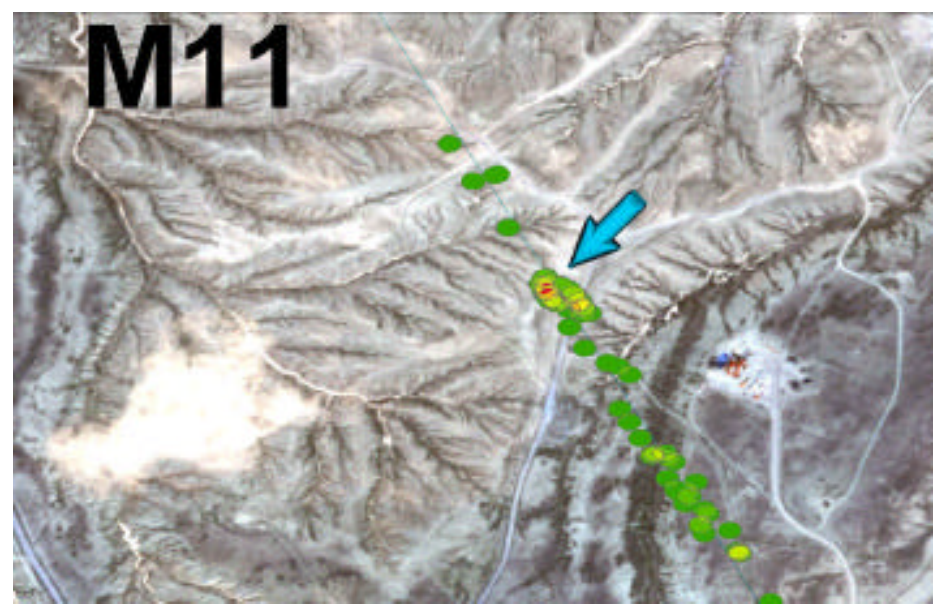
○ N 431857.0096
○ W - 1061330.9792
- Detected on 5 passes
- South of M11 


\section{Special Case Analysis}

From the collection on Tuesday, September 14, 2004 one location north of M8 stood out above all the others and warranted additional analysis. A raster-based analysis and methane images of the area north of the RMOTC Gas Plant area and an area of significant emission are shown below. This is the methane image map from pass 4 on the AM of Tuesday, September $14^{\text {th }}, 2004$.

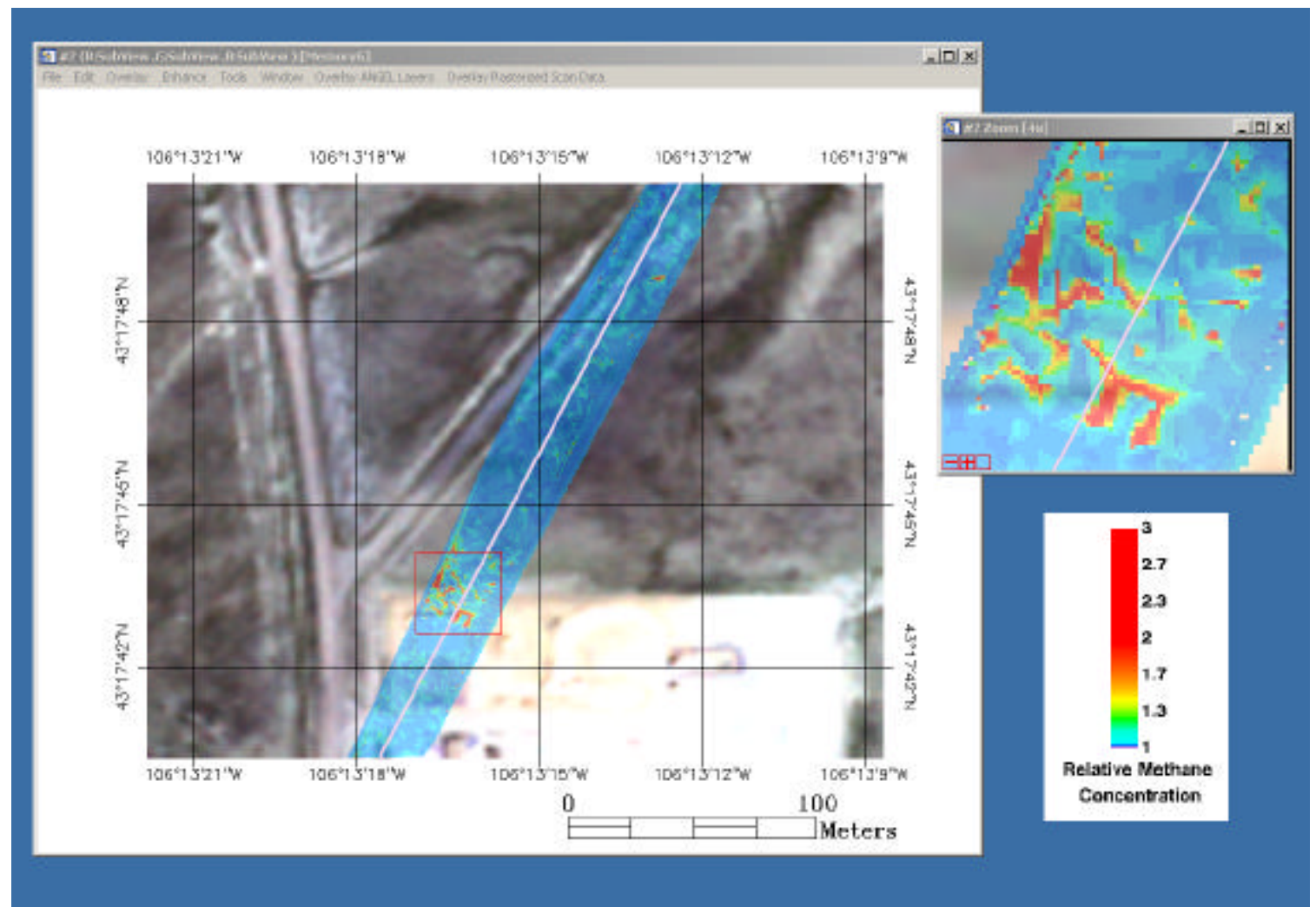

\section{Right of Way Coverage}

ANGEL collection planning starts with developing a flight plan that will place the aircraft over the pipeline route. In most cases the aircraft flight path cannot perfectly match the pipeline route but the ANGEL sensor can still track the full right of way. This is important to ensure that we provide adequate collection coverage of the full right of way for the entire length of the pipeline segment being surveyed. As the aircraft then flies the designated route, the sensor tracks and images the actual right of way, even when not directly under the aircraft and regardless of minor flight variations. The information collected from each flight is analyzed to determine that the right of way was fully covered as planned. The graphic below shows the actual results from a small segment of one such flight path over the designated pipeline route. The green line is the path of the aircraft and the red band is made up of all the individual sensor collects throughout the flight. In this case the sensor accurately tracked the pipeline and provided full coverage of the right of way. This post flight analysis provides confidence that we have adequately covered the pipeline path and right-of-way for the full 7.5-mile length of the survey. 


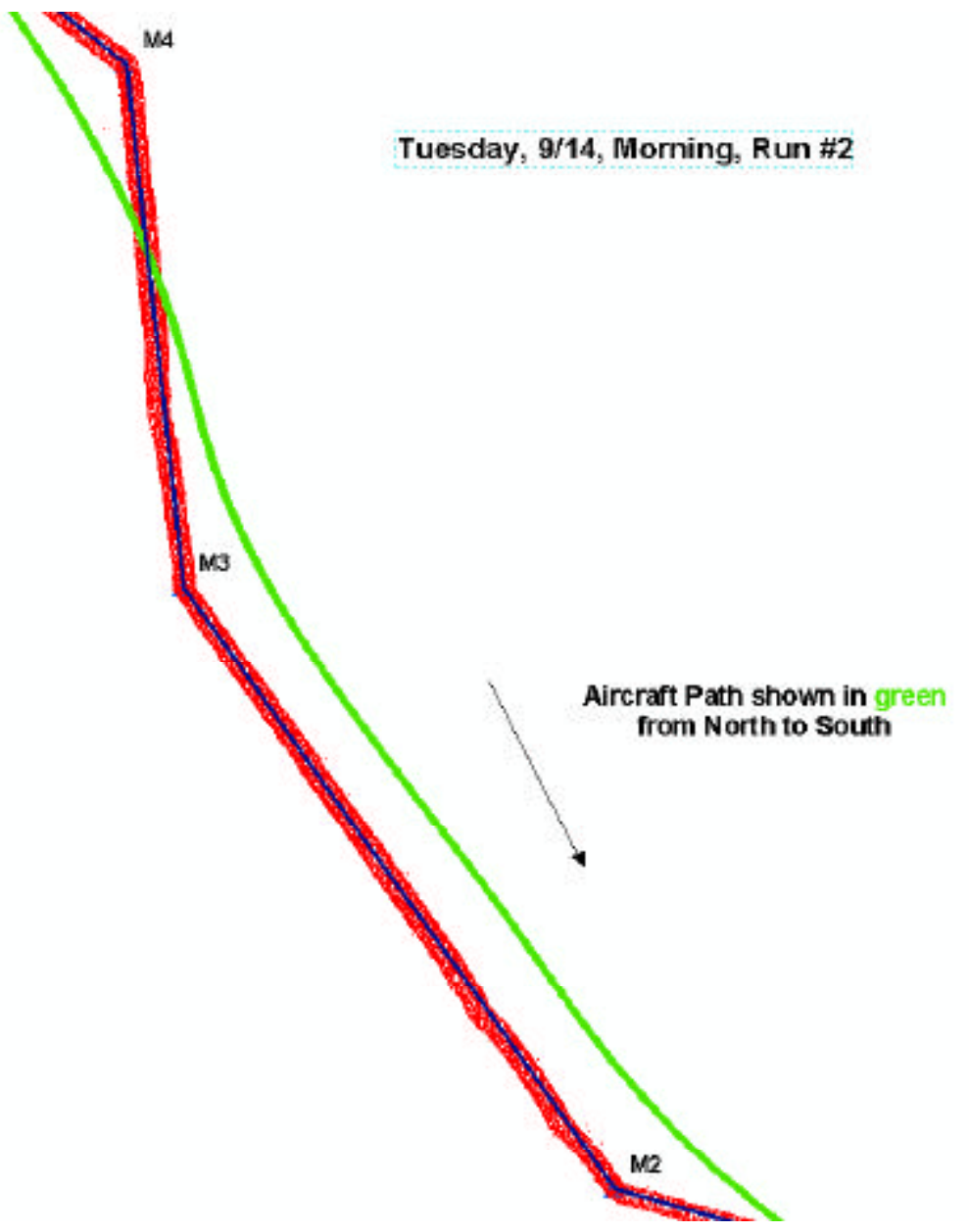

\section{Flight Path Verification}

The base imagery for this analysis is from Quickbird multispectral collection provided by DOE/NETL. The methane concentration pathlengths were measured from a single pass $\left(4^{\text {th }}\right.$ flight on the morning of September 14, 2004) and the colors represent the relative concentration pathlength of methane within the ANGEL swath. Normal background methane levels are shown in dark blue. ANGEL collector scan swath is approximately 25 meters wide and is superimposed on the base image. Elevated concentrations of methane clearly stand out in red and the highest concentrations are located north of the Gas Plant (north of location M8 on the Virtual Pipeline route). It should be noted that the imagery used as purchased was not perfectly geo-registered and is provided to give approximate context (+/- 15 meters) to the ANGEL analysis data, not absolute positioning. 
If no satellite or aerial photography imagery is available for a survey, the ANGEL aircraft has been fitted with a monochrome video camera that is used for flight path verification. This camera collects looking forward at 15 degrees from nadir and provides MPEG2 motion video imagery with approximately $1.4 \mathrm{ft}$ raw GSD resolution. A sample frame is shown below. The video camera currently in use was designed only to provide engineering flight test information and will soon be replaced with a much higher resolution color and false color IR digital camera designed to collect a continuous strip of geo-referenced imagery as the sensor is flown along the pipeline right-of-way.

The ANGEL aircraft image below shows the RMOTC Gas Plant viewed from the North during one of the early morning passes. The yellow circle indicates the approximate location of the elevated levels of methane seen throughout the day in the Northwest corner of the Gas Plant.

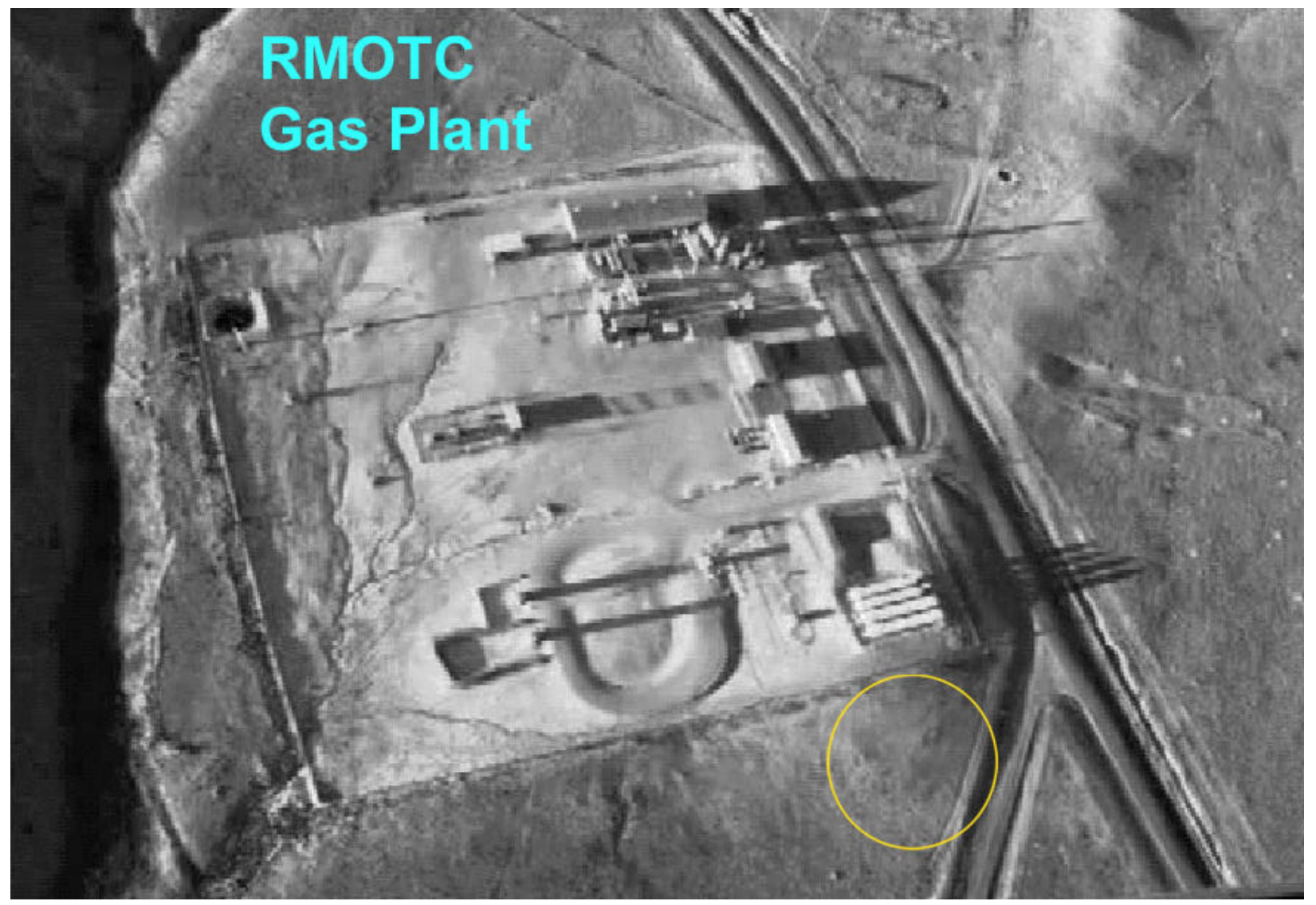


Attachment 3: ITT ANGEL Customer Report - 15 Sept 2004 Collection 


\section{ANGEL Service Customer Report}

\section{Rocky Mountain Oilfield Testing Center (RM OTC) Virtual Pipeline Inspection}

\section{DATE(s) INSPECTION DATA ACQUIREID:}

September 15, 2004

CONTRACT NUMBER:

DOE/National Energy Technology Laboratory Cooperative Development Agreement \# DE-FC26-03NT41877

IN RESPONSE TO RFP:

DOE Program Solicitation (PS) No. DE-PS26-02NT41613

\section{SUBMITTED BY:}

Steven Stearns

ITT Industries Space Systems Division

1447 St. Paul St.

Rochester, NY 14653-7225

Tel. (585) 762-5494

steven.stearns@itt.com

\section{SUBMITTED TO:}

Chris Buckingham

Southwest Research Labs

6220 Culebra Road (78238-5166)

P.O. Drawer 28510 (78228-0510)

San Antonio, Texas

REPORT DATE:

October 8, 2004 


\section{Executive Summary:}

On September 15, 2004 the route identified as "RMOTC Virtual Pipeline" was flown with the ITT Industries ANGEL Sensor. This route was flown multiple times to ensure the complete Virtual Pipeline Route was fully covered, and to provide increased sample density to improve detection of smaller emissions. Analysis of the information collected indicates a number of areas of significant methane concentration along the pipeline right of way. The locations and relative size/concentration patterns for these are described in detail in this report.

The route flown is depicted below. All detected concentration areas are labeled with crosses. Color-coding is used to indicate detection of the methane concentration on multiple passes, with red indicating that the specific methane concentration was detected (within 30 meters) on eight separate passes. Six distinct methane concentration areas were detected with sufficient quantity and frequency (7 or 8 passes) that they are high confidence.

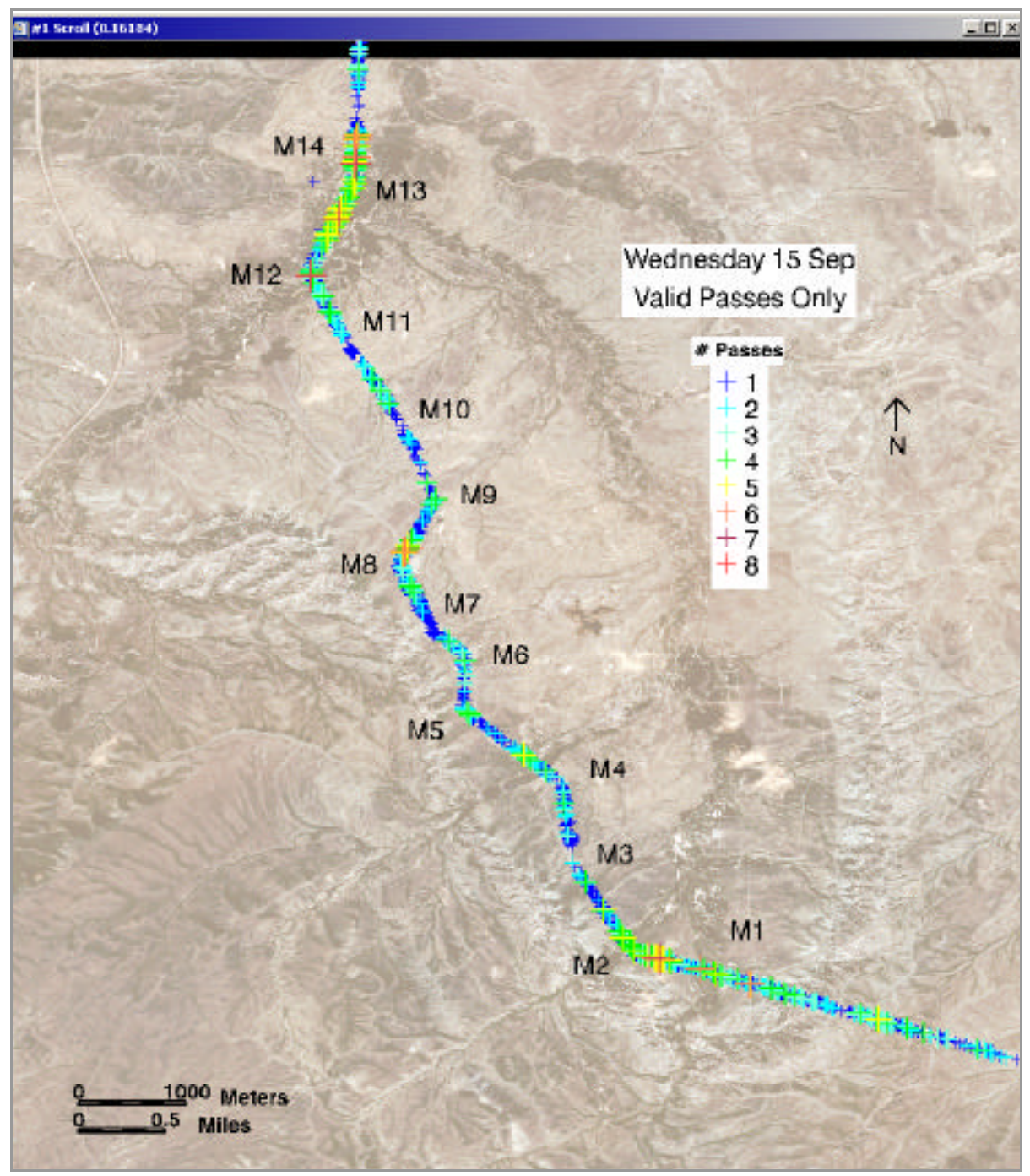


Methane Detections

\begin{tabular}{|l|l|l|l|l|l|}
\hline NAD 27 Data (DMS) & & & & & \\
\hline Latitude & Longitude & Date & AM Passes & PM Passes & Comments \\
\hline 431513.374 & -1061124.1836 & $15-$ Sep-04 & $1,2,3,4,5,6$ & $1,5,6$ & between M1 \& M2 \\
\hline 431521.69 & -1061139.5916 & $15-$ Sep-04 & $4,5,6$ & $1,2,4,5$ & northwest of M2 \\
\hline 431758.9236 & -106138.9328 & $15-$ Sep-04 & $1,2,4,5,6$ & $1,3,4,5,6$ & north of gas plant (high confidence) \\
\hline 43209.312 & -1061339.972 & $15-$ Sep-04 & $2,3,4,6$ & $1,4,5$ & area \#1 between M12 \& M13 \\
\hline 432015.0252 & -1061336.498 & $15-$ Sep-04 & $2,3,4,5,6$ & 1,6 & area \#2 between M12 \& M13 \\
\hline 432038.0976 & -1061329.28 & $15-$ Sep-04 $1,4,5,6$ & $2,3,4,5,6$ & area between M13 \& M14 \\
\hline
\end{tabular}

The methane emissions with the highest confidence were captured on a relatively large number of passes as indicated in the above table. The geographic coordinates provide the location of the aggregated multiple detections.

Methane emissions detected with lesser, but still significant confidence is listed in the table below. In all cases these were detected on multiple passes as well, but not as consistently as the detections documented above.

\begin{tabular}{|c|c|c|c|}
\hline NAD 27 Data (DMS) & & & \\
\hline Latitude & Longitude & Date & Comments \\
\hline 431457.948 & -1061127.7332 & 15-Sep-04 & M1-M2 middle \\
\hline 431929.9784 & -1061350.232 & 15-Sep-04 & M11-M12 \\
\hline 431938.6472 & -1061354.2496 & 15-Sep-04 & M12 corner - large area extent \\
\hline 43204.1208 & -1061342.4884 & 15-Sep-04 & M12-M13 \\
\hline 43151.98 & -1061142.324 & 15-Sep-04 & $\mathrm{M} 2$ \\
\hline 43178.7396 & -1061258.0896 & 15-Sep-04 & M6-M7 \\
\hline 431730.8184 & -1061314.16 & 15-Sep-04 & M7-M8 \\
\hline 43156.786 & -1061146.5684 & 15-Sep-04 & \\
\hline 431459.316 & -1061133.0324 & 15-Sep-04 & M1-M2 - big leak \\
\hline 43200.9492 & -1061343.8204 & 15-Sep-04 & M12-M13 \\
\hline 431744.5092 & -1061315.8808 & 15-Sep-04 & just north of $\mathrm{M} 8$ \\
\hline 432023.9784 & -1061336.3252 & 15-Sep-04 & just south of M14 \\
\hline 431954.714 & -1061347.1072 & 15-Sep-04 & north of M12 \\
\hline 432017.142 & -1061336.966 & 15-Sep-04 & just north of M13 \\
\hline 43153.6936 & -1061143.62 & 15-Sep-04 & just north of M2 \\
\hline 431620.046 & -1061224.4044 & 15-Sep-04 & just north of M4 \\
\hline 43151.1808 & -1061138.8716 & 15-Sep-04 & just south of M2 - many discrete areas \\
\hline 431659.9124 & -1061251.7608 & 15-Sep-04 & just south of M6 \\
\hline 432013.3116 & -1061337.6644 & 15-Sep-04 & just south of M13 \\
\hline 431949.0008 & -1061349.9116 & 15-Sep-04 & north of M12 \\
\hline 43155.1228 & -1061144.7972 & 15-Sep-04 & north of M2 \\
\hline
\end{tabular}




\begin{tabular}{|c|c|c|c|}
\hline NAD 27 Data (DMS) & & & \\
\hline Latitude & Longitude & Date & Comments \\
\hline 431747.1984 & -1061314.5956 & 15-Sep-04 & north of M8 \\
\hline 431957.9792 & -1061345.0264 & 15-Sep-04 & north of M12 \\
\hline 431622.3572 & -1061227.3528 & 15-Sep-04 & north of M4 \\
\hline 431951.8916 & -1061348.0252 & 15-Sep-04 & north of M12 \\
\hline 43159.5652 & -1061148.3612 & 15-Sep-04 & north of $\mathrm{M} 2$ \\
\hline 432031.2504 & -1061336.5376 & 15-Sep-04 & on $\mathrm{M} 14$ \\
\hline 431518.63 & -1061155.0932 & 15-Sep-04 & single M2-M3 \\
\hline 431845.8568 & -1061322.3068 & 15-Sep-04 & single north of M10 \\
\hline 431529.7684 & -106121.8612 & 15-Sep-04 & single south of M3 \\
\hline 431638.9388 & -1061249.554 & 15-Sep-04 & small areas just south of M5 \\
\hline 43167.2192 & -1061211.3256 & 15-Sep-04 & small area just south of M4 \\
\hline 432028.6656 & -1061336.2064 & 15-Sep-04 & small areas just south of $\mathrm{M} 14$ \\
\hline 43165.502 & -1061211.2752 & 15-Sep-04 & south of M4 \\
\hline 43208.9772 & -1061340.2024 & 15-Sep-04 & tiny area south of $\mathrm{M} 13$ \\
\hline 431641.1564 & -1061251.678 & 15-Sep-04 & tiny area at M5 \\
\hline 431738.5584 & -1061317.076 & 15-Sep-04 & tiny area just south of M8 \\
\hline 43185.2884 & -106134.278 & 15-Sep-04 & tiny areas just south of M9 \\
\hline 431922.0044 & -1061345.6276 & 15-Sep-04 & tiny area north of M11 \\
\hline 431454.7188 & -1061115.9504 & 15-Sep-04 & vicinity of calibration leak \\
\hline
\end{tabular}




\section{Significant Emissions}

In this survey there are six areas that stand out due to the size and concentration-pathlength values of methane plume and frequency of detection. These are identified in the images provided below with red and orange plume markers. The green markers are areas where there were potential indicators for methane but these were only detected on single passes. These do not represent highly significant indicators.

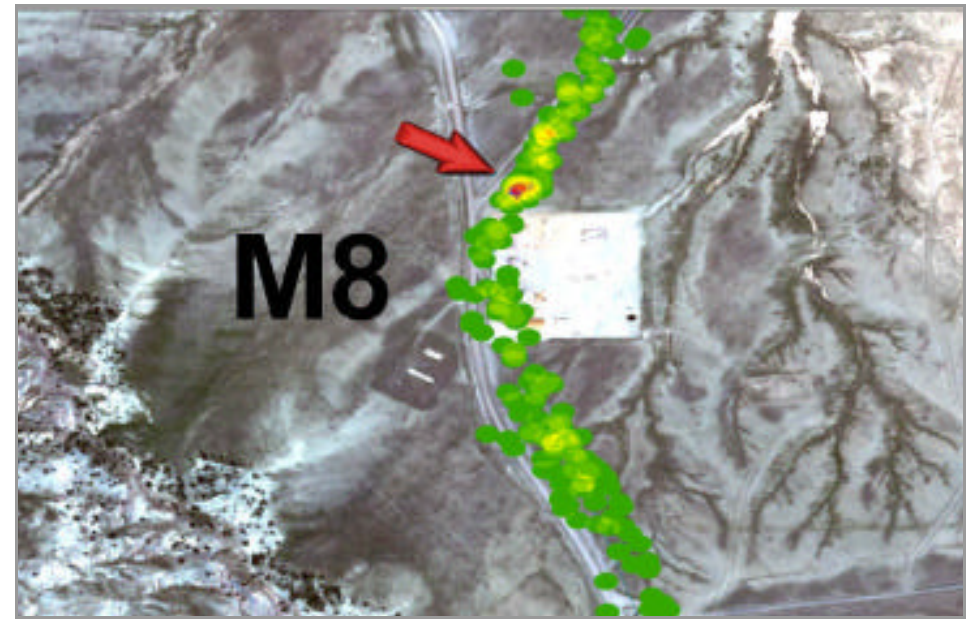

- $\quad \mathrm{N} 431758.9236$

- W-106 138.9328

- Detected on 10 passes

- North of Gas Plant

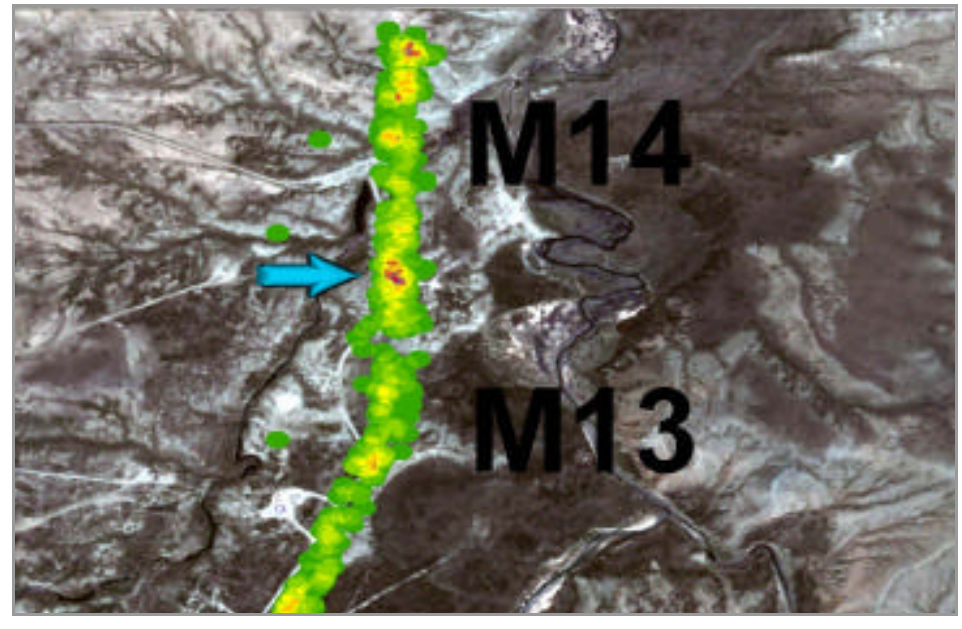

- N 432023.68

- W-106 1336.43

- Detected on 9 passes 


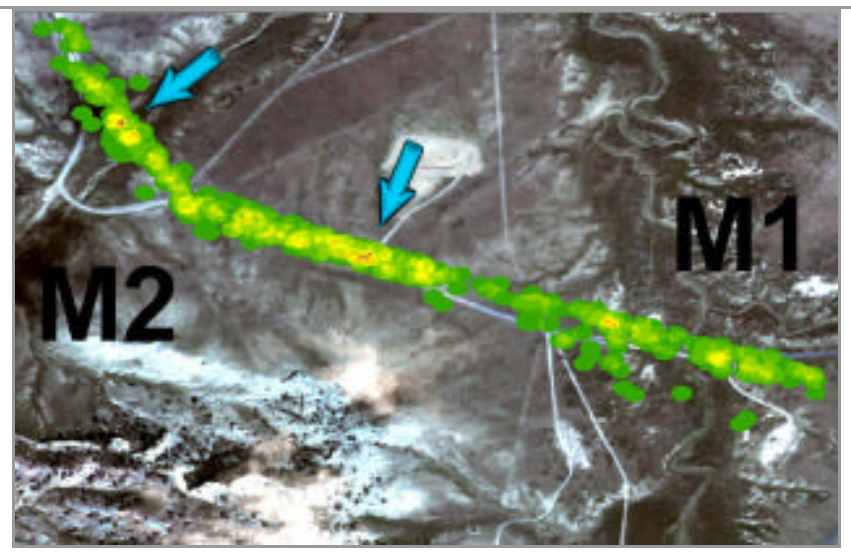

- $\quad \mathrm{N} 43157.23$

- W-106 1146.72

- Detected on 7 passes

- $\quad \mathrm{N} 431458.91$

- W-106 1131.31

- Detected on 9 passes

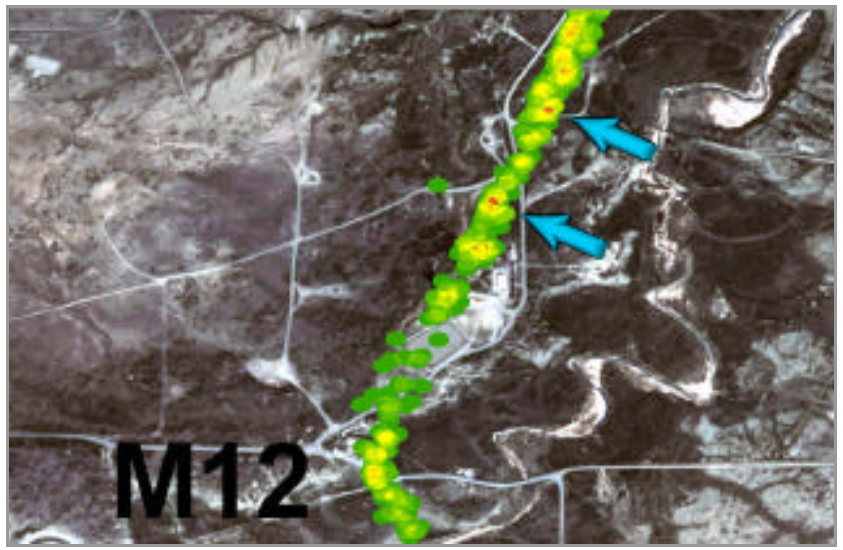

- $\quad \mathrm{N} 43209.312$

- W-1061339.972

- Detected on 7 passes

- $\quad \mathrm{N} 432015.0252$

- W-106 1336.498

- Detected on 7 passes

\section{Special Case Analysis}

From the collection on Wednesday, September 15, 2004, a location North of the Gas Plant stood out above all the others and warranted additional analysis. A raster-based analysis and methane images of the RMOTC Gas Plant area are shown below. The methane concentration pathlengths were measured from a single pass $\left(2^{\text {nd }}\right.$ pass on the morning of September 15,2004$)$ and the colors represent the relative concentration pathlength of methane within the ANGEL swath. Normal background methane levels are shown in dark blue. ANGEL collector scan swath is approximately 25 meters wide and is superimposed on the base image. Elevated concentrations of methane clearly stand out in red. Over the course of the day, elevated level of methane were seen in a zone stretching from the NW corner of the Gas Plant to a point roughly 30-40 meters to the northeast. The image shown below is the result of analysis of thousands of individual methane measurements. The patchy nature of the highlighted plume is at least partially due to the algorithms used to analyze the ANGEL data stream. In reality the plume is likely to be somewhat more homogenous in nature.

The base imagery for this analysis is from a Quickbird multispectral collection provided by DOE/NETL. It should be noted that the imagery used as purchased was not perfectly georegistered and is provided to give approximate context (+/- 15 meters) to the ANGEL analysis data, not absolute positioning. 

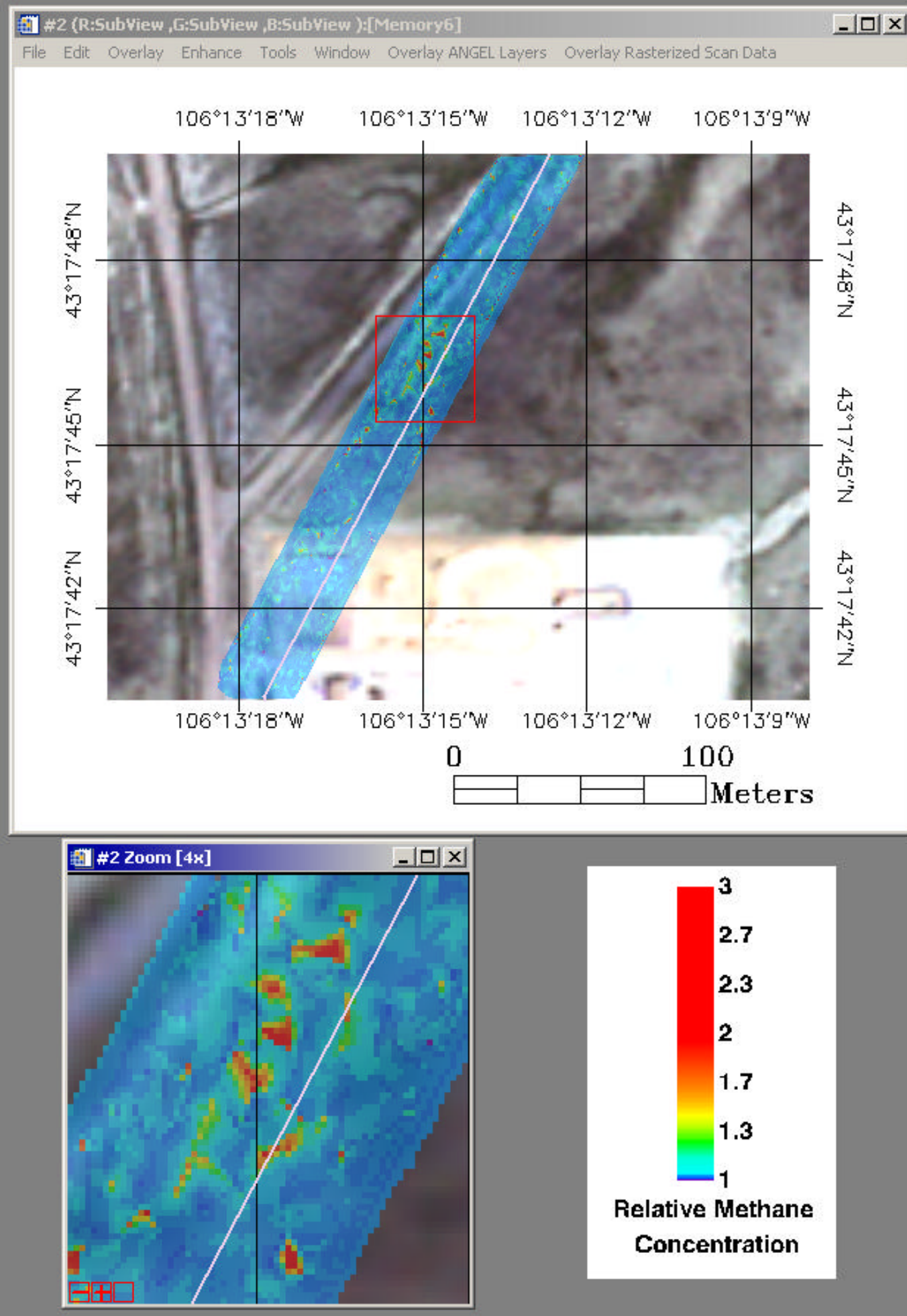

Relative Methane

Concentration 


\section{Right of Way Coverage}

ANGEL collection planning starts with developing a flight plan that will place the aircraft over the pipeline route. In most cases the aircraft flight path cannot perfectly match the pipeline route but the ANGEL sensor can still track the full right of way. This is important to ensure that we provide adequate collection coverage of the full right of way for the entire length of the pipeline segment being surveyed. As the aircraft flies the designated route, the sensor tracks and images the actual right of way, even when not directly under the aircraft and regardless of minor flight variations. The information collected from each flight is analyzed to determine that the right of way was fully covered as planned. The graphic below shows the actual results from a small segment of one such flight path over the designated pipeline route. The green line is the path of the aircraft and the red band is made up of all the individual sensor collects throughout the flight. In this case the sensor accurately tracked the pipeline and provided full coverage of the right of way. This post flight analysis provides confidence that we have adequately covered the pipeline path and right-of-way for the full 7.5-mile length of the survey.

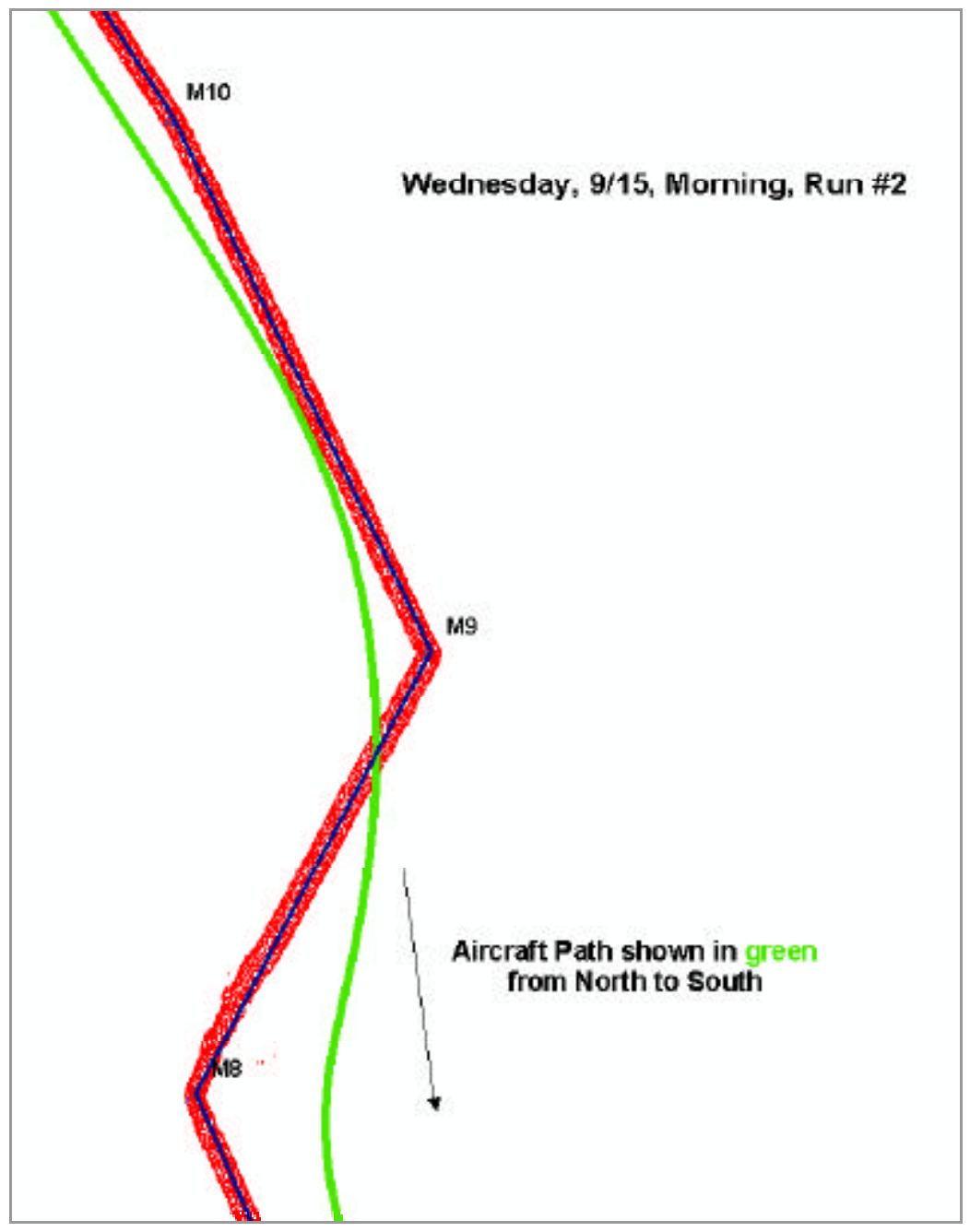




\section{Flight Path Verification}

The ANGEL aircraft has been fitted with a monochrome video camera that is used for flight path verification. This camera collects looking forward at 15 degrees from nadir and provides MPEG2 motion video imagery with approximately $1.4 \mathrm{ft}$ raw GSD resolution. A sample frame is shown below from one of the PM passes. The video camera currently in use was designed only to provide engineering flight test information. It will soon be replaced with a much higher resolution color and false color IR digital camera designed to collect a continuous strip of georeferenced imagery as the sensor is flown along the pipeline right-of-way. The image below was acquired during a PM run as the ANGEL aircraft was inspecting the pipe from North to South. The yellow circle indicates the approximate area North of the RMOTC Gas Plant in which elevated levels of methane were detected.

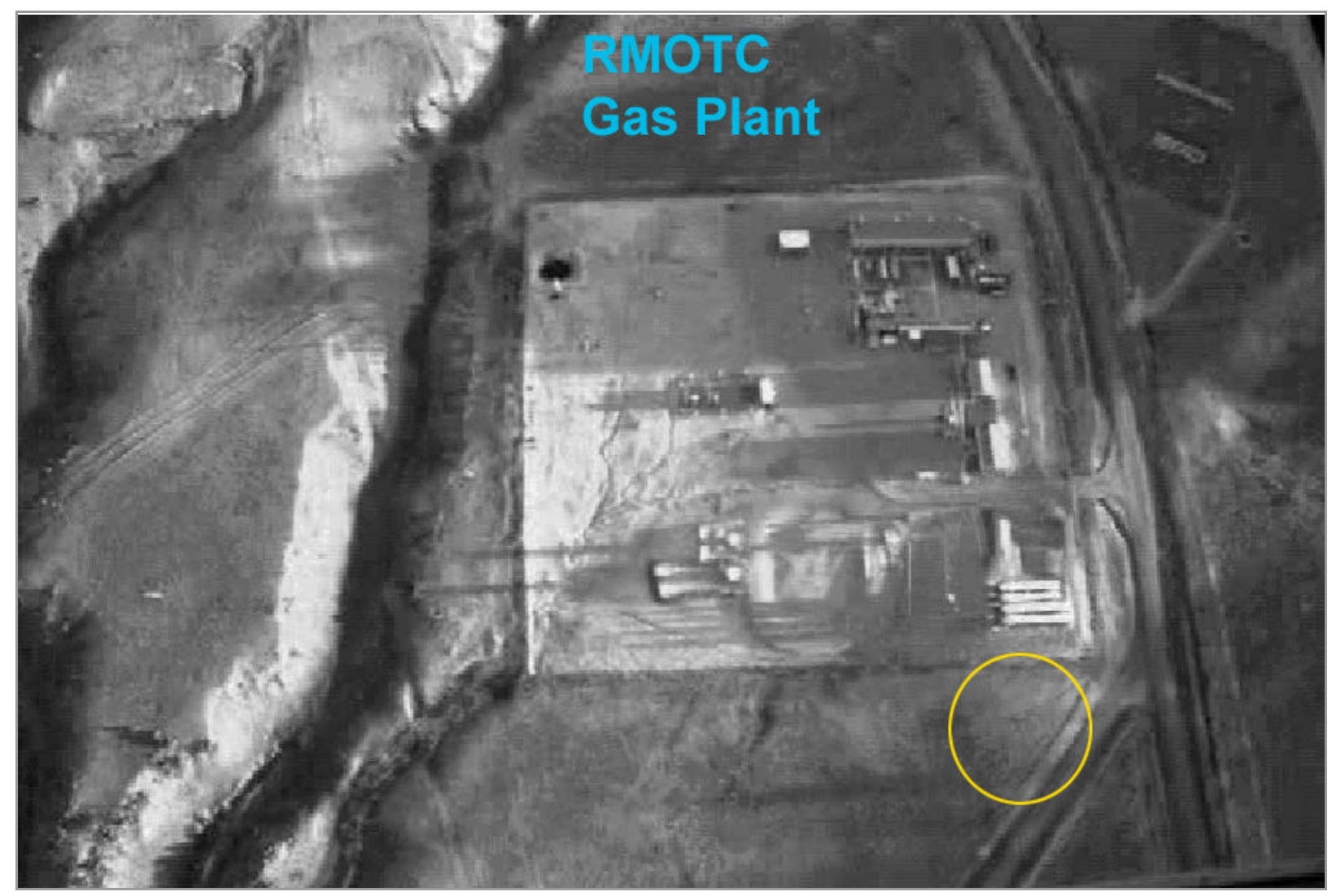




\section{Attachment 4: ITT ANGEL Customer Report - 16 Sept 2004 Collection}




\section{ANGEL Service Customer Report}

Rocky Mountain Oilfield Testing

Center (RMOTC)

Virtual Pipeline Inspection

\section{DATE(s) INSPECTION DATA ACQUIREID:}

September 16, 2004

CONTRACT NUMBER:

DOE/National Energy Technology Laboratory Cooperative Development Agreement \# DE-FC26-03NT41877

IN RESPONSE TO RFP:

DOE Program Solicitation (PS) No. DE-PS26-02NT41613

\section{SUBMITTED BY:}

Steven Stearns

ITT Industries Space Systems Division

1447 St. Paul St.

Rochester, NY 14653-7225

Tel. (585) 762-5494

steven.stearns@itt.com

\section{SUBMITTED TO:}

Chris Buckingham

Southwest Research Labs

6220 Culebra Road (78238-5166)

P.O. Drawer 28510 (78228-0510)

San Antonio, Texas

REPORT DATE:

October 8, 2004

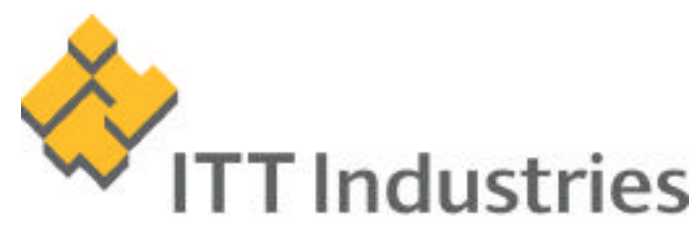

Engineered for life 


\section{Executive Summary:}

On September 16, 2004 we flew the route identified as "RMOTC Virtual Pipeline" with the ITT Industries ANGEL Sensor. This route was flown multiple times to ensure we had fully covered the complete Virtual Pipeline Route and to provide increased sample density to improve detection of smaller emissions. Analysis of the information collected indicates a number of areas of significant methane concentration along the pipeline right of way. The locations and relative size/concentration patterns for these are described in detail in this report.

The route flown is depicted below. All detected concentration areas are labeled with crosses. Color-coding is used to indicate detection of the methane concentration on multiple passes, with red indicating that the specific methane concentration was detected (within 30 meters) on seven separate passes. A number of distinct methane concentration "hot spots" were detected with sufficient quantity and frequency that they are very high confidence. Note that there are multiple "hot spots" in the vicinity of M2, which could indicate several smaller or a single large methane emission (see the Special Case Analysis later in this report).

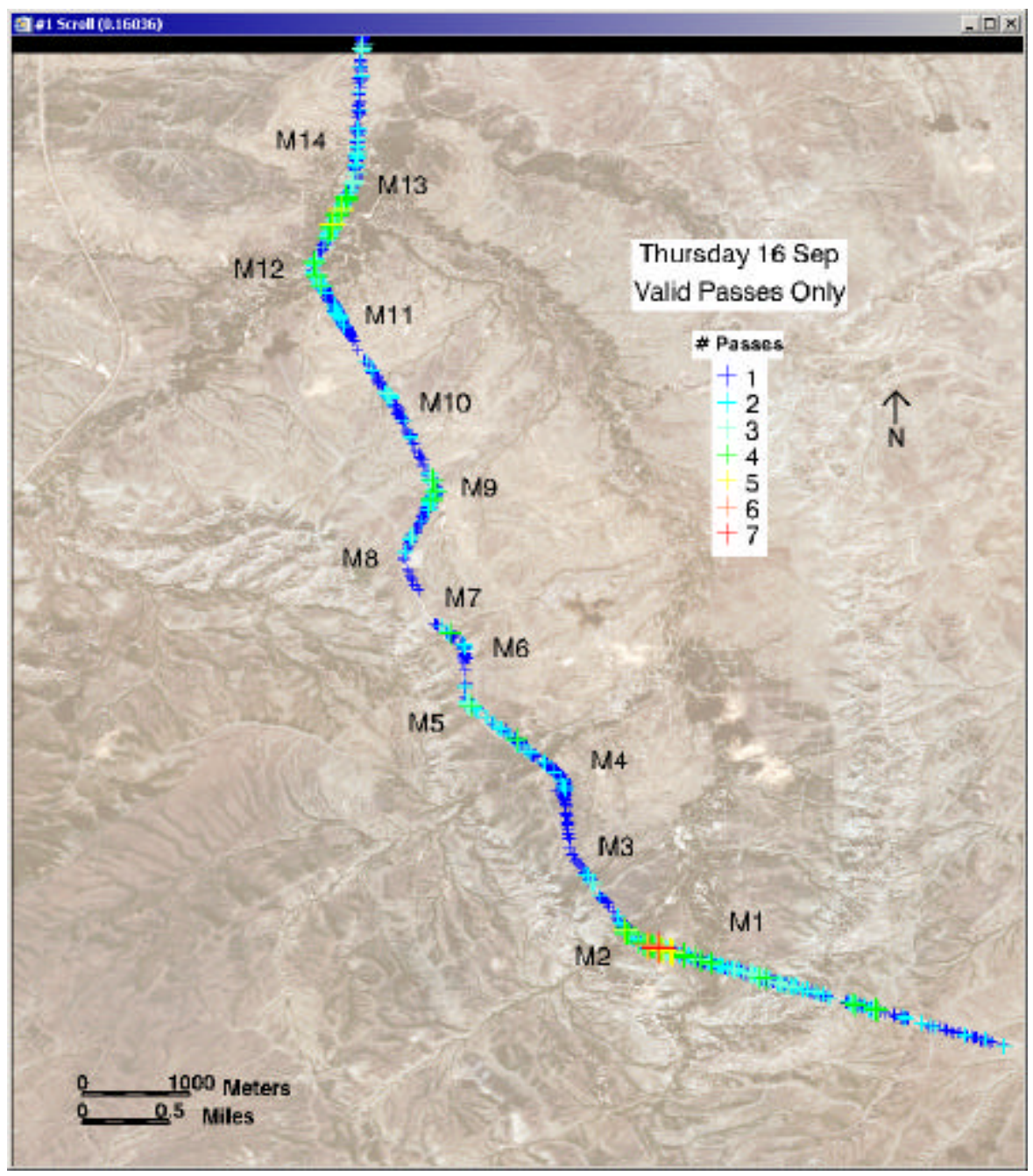




\section{Methane Detections}

The methane emissions with the highest confidence were captured on a relatively large number of passes as indicated in this table. The geographic coordinates provide the location of the aggregated multiple detections.

\begin{tabular}{|l|l|l|l|l|l|}
\hline NAD 27 Data (DMS) & & & & & \\
\hline Latitude & Longitude & Date & AM Passes & PM Passes & Comments \\
\hline 431455.2408 & -1061117.322 & $16-$ Sep-04 & $1,2,3,4,6$ & 5,6 & area \#1 between M1 \& M2 \\
\hline 431458.1352 & -1061127.726 & $16-$ Sep-04 & $1,2,3,4,5,6,7$ & 5,6 & area \#2 between M1 \& M2 \\
\hline 431459.6544 & -1061132.8236 & $16-$ Sep-04 & $1,2,3,4,6,7$ & 5,6 & area \#3 between M1 \& M2 \\
\hline 43150.7272 & -1061136.8484 & 16 -Sep-04 & $1,2,3,4,6,7$ & 5,6 & area \#4 between M1 \& M2 \\
\hline 431639.0504 & -1061250.0508 & $16-$ Sep-04 & $2,3,4,5,7$ & 5,6 & area southeast of M5 \\
\hline 431811.2464 & -106135.2284 & $16-$ Sep-04 & $1,2,3,4,7$ & 5,6 & area northwest of M9 \\
\hline 431940.9188 & -1061353.9472 & $16-$ Sep-04 & $1,2,3,4,6,7$ & 5,6 & area \#1 between M12 \& M13 \\
\hline 43200.24 & -1061344.04 & $16-$ Sep-04 & $1,2,5,6,7$ & 6 & area \#2 between M12 \& M13 \\
\hline 43203.2892 & -1061342.6108 & $16-$ Sep-04 & $1,2,3,6,7$ & 5,6 & area \#3 between M12 \& M13 \\
\hline
\end{tabular}

Methane emissions detected with lesser, but still significant confidence are listed in the table below. In all cases these were detected on multiple passes as well, but not as consistently as the detections documented above.

\begin{tabular}{|c|c|c|c|}
\hline NAD 27 Data (DMS) & & & \\
\hline Latitude & Longitude & Date & Comments \\
\hline 431459.4276 & -1061132.4816 & 16-Sep-04 & M1-M2 \\
\hline 431453.2212 & -1061110.8924 & 16-Sep-04 & M1 \\
\hline 432014.5392 & -1061337.6788 & 16-Sep-04 & M13 \\
\hline 431624.8268 & -1061230.69 & 16-Sep-04 & M4-M5 \\
\hline 431639.6264 & -1061250.6016 & $16-$ Sep-04 & M5 \\
\hline 43178.6028 & -1061258.428 & 16-Sep-04 & M6-M7 \\
\hline 43187.4916 & -106134.2852 & 16-Sep-04 & M9 \\
\hline 431940.8972 & -1061353.9652 & 16-Sep-04 & just north of M12 \\
\hline 431615.8808 & -1061219.728 & 16-Sep-04 & just north of M4 \\
\hline 431619.1316 & -1061224.8364 & 16-Sep-04 & just north of M4 \\
\hline 431935.76 & -1061352.8996 & 16-Sep-04 & just south of $\mathrm{M} 12$ \\
\hline 431954.8292 & -1061347.0424 & 16-Sep-04 & large area M12-M13 \\
\hline 43200.4416 & $-106 \quad 1344.4$ & 16-Sep-04 & medium area M12-M13 \\
\hline 431454.3012 & -1061115.4608 & 16-Sep-04 & north of M1 \\
\hline 431846.7712 & -1061323.0952 & 16-Sep-04 & north of M10 \\
\hline 432023.7336 & -1061336.2496 & 16-Sep-04 & north of M13 \\
\hline 43156.3324 & -1061145.6072 & 16-Sep-04 & north of $\mathrm{M} 2$ \\
\hline 431748.5916 & -1061313.7388 & 16-Sep-04 & north of $M 8$ \\
\hline 431811.1312 & -106135.0448 & 16-Sep-04 & north of $\mathrm{M9}$ \\
\hline 431456.3856 & -1061122.1028 & 16-Sep-04 & north of north of M1 \\
\hline 431813.1616 & -106136.24 & 16-Sep-04 & north of north of M9 \\
\hline 43206.8676 & -1061340.8 & 16-Sep-04 & northern M12-M13 \\
\hline 43203.1704 & -1061342.5928 & 16-Sep-04 & northern area $\mathrm{M} 12-\mathrm{M} 13$ \\
\hline 431527.7668 & -106120.3528 & 16-Sep-04 & single poly \\
\hline 431931.2276 & -1061350.862 & $16-$ Sep-04 & south of M12 \\
\hline 43183.4668 & -106135.9772 & 16-Sep-04 & south of M9 \\
\hline
\end{tabular}




\section{Significant Emissions}

In this survey there are a number of areas that stand out due to the size and concentrationpathlength values of methane plume and frequency of detection. These are identified in the images provided below with red and orange plume markers. The green markers are areas where there were potential indicators for methane but these were only detected on single passes. These do not represent highly significant indicators. Arrows indicate the positions of each significant emission detected.

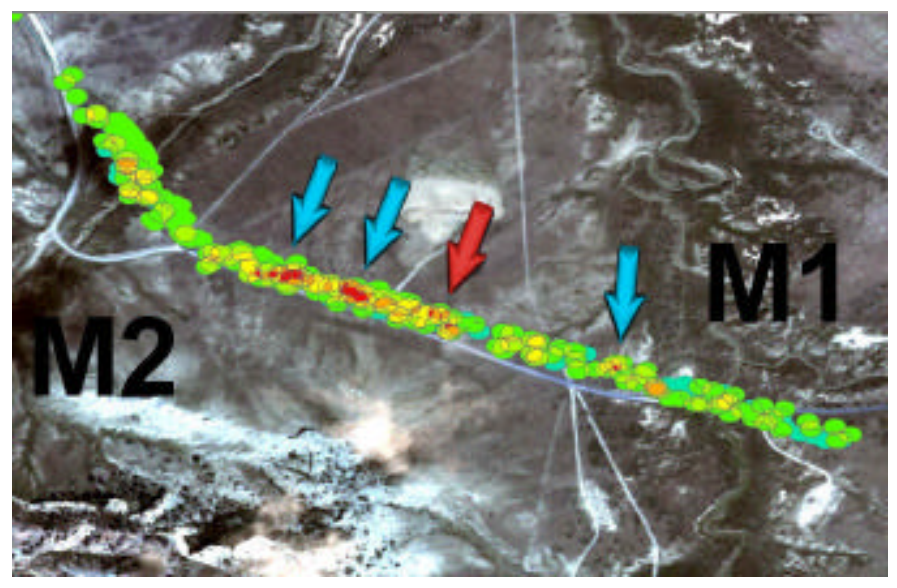

○ $\quad \mathrm{N} 43150.7272$

○ W - 1061136.8484

○ Detected on 8 passes

○ N 431459.6544

○ W - 1061132.8236

○ Detected on 8 passes

- N 431458.1352

○ W - 1061127.726

- Detected on 9 passes

- High confidence

○ N 431455.2408

○ W - 1061117.322

- Detected on 7 passes

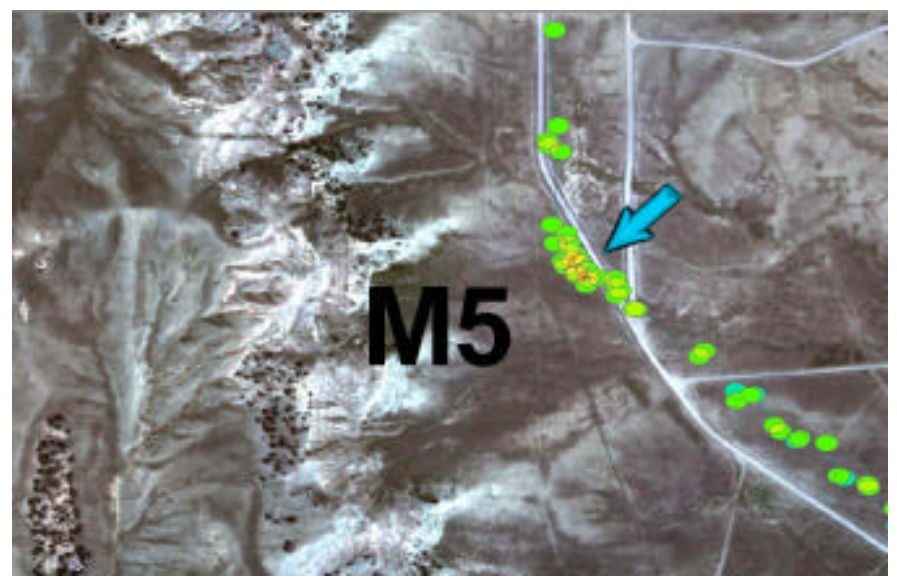

$\begin{array}{ll}\circ & \mathrm{N} 431639.0504 \\ \circ & \mathrm{W}-1061250.0508 \\ \circ & \text { Detected on } 7 \text { passes }\end{array}$ 


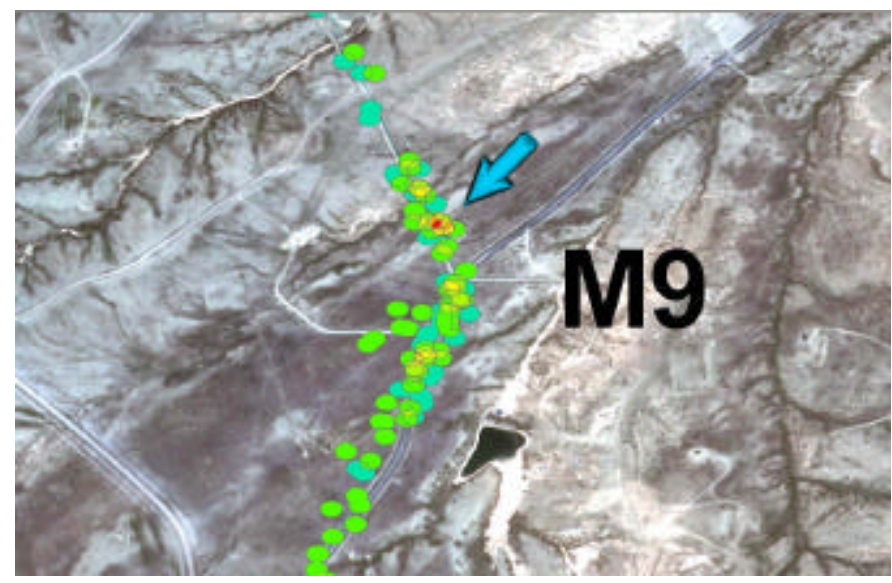

○ N 431811.2464

○ W-106 135.2284

○ Detected on 7 passes

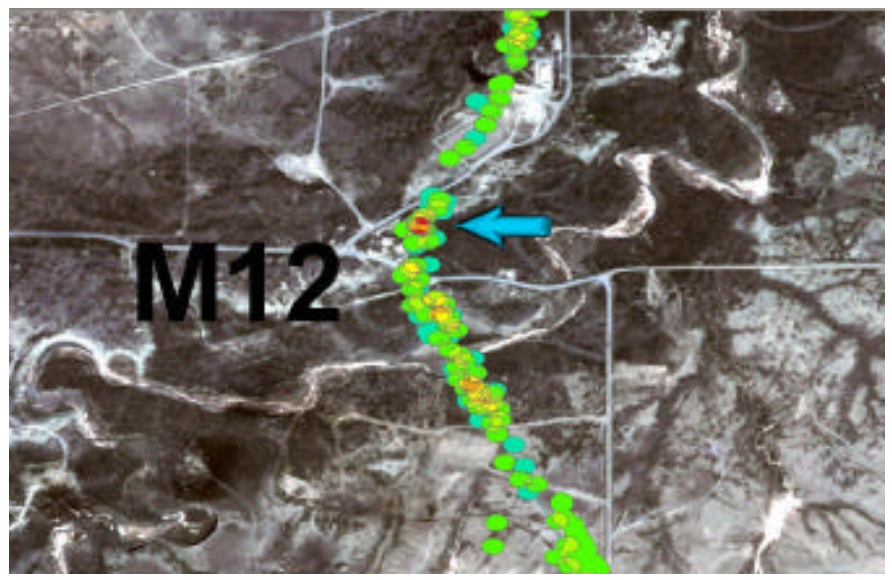

○ N 431940.9188

○ W - 1061353.9472

○ Detected on 8 passes

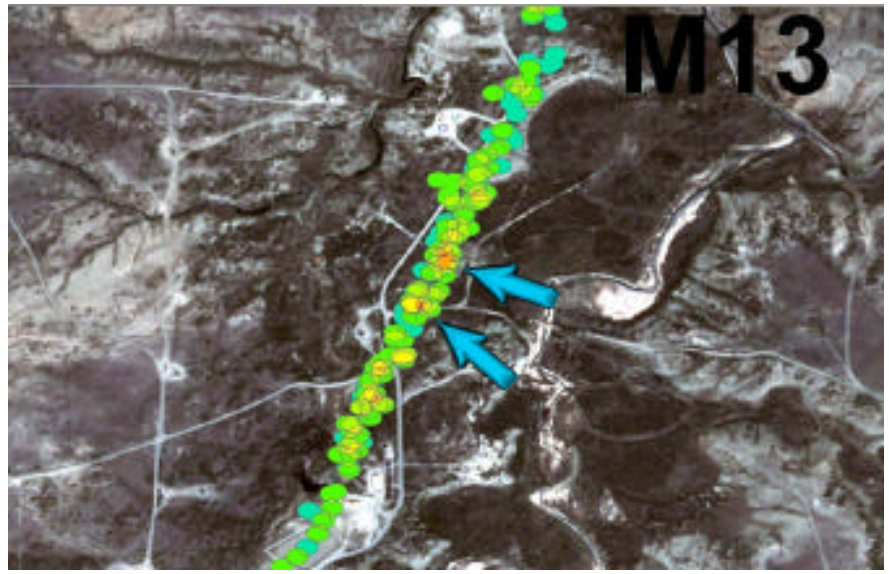

○ N 43203.2892

○ W - 1061342.6108

○ Detected on 7 passes

○ N 43200.24

○ W - 1061344.04

- Detected on 6 passes 


\section{Special Case Analysis}

From the collection on Thursday, September 16, 2004, one location stood out and warranted additional analysis. This was the area of multiple methane "hot spots" east of Virtual Pipeline Marker 2 (M2). Multiple high methane areas were seen on multiple passes throughout the day. Raster-based analysis and methane images of the significant emissions are shown below. ANGEL data analysis suggests the possibility of leaks in the area between M1 and M2.

The base imagery for this analysis is from a Quickbird multispectral collection provided by DOE/NETL. The methane concentration pathlengths were measured from a single pass $\left(4^{\text {th }}\right.$ pass on the afternoon of September 16, 2004) and the colors represent the relative concentration pathlength of methane within the ANGEL swath. Normal background methane levels are shown in dark blue. ANGEL collector scan swath is approximately 25 meters wide and is superimposed on the base image. It should be noted that the imagery used as purchased was not perfectly georegistered and is provided to give approximate context (+/- 15 meters) to the ANGEL analysis data, not absolute positioning.

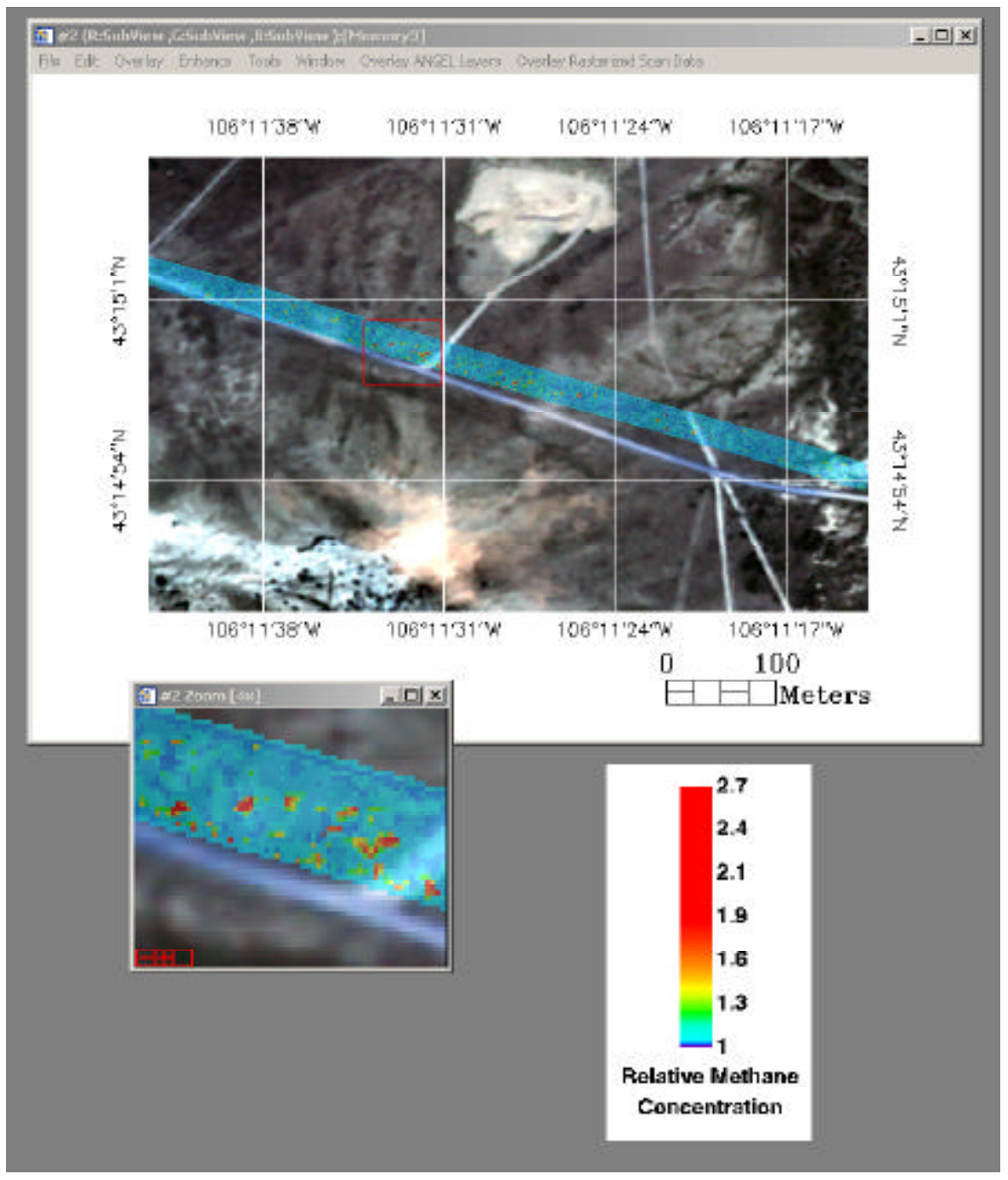




\section{Right of Way Coverage}

ANGEL collection planning starts with developing a flight plan that will place the aircraft over the pipeline route. In most cases the aircraft flight path cannot perfectly match the pipeline route but the ANGEL sensor can still track the full right of way. This is important to ensure that we provide adequate collection coverage of the full right of way for the entire length of the pipeline segment being surveyed. As the aircraft then flies the designated route, the sensor tracks and images the actual right of way, even when not directly under the aircraft and regardless of minor flight variations. The information collected from each flight is analyzed to determine that the right of way was fully covered as planned. The graphic below shows the actual results from a small segment of one such flight path over the designated pipeline route. The green line is the path of the aircraft and the red band is made up of all the individual sensor collects throughout the flight. In this case the sensor accurately tracked the pipeline and provided full coverage of the right of way. This post flight analysis provides confidence that we have adequately covered the pipeline path and right-of-way for the full 7.5-mile length of the survey.

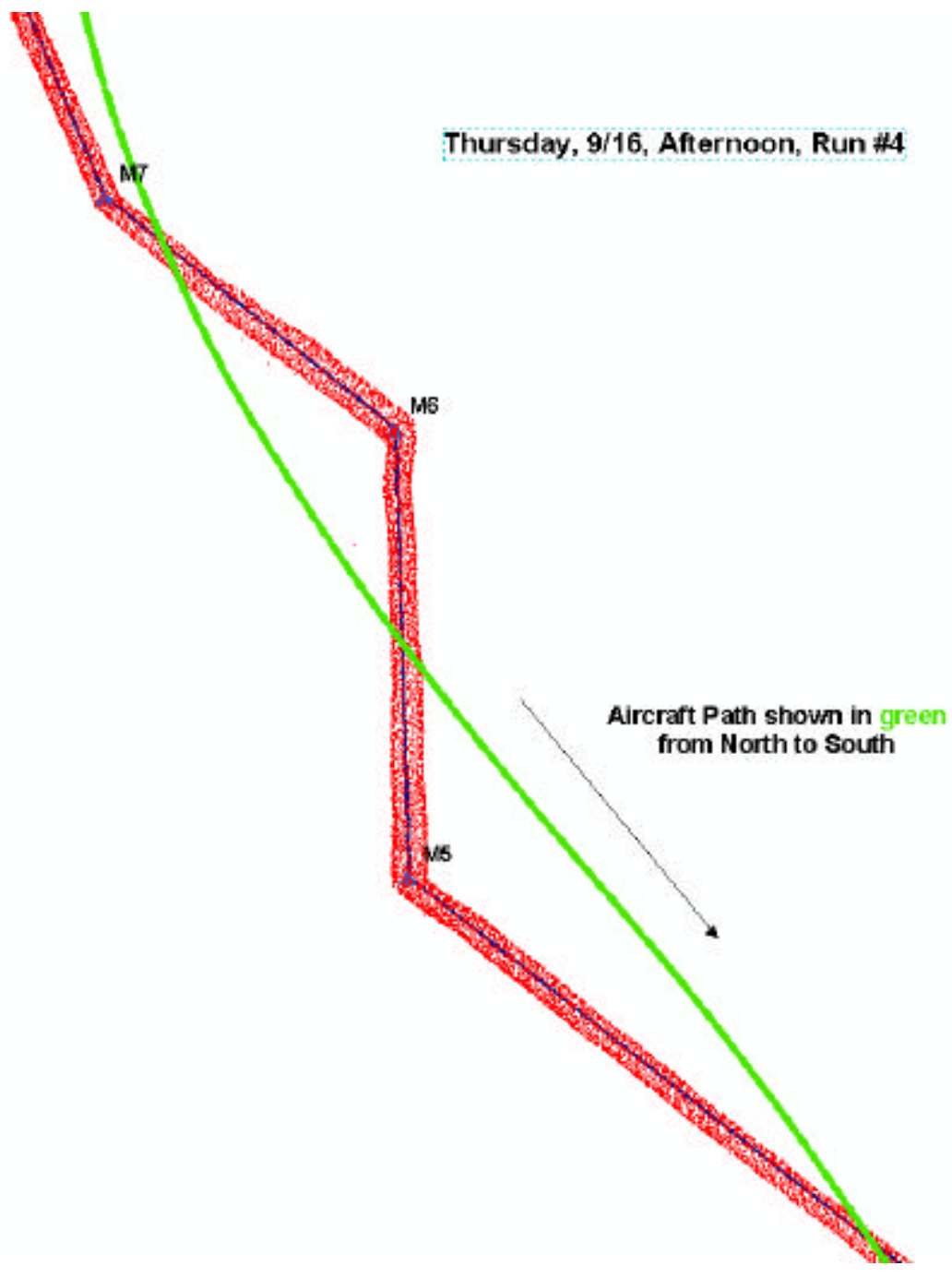




\section{Flight Path Verification}

The ANGEL aircraft has been fitted with a monochrome video camera that is used for flight path verification. This camera collects looking forward at 15 degrees from nadir and provides MPEG2 motion video imagery with approximately $1.4 \mathrm{ft}$ raw GSD resolution. A sample frame is shown below. The video camera currently in use was designed only to provide engineering flight test information and will soon be replaced with a much higher resolution color and false color IR digital camera designed to collect a continuous strip of geo-referenced imagery as the sensor is flown along the pipeline right-of-way.

The image below was taken from the East as the ANGEL aircraft was finishing up a North to South inspection pass. The approximate location of Marker 2 is noted. The location of the western edge of the M1-M2 zone of elevated methane detections is highlighted with a yellow ellipse.

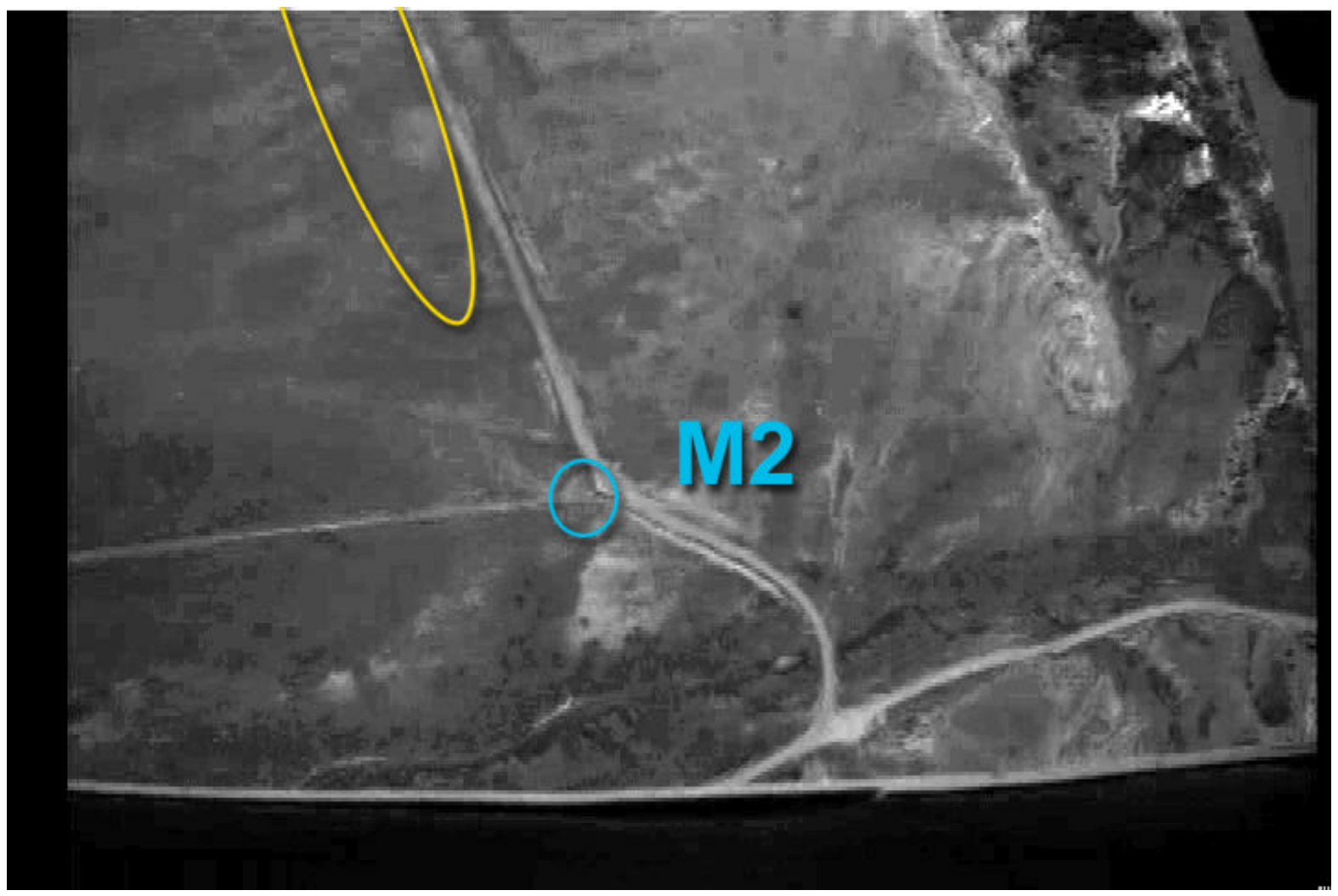




\section{Attachment 5: ITT ANGEL Customer Report - 17 Sept 2004 Collection}




\section{ANGEL Service Customer Report}

\section{Rocky Mountain Oilfield \\ Testing Center (RMOTC) \\ Virtual Pipeline Inspection}

DATE(s) INSPECTION DATA ACQUIRED:

September 17,2004

CONTRACT NUMBER:

DOE/National Ene rgy Technology Laboratory Cooperative Development Agreement \# DE-FC26-03NT41877

IN RESPONSE TO RFP:

DOE Program Solicitation (PS) No. DE-PS26-02NT41613

SUBMITTED BY:

STEVEN STEARNS

ITT Industries Space Systems Division

1447 St. Paul St.

Rochester, NY 14653-7225

Tel. (585) 762-5494

steven.stearns@itt.com

SUBMITTED TO:

Chris Buckingham

Southwest Research Labs

6220 Culebra Road (78238-5166)

P.O. Drawer 28510 (78228-0510)

San Antonio, Texas

REPORT DATE:

October 8, 2004

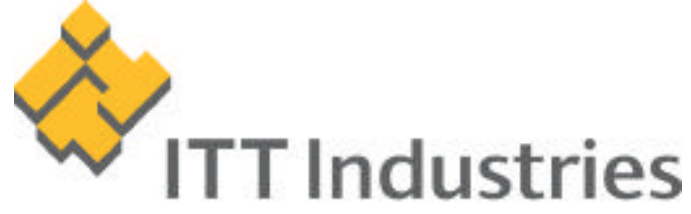

Engineered for life 


\section{Executive Summary:}

On September 17, 2004 we flew the route identified as "RMOTC Virtual Pipeline" with the ITT Industries ANGEL Sensor. This route was flown multiple times to ensure we had fully covered the complete Virtual Pipeline Route and to provide increased sample density to improve detection of smaller emissions. Analysis of the information collected indicates a number of areas of significant methane concentration along the pipeline right of way. The locations and relative size/concentration patterns for these are described in detail in this report.

The route flown is depicted below. All detected concentration areas are labeled with crosses. Color-coding is used to indicate detection of the methane concentration on multiple passes, with red indicating that the specific methane concentration was detected (within 30 meters) on nine separate passes. Six distinct methane concentration areas were detected with sufficient quantity and frequency ( 7,8 or 9 passes) that they are very high confidence.

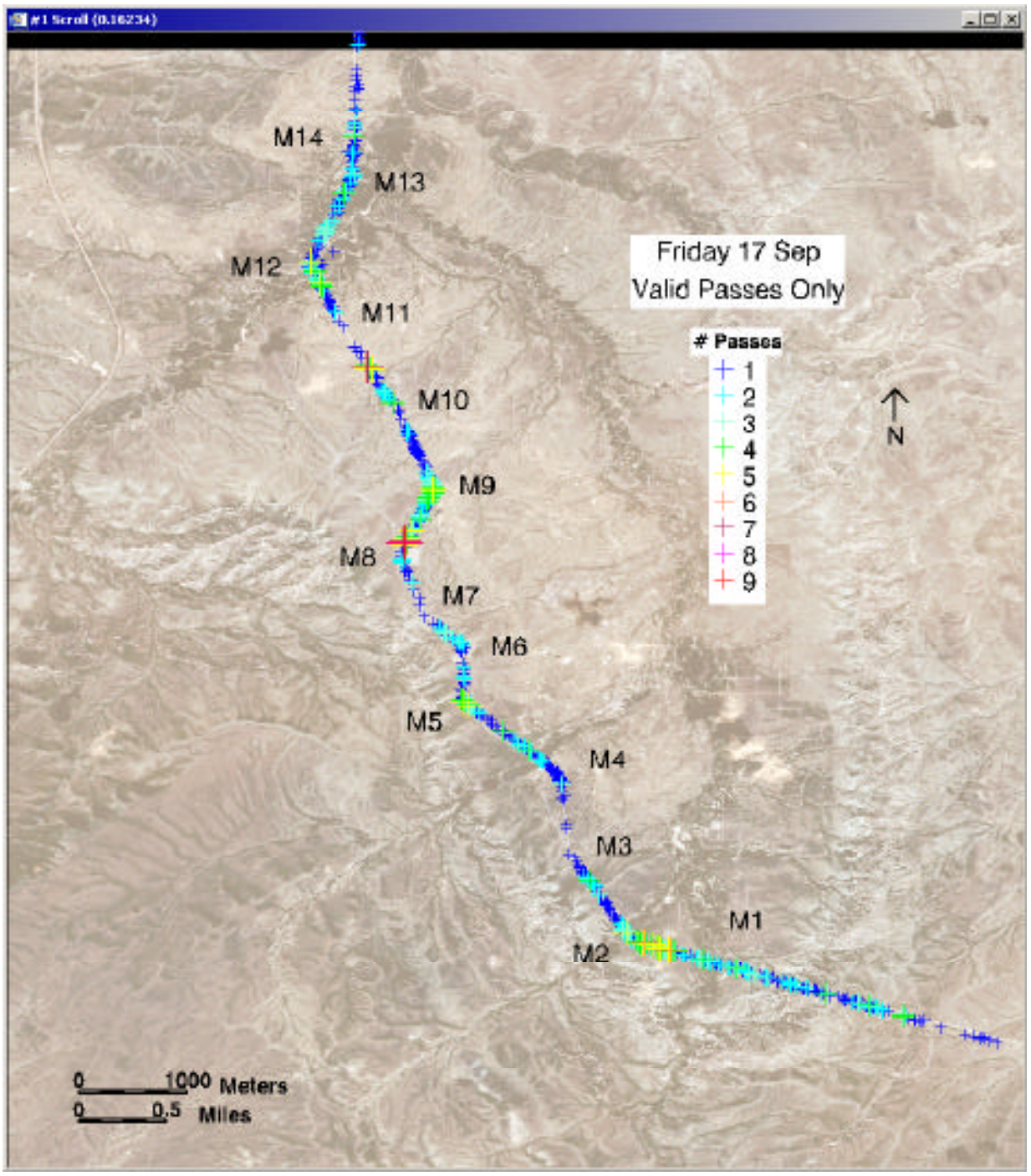




\section{Methane Detections}

The methane emissions with the highest confidence were captured on a relatively large number of passes as indicated in this table. The geographic coordinates provide the location of the aggregated multiple detections.

\begin{tabular}{|l|l|l|l|l|l|}
\hline NAD 27 Data (DMS) & & & & & \\
\hline Latitude & Lonqitude & Date & AM Passes & PM Passes & Comments \\
\hline 431457.8148 & -1061127.4776 & $17-$ Sep-04 & $2,3,4,5,6$ & 2,3 & area \#1 between M1 \& M2 \\
\hline 431458.7472 & -1061131.8408 & $17-$ Sep-04 & $1,2,3,4,6$ & 2.3 & area \#2 between M1 \& M2 \\
\hline 43151.1592 & -1061137.8132 & $17-$ Sep-04 & $1,2.3,6.7$ & 1.3 & area \#3 between M1 \& M2 \\
\hline 431744.8908 & -1061315.8556 & $17-$ Sep-04 & $1,2,4,5,6,7$ & $1,2,3$ & north of gas plant (high confidence) \\
\hline 431856.9124 & -1061331.0548 & $17-$ Sep-04 & $2,3,4,5,6,7$ & 2 & area between M10 \& M11 \\
\hline 431940.0116 & -1061353.8824 & $17-$ Sep-04 & $1,2,3,4,5$ & 3,4 & area northeast of M12 \\
\hline
\end{tabular}

Methane emissions detected with lesser, but still significant confidence are listed in the table below. In all cases these were detected on multiple passes as well, but not as consistently as the detections documented above.

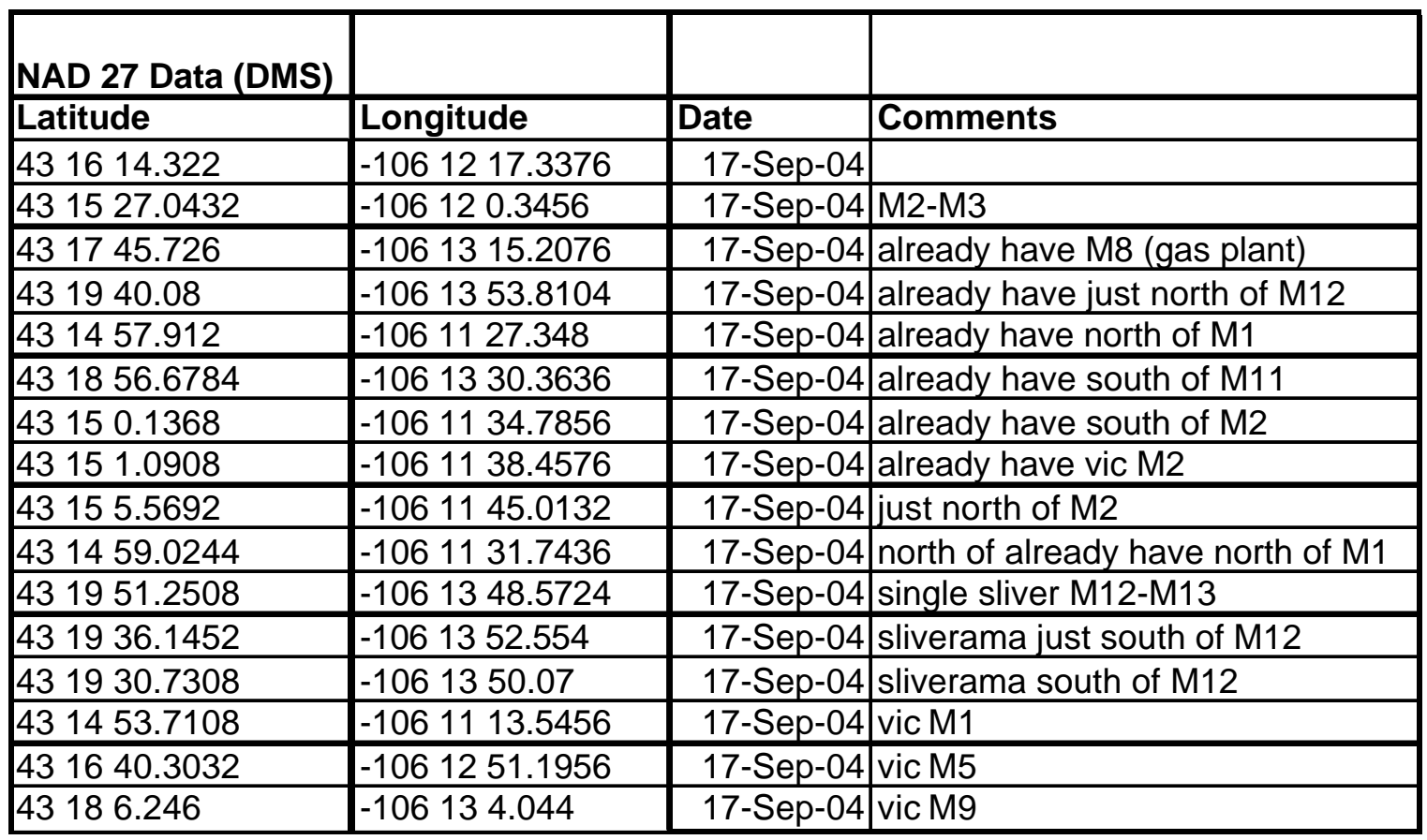

Methane emissions detected at the location of the 5,000 scfh "calibration leak" were analyzed separately. A GIS analysis of just the Friday PM passes indicate that the leak was detected on three passes. The position of that leak is shown in the following table.

\begin{tabular}{|l|l|l|l|l|l|}
\hline NAD 27 Data (DMS) & & & & & \\
\hline Latitude & Lonqitude & Date & AM Passes & PM Passes & Comments \\
\hline 431453.7036 & -1061113.434 & $17-$ Sep-04 & N/A & $1,2,3$ & Calibration leak \\
\hline
\end{tabular}




\section{Significant Emissions}

In this survey there are six areas that stand out due to the size and concentration-pathlength values of methane plume and frequency of detection. These are identified in the images provided below with red and orange plume markers. The green markers are areas where there were potential indicators for methane but these were only detected on single passes and at low concentration pathlengths. These do not represent highly significant indicators. In addition, the 5,000 scfh calibration leak near M1was overflown and detected three times on Friday PM and is illustrated below.

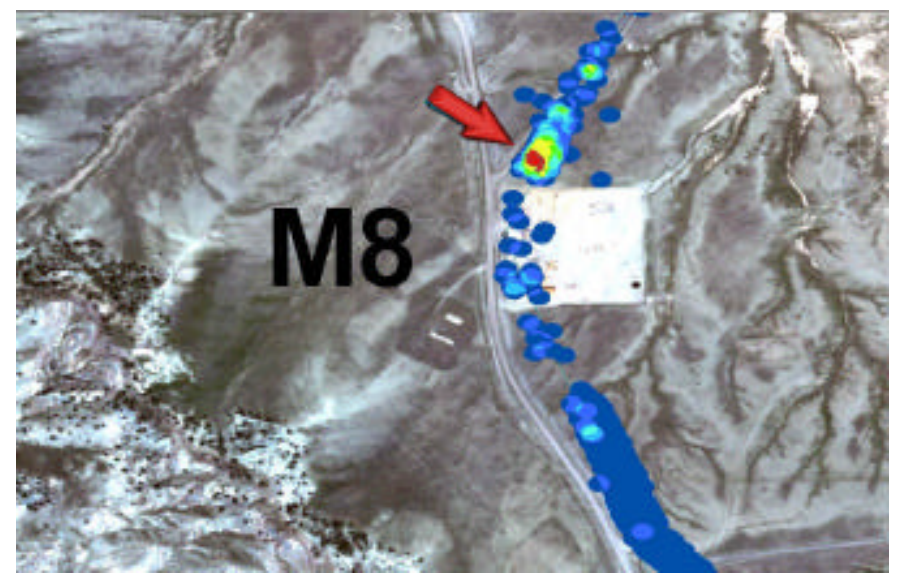

- N 431744.8908

○ W - 1061315.8556

○ Detected on 9 passes

- N of Gas Plant (High Confidence)

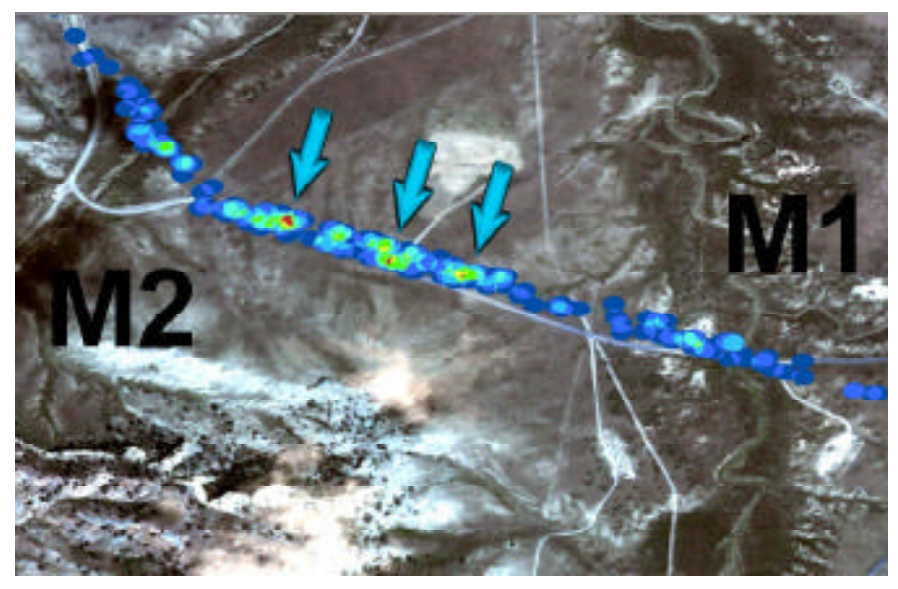

○ N 43151.1592

○ W - 1061137.8132

○ Detected on 7 passes

○ N 431458.7472

○ W - 1061131.8408

○ Detected on 7 passes

○ N 431457.8148

○ W - 1061127.4776

○ Detected on 7 passes 


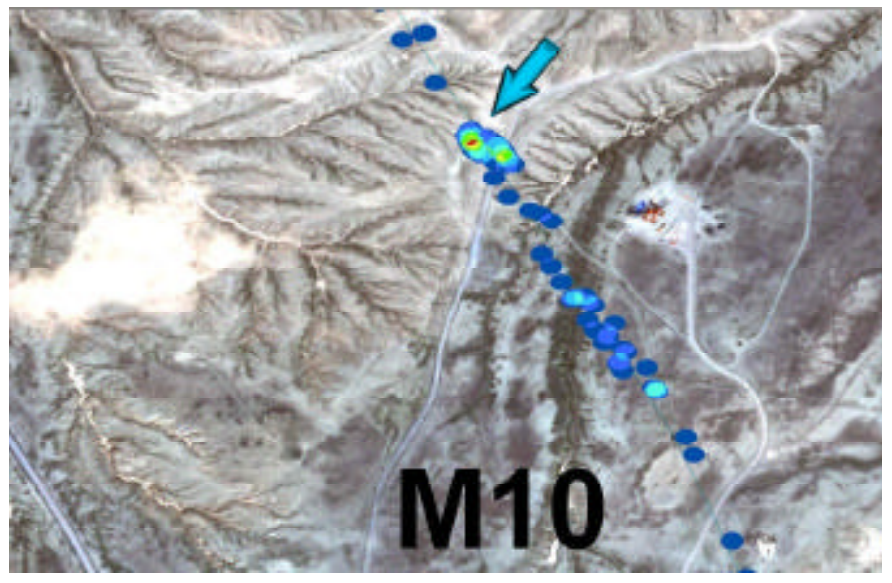

- N 431856.9124

○ W - 1061331.0548

○ Detected on 7 passes

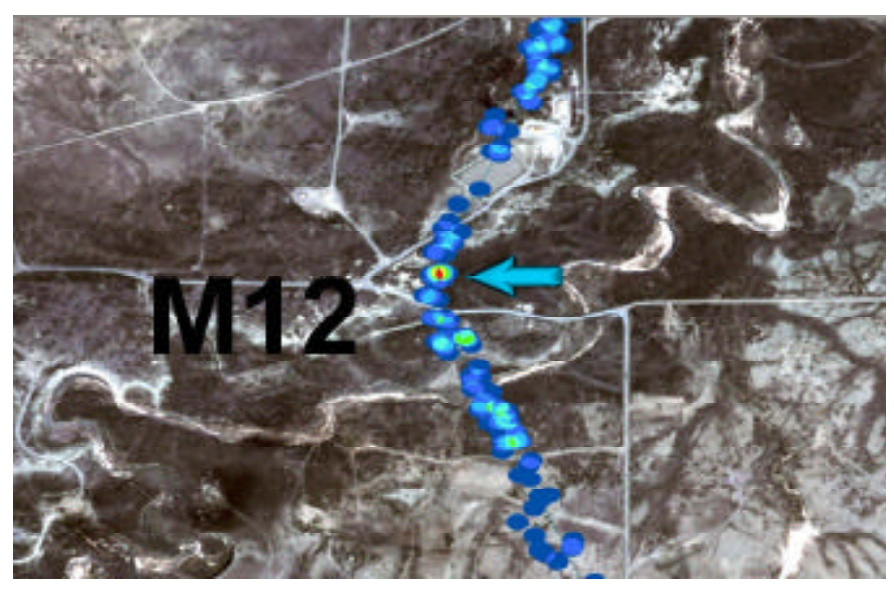

○ $\quad \mathrm{N} 431940.0116$

○ W - 1061353.8824

○ Detected on 7 passes

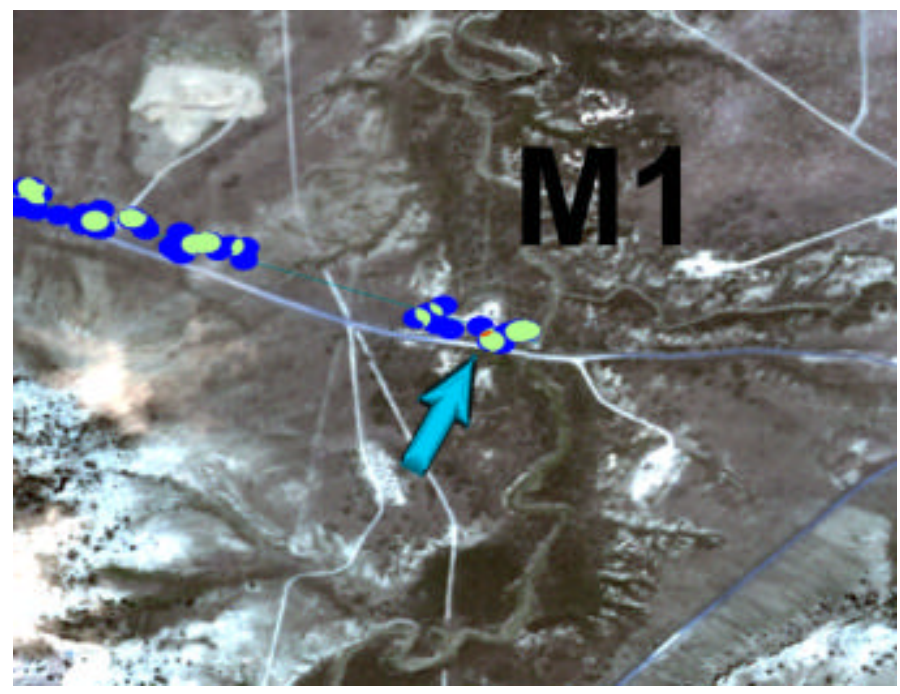

○ $\quad \mathrm{N} 431453.7036$

○ W - 1061113.434

○ 5,000 scfh Calibration Leak detected on all three of PM passes 


\section{Special Case Analysis}

From the collection on Friday, September 17, 2004 one location stood out above all the others and warranted additional analysis. This was the 5,000 scfh "calibration leak"near M1 observed on the $3^{\text {rd }}$ flight that afternoon. A raster-based analysis and methane images of the significant emissions are shown below. In this case the methane detected from the calibrated leak appears as an elongate plume.

The base imagery for this analysis is from Quickbird multispectral collection provided by DOE/NETL. The methane concentration pathlengths were measured from a single pass and the colors represent the relative concentration pathlength of methane within the ANGEL swath. Normal background methane levels are shown in dark blue. The ANGEL collection scan swath is approximately 25 meters wide and is superimposed on the base image. It should be noted that the imagery used as purchased was not perfectly geo-registered and is provided to give approximate context (+/- 15 meters) to the ANGEL analysis data, not absolute positioning.

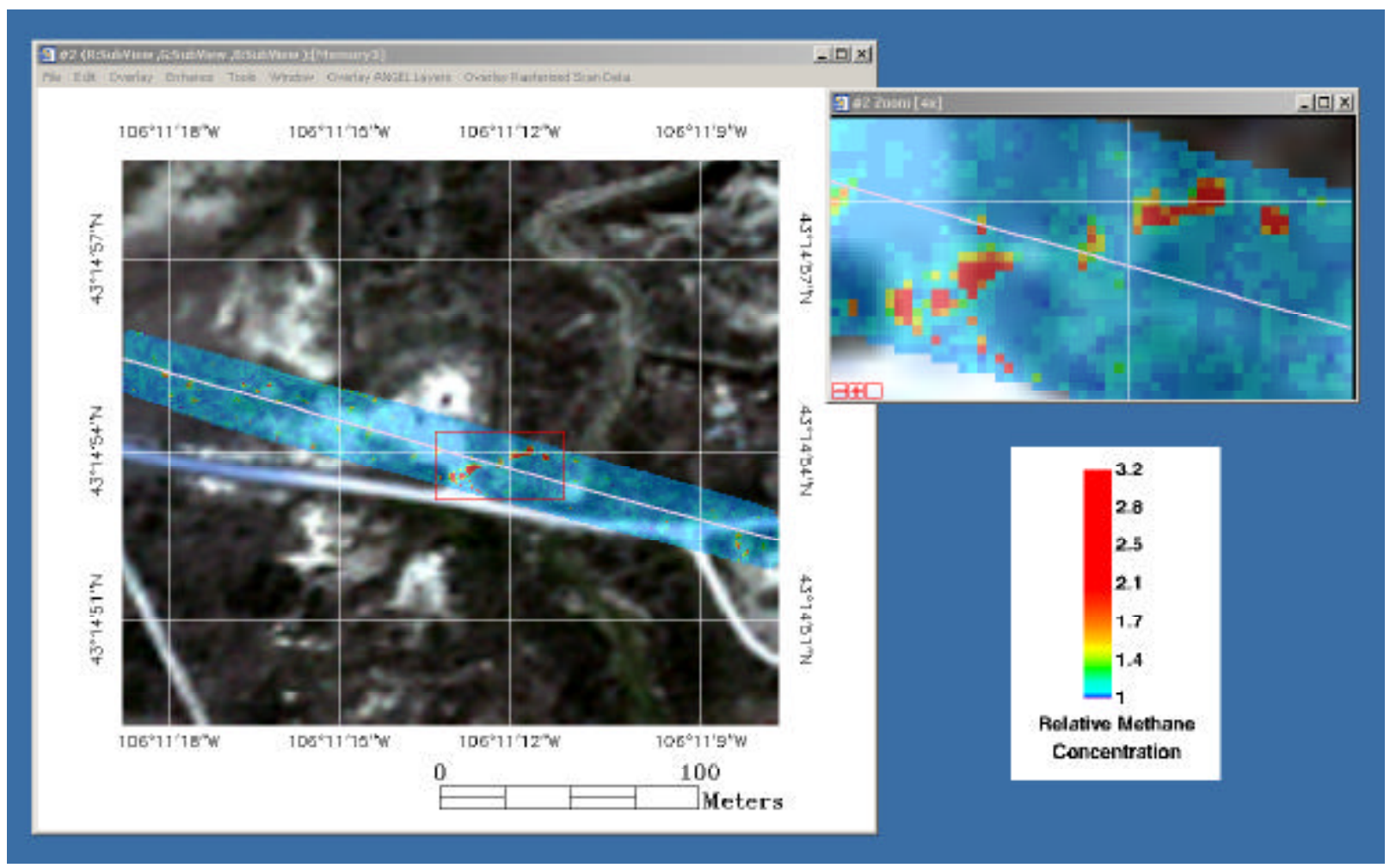




\section{Right of Way Coverage}

ANGEL collection planning starts with developing a flight plan that will place the aircraft over the pipeline route. In most cases the aircraft flight path cannot perfectly match the pipeline route but the ANGEL sensor can still track the full right of way. This is important to ensure that we provide adequate collection coverage of the full right of way for the entire length of the pipeline segment being surveyed. As the aircraft then flies the designated route, the sensor tracks and images the actual right of way, even when not directly under the aircraft and regardless of minor flight variations. The information collected from each flight is analyzed to determine that the right of way was fully covered as planned. The graphic below shows the actual results from a small segment of one such flight path over the designated pipeline route. The green line is the path of the aircraft and the red band is made up of all the individual sensor collects throughout the flight. In this case the sensor accurately tracked the pipeline and provided full coverage of the right of way. This post flight analysis provides confidence that we have adequately covered the pipeline path and right-of-way for the full 7.5-mile length of the survey.

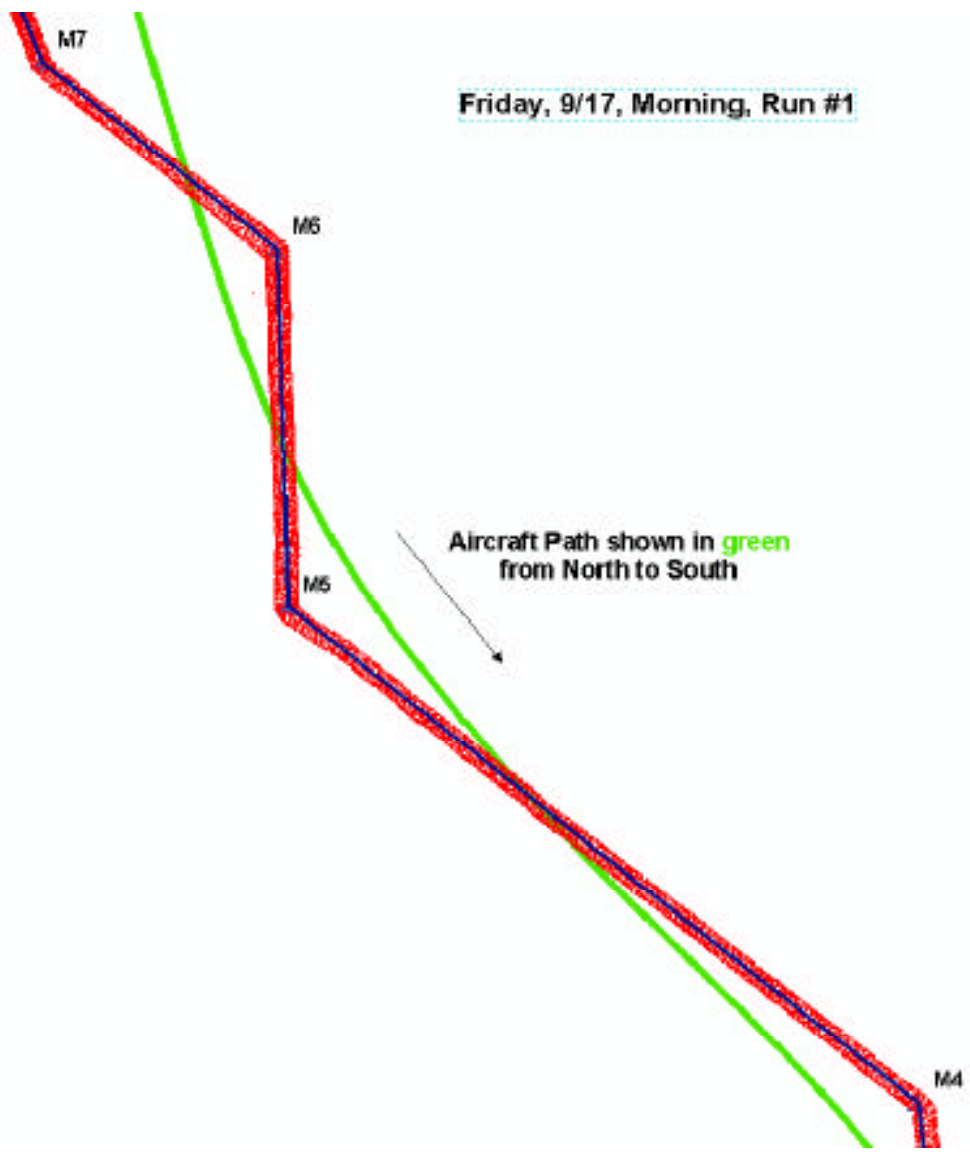




\section{Flight Path Verification}

The ANGEL aircraft has been fitted with a monochrome video camera that is used for flight path verification. This camera collects looking forward at 15 degrees from nadir and provides MPEG2 motion video imagery with approximately $1.4 \mathrm{ft}$ raw GSD resolution. The video camera currently in use was designed only to provide engineering flight test information and will soon be replaced with a much higher resolution color and false color IR digital camera designed to collect a continuous strip of geo-referenced imagery as the sensor is flown along the pipeline right-of-way.

In image of the RMOTC Gas Plant shown below was captured during an early AM S to N pass. The yellow circle North of the Gas Plant indicates the approximate position of elevated methane levels detected throughout the day on Friday 9/17/2004.

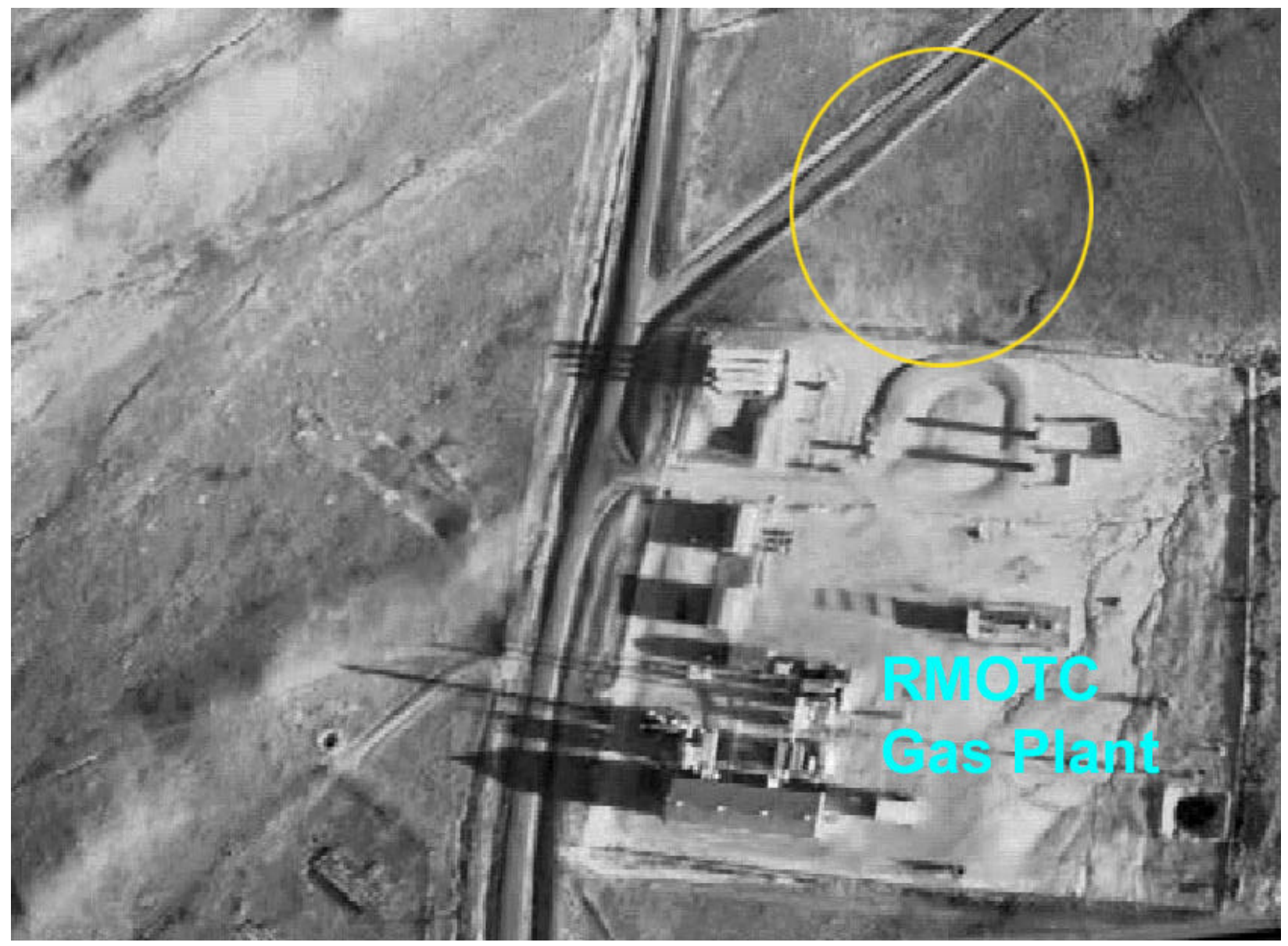

